\title{
PROJECT CONSIDERATIONS AND DESIGN OF SYSTEMS FOR WHEELING COGENERATED POWER
}

\author{
DISCLAIMER
}

This report was prepared as an account of work sponsored by an agency of the United States Government. Neither the United States Government nor any agency thereof, nor any of their employees, makes any warranty, express or implied, or assumes any legal liability or responsibility for the accuracy, completeness, or usefulness of any information, apparatus, product, or process disclosed, or represents that its use would not infringe privately owned rights. Reference herein to any specific commercial product, process, or service by trade name, trademark, manufacturer, or otherwise does not necessarily constitute or imply its endorsement, recommendation, or favoring by the United States Government or any agency thereof. The views and opinions of authors expressed herein do not necessarily state or reflect those of the United States Government or any agency thereof.

\section{By:}

Raymond G. Tessmer Jr., PE

John R. Boyle, PE

John H. Fish III, PE

William A. Martin

August 1994 


\section{DISCLAIMER}

Portions of this document may be illegible in electronic image products. Images are produced from the best available original document. 
ABBREVIATIONS AND ACRONYMS

BTU

British Thermal Unit

Co-op

Cooperative Electric Utility

DOE

U.S. Department of Energy

ECAR

East Central Area Reliability Coordination Agreement

ELCON

Electricity Consumers Resource Council

EPAct

1992 Comprehensive National Energy Policy Act

EWG

Exempt Wholesale Generator

FERC

Federal Energy Regulatory Commission

FPA

Federal Power Act of 1920

G\&T

Generating \& Transmission Cooperative Electric Utility

HRSG

Heat Recovery Steam Generator

ICU

Interconnected Utility

IOU

Investor-Owned Utility

ITCF

Interregional Transmission Coordination Forum

kV

Kilovolt

$\mathrm{kVa}$

Kilovolt-amp

kW

Kilowatt

kWh

Kilowatt-hour

MAAC

Mid-Atlantic Area Council

MAIN

Mid-American Interpool Network

MAPP

Mid-Continent Area Power Pool

Muni

Municipal Electric System

MW

Megawatt

NEPOOL

New England Power Pool

NPCC

Northeast Power Coordinating Council

NUG

Non-Utility Generator

PUC

Public Utilities Commission, Public Service Commission, Dept. of Public Utilities, State Corporation Commission, Energy Commission, etc. (state agencies)

PUHCA Public Utility Holding Company Act of 1935

PURPA Public Utility Regulatory Policies Act of 1978

QF

Qualified Facility

RTG

Regional Transmission Group

SCR

Short Circuit Ratio

SERC

Southeastern Electric Reliability Council

SPP

Southwest Power Pool

TES

Thermal Energy Storage

TVA

Tennessee Valley Authority

WCP

Wheeling Cogenerated Power

wscc

Western Systems Coordinating Council 


\author{
A GUIDEBOOK
}

\title{
PROJECT CONSIDERATIONS AND DESIGN OF SYSTEMS FOR WHEELING COGENERATED POWER
}

\author{
By: \\ Raymond G. Tessmer Jr., PE \\ John R. Boyle, PE \\ John H. Fish III, PE \\ William A. Martin \\ ERC, INC. \\ Tullahoma, TN 37388

\begin{abstract}
Prepared for:
U.S. Department of Energy

Office of Energy Efficiency and Renewable Energy Office of Industrial Technologies
\end{abstract}

August 1994 
The Goverment reserves for itself and others acting on its behalf a royalty free, nonexclusive, irrevocable, world-wide license for govermental purposes to publish, distribute, translate, duplicate, exhibit, and perform any such data copyrighted by the contractor.

\begin{abstract}
AVAILABILITY
Available to DOE and DOE contractors from the Office of Scientific and Technical Information, P.O. Box 62, Oak Ridge, TN 37831; Attn: Information Services. For further informaion, call 615-576-8401.

Available to the public from National Technical Information Service, U.S. Department of Commerce, 5285 Port Royal Rd., Springfield, VA 22161. 703-487-4650
\end{abstract}

\title{
DISCLAIMER
}

This report describes work performed under Contract No. DE-AC02-91CE40942 with the United States Department of Energy. The views and opinions expressed herein are those of the authors alone, and they do not necessarily state or reflect those of the United States Government or any agency thereof. While every effort is made to provide dependable information, the authors cannot be held responsible for any errors or ommissions. 


\section{FORWARD}

Research leading to this book was provided by the U.S. Department of Energy under Contract Number DEAC02-91CE40942 while the authors were employed by ERC, Inc. of Tullahoma, TN. With the Contract beginning a year before passage of the 1992 Comprehensive Energy Policy Act (EPAct), DOE exhibited foresight in anticipating emerging markets for wheeling electric power. This book is intended to continue the impetus for conservation of energy through cogeneration that began with passage of PURPA.

Various levels of technical detail are presented in different chapters of the book in order to broaden its usefulness to all professionals that might be involved in a wheeling project. For example, an engineering specialist will find basic economic theory on transmission pricing as well as alternate solutions to his own technical design problems.

Items of interest to non-technical managers who must approve wheeling projects include business opportunities and risks (Chapter 1), discussion of load following strategies (Chapter 2), competition for transmission lines (Chapter 3), market opportunities (Chapter 3), fuel supply alternatives (Chapter 4), and regulatory constraints (Chapter 7 ).

Background information is also presented for technical specialists in disciplines other than their own. This includes new project considerations to be addressed with wheeling (Chapter 2), classification of utilities (Chapter 3), a discussion of how power is actually wheeled (Chapter 6), contracting considerations (Chapter 8), and the economic bases for transmission service pricing (Chapter 8 ).

Technical detail and project options are described for project developers and design engineers in Chapters 4 to 6. Finally, the discussion of regulatory constraints and uncertainties contained in Chapter 7 is a comprehensive compilation and assessment that should prove valuable to anyone involved with a wheeling project.

Regulations at the state and federal level are still in an evolutionary stage. However, much uncertainty has been removed since passage of EPAct, and issues remaining to be resolved have been identified and are being debated. As in other industries that have recently undergone deregulation, the market for electricity is becoming extremely competitive. Cogenerators will face increased competion in the form of utility repowering, seasonal utility purchases of peaking power, conversion of combustion turbine plants to combined cycles, market-based prices, etc. It is therefore imperative that cogenerators stay abreast of market and regulatory developments, using legal experts to the extent necessary. With up-to-date information about the market, cogenerators will be able to compete in this new opportunity for wheeling cogenerated power. 


\section{TABLE OF CONTENTS}

Chapter 1: Introduction To Wheeling Opportunities 1 - 1

Business Opportunities $\quad 1-2$

Business Risks $1-2$

Chapter 2: Basic Project Development Considerations 2 - 1

The Wheeling Cogenerated Power System 2 - 1

$\begin{array}{ll}\text { Project Considerations } & 2-2\end{array}$

Load Following Strategies $\quad 2-3$

$\begin{array}{lr}\text { Thermal Load Following } & 2-4\end{array}$

$\begin{array}{lr}\text { Power Load Following } & 2-5\end{array}$

$\begin{array}{ll}\text { Double Dispatch } & 2-5\end{array}$

Chapter 3: Markets For Wheeled Power $\quad 3-1$

Utility Classification $\quad 3-1$

Current Competition For Transmission Lines $\quad 3-2$

Niche Market Opportunities $\quad 3$ - 4

$\begin{array}{lr}\text { Utilities With High Avoided Costs } & 3-5\end{array}$

Requirements Utilities $3-5$

Retail Customers In A Requirements Utility's Service Territory 3 - 5

$\begin{array}{ll}\text { Retail Affiliate Of A Non-Utility Generator } & 3 \text { - } 5\end{array}$

$\begin{array}{lr}\text { Mutually Beneficial Situations } & 3-6\end{array}$

Market Potential $3-6$

Chapter 4: Decoupling Electrical \& Thermal Power Production 4 - 1

Fuel Flexibility And Supply $\quad 4$ - 1

Mechanical System Design 4 - 3

Topping Cycles $4-3$

Steam Turbine Cycles $\quad 4-3$

Gas Turbines \& Combined Cycles $\quad 4$ - 6

Gas Turbine With Thermal Storage $\quad 4-11$

Diesel/Coal Combined Cycle $\quad 4-11$

$\begin{array}{lr}\text { Bottoming Cycles } & 4-13\end{array}$

Waste Heat Recovery Types $\quad 4-13$

Waste-Fuel-Fired Types $\quad 4-14$

Flexibility Of Operation $\quad 4-15$ 
Chapter 5: Cogeneration System Operational Limitations

Performance Limitations, Ratings, and Restrictions

System Response Times

$5-1$

Maximum And Minimum Ratings

$5-2$

Minimum Load Operation

$5-4$

Utility Vs. Commercial Grade Equipment

$5-5$

Generation Without Interconnection - Utility Blackout

$5-5$

Chapter 6: Utility Treatment of Wheeling Cogenerators

Transmission System Operations

$6-1$

Interconnected Networks

$6-2$

Control Areas

$6-2$

Contract Path Flows

$6-3$

Loop Flows

$6-4$

Wheeling Transactions By Cogenerators

$6-4$

Transmission System Capacity Constraints

$6-5$

Cogenerator Effects On System Stability

$6-8$

Steady-State Stability

$6-9$

Generator Impedance

$6-9$

Excitation System

$6-9$

Generator Step-Up Transformer

$6-9$

Transient Stability

$6-9$

Switching Time

$6-10$

Types Of Faults

$6-10$

Generator Inertia

$6-11$

Network Factors

$6-11$

Hunting

$6-12$

$6-12$

Transmission System Security Constraints

$6-13$

System Protection Requirements

$6-13$

Utility Connections

$6-16$

Fault Currents

$6-16$

Utility Requirements

$6-17$

Distribution Protective Devices

$6-17$

Fault Detection

$6-17$

Reclosing

$6-19$

Protection Of Cogenerators

$6-19$ 
Chapter 7: Regulatory Constraints and Uncertainties

Wholesale Transmission Access

$7-2$

Qualified Facility Vs. Exempt Wholesale Generator Status

$7-3$

Retail Transmission Access

$7-5$

Retail Wheeling Proposals

$7-6$

Rate Regulation Of The Interconnected Utility

$7-6$

Regional Transmission Groups

$7-7$

Regional Transmission Arrangement (RTA)

$7-8$

Interregional Transmission Coordination Forum

7 - 8

Chapter 8: Contracting Considerations

8 - 1

Contracting With The Electricity Purchaser And Thermal Host

$8-1$

Contracting With The Interconnected Utility

$8-2$

Pricing Of Transmission Services

8 - 3

Embedded (Average) Cost

$8-3$

Marginal Cost

$8-4$

Opportunity Cost

$8-4$

Market-Based Price

8 - 4

The Penelec Case

$8-5$

Which Cost Elements To Include

$8-6$

Additional References

$\mathbf{R} \cdot \mathbf{1}$ 


\section{CHAPTER 1. \\ INTRODUCTION TO WHEELING OPPORTUNITIES}

Wheeling electric power, the transmission of electricity not owned by an electric utility over its transmission lines, is a term not generally recognized outside the electric utility industry. Investigation of the term's origin is intriguing.

For centuries, wheel has been used to describe an entire machine, not just individual wheels within a machine. Thus we have waterwheel, spinning wheel, potter's wheel and, for an automobile, wheels. Wheel as a verb connotes transmission or modification of forces and motion in machinery. With the advent of an understanding of electricity, use of the word wheel was extended to the transmission of electric power as well as mechanical power. Today, use of the term wheoling electric power is restricted to utility transmission of power that it doesn't own.

Cogeneration refers to simultaneous production of electric and thermal power from an energy source. This is more efficient than separate production of electricity and thermal power and, in many instances, less expensive.

Rebirth of interest in cogeneration resulted from the oil crises of the 1970's. Important institutional support for construction of cogeneration facilities came from the Public Utility Regulatory Policies Act of 1978 (PURPA). This law put utility and nonutility generation on an equal economic basis.
Industry could now sell power to its utility if it could match the utility's marginal cost of generation.

The 1992 Comprehensive Energy Policy Act (EPAct) extends this sales opportunity to distant utilities through wheeling of wholesale power. Many believe that this will lead to widespread wheeling to retail customers. These new business opportunities for sale of electric power by industries, large commercial establishments and government agencies are the subject of this book.

The purpose here is to describe all of the new aspects in a cogeneration project when wheeling becomes an option. These new considerations include interaction and coordination with the interconnected utility (ICU), potential markets for wheeled power, decoupling of electric and thermal production, plant operation considerations, legal and regulatory constraints, and contract issues.

A wheeling project will involve many different decision makers: managers (at all levels), engineers, lawyers, economists and utility regulators. However, few of these people will have a comprehensive background in all of the issues that must be addressed during project development. The basic intent of this booklet is to facilitate communication among all of the abovementioned decision makers and to present institutional issues and project design options that 
should be considered. For example, regulatory constraints are explained for engineers as well as design options for improving project economics.

This is an information and an idea booklet. It is not a cookbook on how to develop a project. Many excellent guidebooks on project development already exist. A large amount of background information is presented on both technical and institutional matters that may be outside of one's own particular expertise. Such information includes a discussion of the physical manner in which utilities actually wheel power, the economic basis for various transmission pricing schemes, and the relevant legal requirements under EPAct.

Wheeling is a new and evolving business option, and it is hoped that this booklet will enhance project development and conservation of energy.

\section{BUSINESS OPPORTUNITIES}

Cogeneration facilities are sited at the thermal host, and the user of electricity is usually colocated. Electricity is delivered to the interconnected utility and/or to the thermal host. If power can be wheeled to a different party, additional opportunities may appear with the removal of the co-location constraint. Other customers may be located that will pay more for electricity.

Wheeling, as an option, permits the consideration of a wider range of plant designs. If electricity production can be increased, economies of scale might improve project economics. If electric generation can be decoupled from the time pattern of steam demand, the high on-peak purchase prices offered by many utilities might also enable project development.

The wheeling option does not only exist for new plants. It can be considered at the time of a major industrial plant expansion that increases heat demand by the thermal host. It can also be considered when major components of a power plant must be replaced, such as a boiler. With older cogeneration facilities, wheeling might present a better alternative at the time that an existing long-term power sales contract expires.

Wheeling is not a new concept, but EPAct now facilitates it. New opportunities do come at a cost, however. Project development requires attention to technical and institutional issues that will not arise with a conventional cogeneration project.

\section{BUSINESS RISKS}

A wheeling project will be more complex. At least one more party will be involved - the distant electricity buyer. This buyer, like the thermal host, could go out of business in the future. Also, the interconnected utility will have a host of concerns that won't appear in a straight electricity purchase. Interaction with the Federal Energy Commission or the state Utility Commission might be necessary, and evolving regulatory policy could introduce uncertainty even after power sales contracts are signed. Finally, project delay can be expected with first-time projects for the ICU or state regulator. Nonetheless, such risks have been abated in the growing number of successful projects. 


\section{CHAPTER 2.}

\section{BASIC PROJECT DEVELOPMENT CONSIDERATIONS}

As with conventional cogeneration projects, each wheeling project will face unique requirements and constraints. Completely new technical and legal issues will also have to be addressed. This chapter first presents a generalized description of the Wheeling Cogenerated Power (WCP) system. Discussed next are the greater amount of planning information needed and the expanded set of technical options that can be considered with wheeling. The chapter then addresses the three alternative thermal and electric load following strategies that should be considered. This is presented as general background information. Detailed discussion of these and other issues are examined in later chapters.

\section{THE WHEELING COGENERATED POWER SYSTEM}

Figure 2.1 depicts a simple wholesale wheeling system. From the project developer's standpoint, the most important decision makers are the thermal host, the cogeneration owner (if different), the interconnected utility $A$ (ICU), the purchasing utility $B$, and any adjacent utilities affected by wheeling (utility $\mathrm{C}$ ). Similar system configurations can be envisioned for other wholesale and retail wheeling situations. For example, the purchasing utility box would be relabeled "industrial customer" with retail wheeling. Also, there might be more than one interconnected utility through which power is wheeled.

Figure 2.1 Wheeling Cogenerated Power System (wholesale)

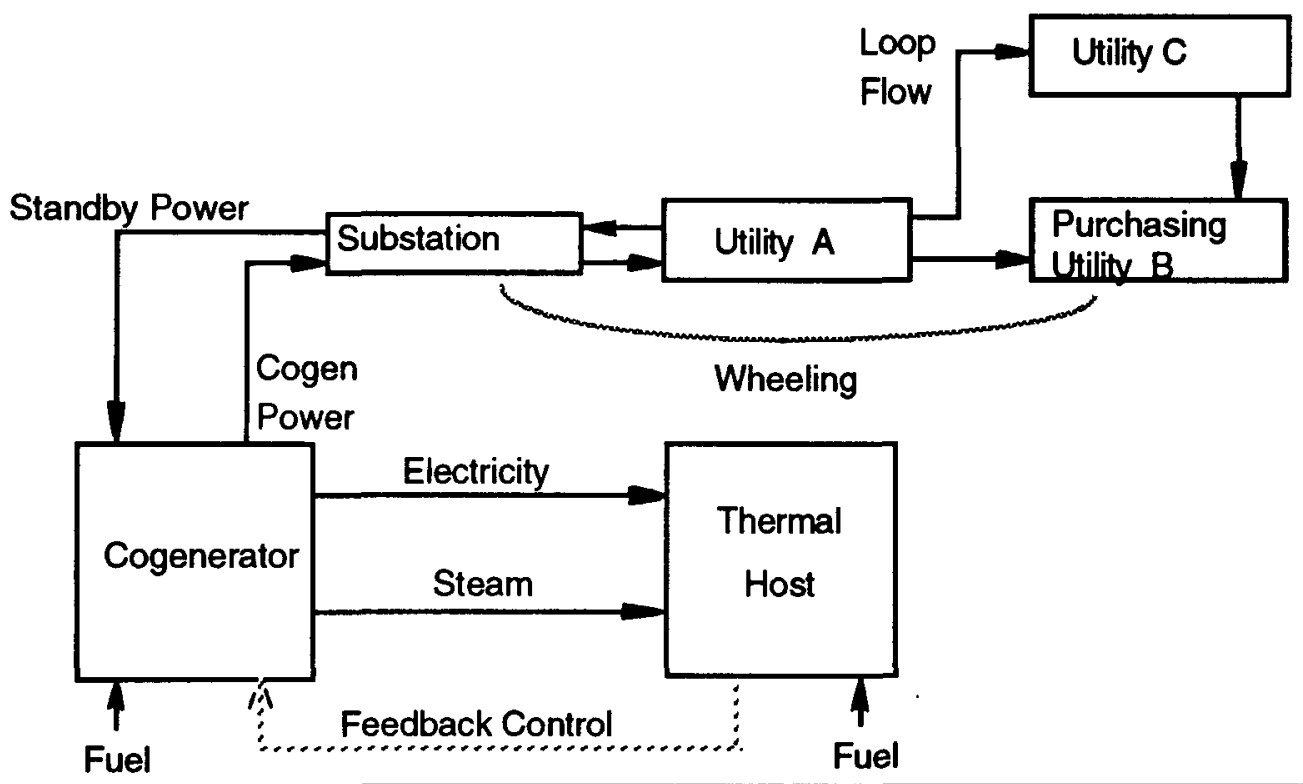


The "feedback control" line between the thermal host and cogenerator represents the instantaneous feedback of electric and/or thermal loads needed to match power supply and demand. A similar feedback line is not shown between the distant electric host and the cogenerator, however. An exact matching of electricity supply and demand is not possible because the ICU can only transmit power in increments of one megawatt (MW). Also, wheeling transactions must be prescheduled with the utility. Thus, an industrial or commercial (retail) host must depend on its own utility to supply part of the electrical load in addition to backup power.

Utility $C$ in Figure 2.1 represents a potential problem that is termed "loop flow." Because electricity follows the paths of least resistance, wheeled power may actually flow over the transmission lines of a neighboring utility. A full explanation of this issue and its implications is presented in Chapter 6.

\section{PROJECT CONSIDERATIONS}

Table 2.1 lists basic data requirements for cogeneration projects, both with and without wheeling. With a WCP project additional data must be collected in order to thoroughly examine all options. Energy costs for the distant electricity host and the cost of wheeling and backup electricity are, of course, needed. Since additional project designs can be evaluated, marginal costs

\section{Table 2.1 Data Requirements}

Without Wheeling

Thermal \& electric costs

Alternative fuel costs

Energy conservation costs

Cogen performance data

Cogen system costs

Interconnection costs
With Wheeling

Energy costs of WCP host

Cost of backup electricity

Wheeling costs

Marginal cost of larger facility

Marginal cost of decoupling

Electric host load profile of the alternatives, such as a larger cogeneration plant size, must also be assembled. Finally, marginal costs of decoupling thermal and electric load production are needed. "Decoupling" describes a plant's ability to separately follow the electric and thermal changes in load, over time.

Other information is also needed as shown in Table 2.2. Much of this can be obtained by adding specialized consultants to the initial project team. Legal counsel will be required that has experience in wheeling legislation and federal and state regulations. There is also a need to stay abreast of the frequent regulatory changes being experienced by the utility and non-utility industries. Consultants having prior experience with the interconnected utility can also be of assistance. Utilities that have a generally negative attitude toward cogeneration can have a similar 
Table 2.2 Other Information Required

\begin{tabular}{cc}
\hline Without Wheeling & With Wheeling \\
\hline ICU cogeneration attitude & Wheeling legislation \\
ICU interconnection needs & Wheeling regulations \\
ICU system protection needs & LegaV/regulatory uncertainty \\
PURPA regulations & ICU wheeling attitude \\
Environmental requirements & Transmission constraints \\
Required permits \& licenses & \\
\hline
\end{tabular}

important is the consideration of future plant expansion. This may not change the size of the initial cogeneration facility. But it may dictate a different mechanical design that will be compatible with subsequent facility expansion.

Evaluation of any cogeneration proposal should include multiple mechanical system designs and fuels. If wheeling is an option, a larger facility with economies of scale should be evaluated. With load decoupling, provision of peaking power is an option when the value of providing on peak electricity is high. Provision for supplemental fuels should be looked at because contract penalties can be large when a established relationships with such experts.

Table 2.3 Technical Options To Be Considered Without Wheeling With Wheeling

Energy conservation at host Larger cogeneration facility

Future plant expansion

Design alternatives Peaking power production Supplemental fuels

Disposition of electricity Wheeling at contract expiration Fuel alternatives QF versus EWG status fuel problem interrupts thermal or electric power production. In certain instances consideration should be given to certifying the facility as an exempt wholesale generator (EWG) versus a qualified facility (QF). This is discussed more fully in Chapter 7. Finally, wheeling should be considered prior to expiration of a power sales contract
A variety of technical options should be considered at the outset of any cogeneration project as shown in Table 2.3. Of prime importance is the opportunity for energy conservation within the thermal host plant, irrespective of cogeneration. If such options are only identified subsequent to construction of a cogeneration facility, the power plant may end up being oversized. Equally at existing cogeneration facilities. There is little that is constant anymore in the increasingly competitive electricity market, and market opportunities do change over time.

\section{LOAD FOLLOWING STRATEGIES}

In any WCP system it is incumbent upon the cogenerator to satisfy the thermal and electrical 
Figure 2.2 Thermal Host Load Profile

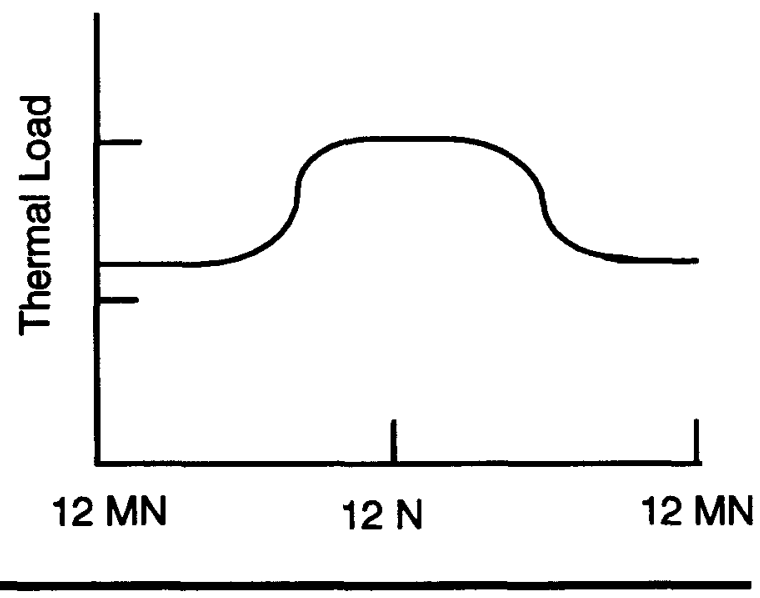

power loads as required by the contract. Simple cogeneration systems are limited in their ability to serve both loads, especially if the timing of the thermal and electrical loads is quite different. For example, consider a host thermal load typical of a building heating and cooling system. This may be a university campus distribution system, or perhaps it is a district heating system. The thermal load could have a daily load profile as shown in Figure 2.2. Their systems are characterized by heavy loads in the early morning hours as the occupants awake, turn up their thermostats, take the morning shower (steam heated water) and start their day. As the sunshine warms the day and outside temperature moderates, the heating load drops. Evening loads decrease as buildings are vacated and building management systems cut back the thermostat. The exact profile and the causes thereof are not important except to serve as an example for discussion.

Similarly, assume the customer is a textile mill whose main loads are lighting and motors used to drive the textile machinery. Since the mill operates three eight-hour shifts the electrical load profile might look like Figure 2.3. From this example the three main load following strategies will be examined, starting with thermal load following.

Figure 2.3 Electric Host Load Profile

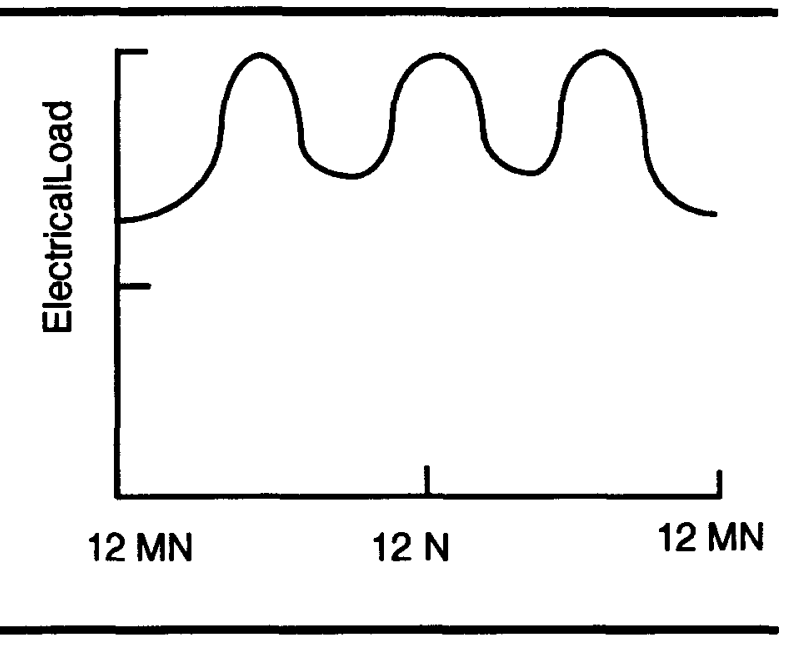

\section{THERMAL LOAD FOLLOWING}

If the WCP system is closely tied to the thermal host and has not made provision for decoupling and independence from the host, the electrical generation will vary proportionally to the thermal load. A simple WCP system might have an electrical output profile as shown in Figure 2.4. This is because the thermal host's consumption of steam dictates the generation level of the plant. To meet the steam demands of the host, the boiler must deliver all of the steam through the turbine generator. There is no alternative. Since the generator output is proportional to steam throughput and depends on the efficiency of the turbine generator, the output is fixed by the steam flow to the process. This is thermal load following. 
Figure 2.4 WCP Electrical Generation

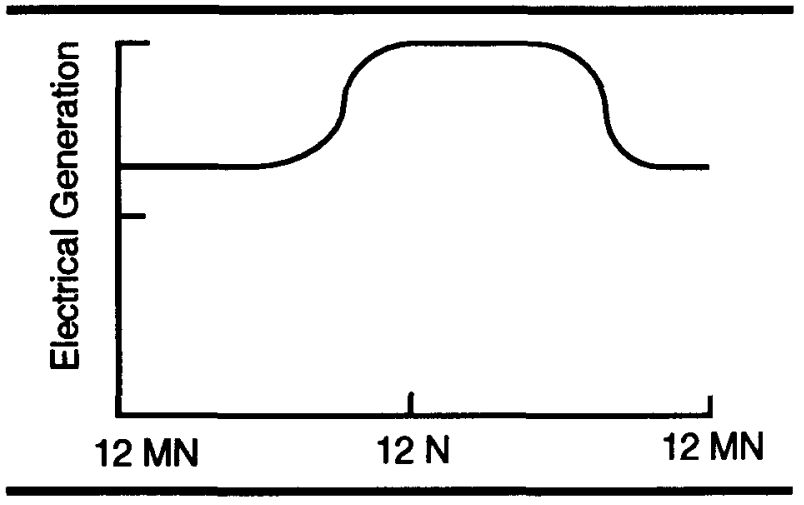

Electrical output is solely dependent on the thermal load demands. If we compare the generated power to the electrical load it might look like Figure 2.5.

Figure 2.5 Generation and Load Mismatch

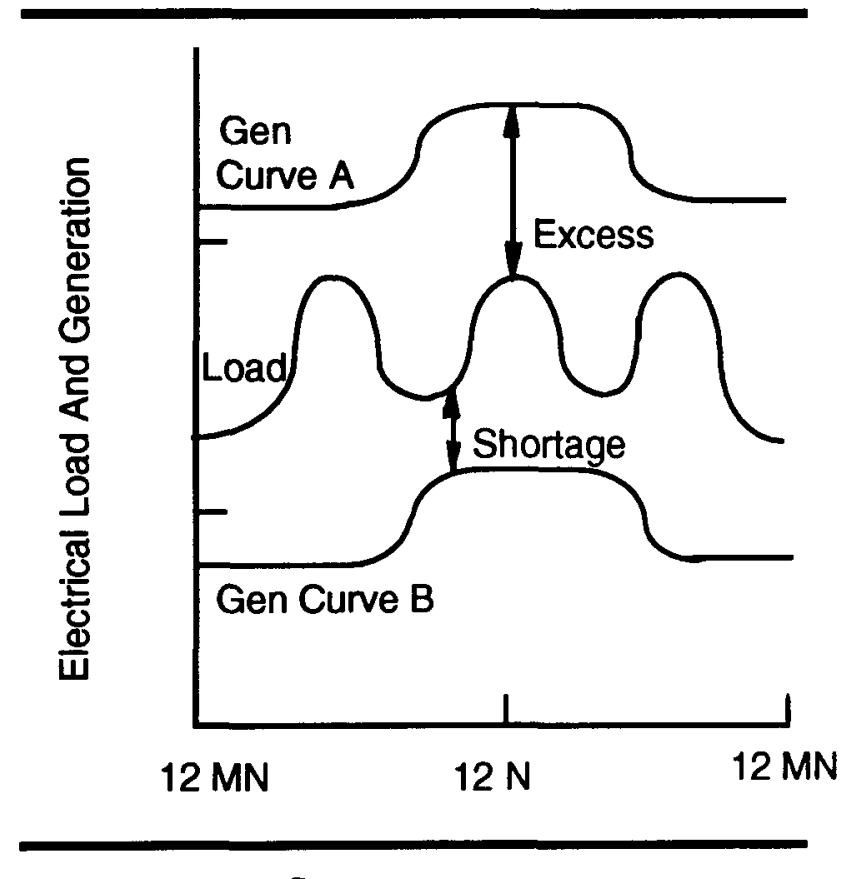

In this example, generation could be more or less than the load. If the generation is more than the load (Curve A), the cogenerator may need to sell the overage to the utility. If generation is less than the load (Curve B), the textile mill will need to buy the shortfall from the utility or else curtail their consumption. In either case the problem of the mismatched generation and load will likely be the cause of buying or selling from the utility at unfavorable rates.

\section{POWER LOAD FOLLOWING}

Power load following occurs when the cogenerator, as nearly as possible, schedules and matches electrical generation to the electrical demand. In this example, the cogenerator would know, beforehand, electrical load of the textile mill. The firing rate of the boiler would be adjusted to produce the steam required by the turbine generator to meet scheduled electrical load. This mode of load following makes the thermal host dependant upon the demands of the electrical host. The steam delivered to the thermal host will vary with electrical generation and may be more or less than the needs of the host process. If the steam delivered is more than required, some must be condensed and the energy lost. If there is a shortage of steam, the shortage must be made up by alternate steam sources or the process curtailed. In any case, the thermal host or cogenerator will face an increased cost of operation.

\section{DOUBLE DISPATCH}

The technique of double dispatch avoids the disadvantages of thermal load following and power load following which were just discussed. For double dispatch load following, an investment in equipment is required to simultaneously meet the 
thermal and electrical load demands. The additional equipment provides the necessary decoupling of thermal and electric loads. The double dispatch system allows the cogenerator to meet and precisely match the load demands of both thermal and electrical customers by providing the flexibility of operation necessary to independently produce both thermal and electrical power.
The equipment that is required usually takes the form of additional boilers, turbines, and generators. Alternate fuel sources and equipment bypasses also are a useful part of the double dispatch system operation. A more complete description of these decoupling techniques is found in the mechanical system design section of Chapter 4. 


\section{CHAPTER 3.}

\section{MARKETS FOR WHEELED POWER}

Post-PURPA events have shown that the higher efficiency of a small cogeneration facility can compete with a utility-built power plant, despite the loss of electrical generation economies of scale. Such economies can be regained with large wheeling projects and thereby further increase opportunities for cogeneration. However, these opportunities will have to be identified and pursued by cogeneration project developers in an increasingly competitive, and sometimes hostile, marketplace.

Market opportunities must present benefits that outweigh the costs of wheeling to all of the parties involved. Because benefits will vary across utilities, a description of utility classes is presented first, with emphasis on their need for long-term purchased power. The present status of the wheeling and bulk power market is addressed next. This constitutes the existing competition for access to transmission lines. Following this, market opportunities for wheeling cogenerated power are identified. Although only niche markets appear to be appropriate, the potential market is quite large. This potential is assessed in the last section of the chapter.

\section{UTILITY CLASSIFICATION}

Electric power in the United States is provided by a mixture of organizations owned by private investors, electricity consumers, local and state governments, and the Federal government. For definitional and reporting purposes, the categories shown in Table. 3.1 are in general use.

\section{Table 3.1 Utility/Power Agency Classification}

Investor-owned (private)

Publicly-owned (public)

Municipals

Public Power Districts

State Authorities and other bodies

Irrigation Districts

Cooperatives

Distributor

Generating \& Transmission

Federal

Alaska Power Administration

Bonneville Power Administration

International Boundary \& Water Commission

Southeastem Power Administration

Southwestern Power Administration

Tennessee Valley Authority

US Army Corps of Engineers

US Bureau of Indian Affairs

US Bureau of Reclamation

Westem Area Power Administration

Although only eight percent of electric utilities are private, they sell 75 percent of the electricity produced in the U.S., and they own the major portion of the bulk power transmission system. 
They are also major suppliers of long-term power to publicly-owned systems.

The largest group of public utilities are municipallyowned systems. However, over two-thirds of their sales are resales of electricity produced by others. Other publicly-owned utilities include public power districts, state authorities, and irrigation districts. These latter types generally produce more power than they can sell to retail customers, selling the remainder to municipally-and cooperatively-owned utilities.

Cooperatively-owned utilities are of two types. One is a distributor (to retail customers) that may or may not own its own electrical generation. The second is a Generating and Transmission (G\&T) cooperative, owned by distributor co-ops, and organized to supply a part or all of their needs. While they account for 7 percent of U.S. retail sales, they only produce 4 percent of total generation, purchasing the remainder from others.

Approximately 20 percent of Federal-produced electricity is sold to retail customers, primarily large industrials or federal installations. The bulk of the remaining power is sold to publicly-owned utilities (municipals and cooperatives) for resale. These customers have a legal preference right to federalproduced electricity.

Utilities that purchase all or part of their electricity needs from others are termed "full" or "partial" requirements utilities. Purchases, for the most part, are under long-term contracts with IOUs, federal power administrations and agencies, and G\&Ts, in that order of importance. Substitution of a new power supply is usually only possible at contract expiration.

\section{CURRENT COMPETITION FOR TRANSMISSION LINES}

Interconnection of utilities' transmission systems occurred historically for several reasons:

- to increase system reliability by providing access to another utility's generation in emergencies;

- to facilitate off-system power sales;

- to improve system security with redundant paths that circumvent localized failures; and

- to facilitate exchange of generation between utilities with peak loads occuring at different times.

Since the mid 1980s the transmission system has also been used increasingly to support the growing market in wholesale trade, both between utilities and between a utility and a non-utility (as a result of PURPA).

Wheeling was the fastest growing type of transaction during the late 1980s, increasing by almost $40 \%$ from 1986 to 1990 . This reflects the opportunities buyers found to reduce their power costs and the opportunities sellers found to maximize their revenue. Generation overcapacity in the industry throughout the 1980 s encouraged this.

The magnitude of bulk power and wheeling transactions is illustrated in Table $\mathbf{3 . 2}$ for each utility classification. Unfortunately, data unavailability prevents separation of the long-term transactions 
Table 3.2 1990 US Electricity Transactions (billion kWh)

\begin{tabular}{lrrrrrr}
\hline \multicolumn{1}{c}{ Source of Energy } & \multicolumn{1}{c}{ IOU } & Federal & State & Muni & Co-op & US Total \\
Net Generation & $2,112.5$ & 253.4 & 180.8 & 122.5 & 152,2 & $2,821.5$ \\
Purchases from utilities & 378.6 & 10.3 & 76.2 & 243.9 & 289.5 & 998.5 \\
Purchases from non-utilities & 113.1 & 1.0 & 0.4 & 1.1 & 0.5 & 116.1 \\
Exchange received & 332.2 & 41.6 & 8.6 & 26.5 & 17.9 & 426.7 \\
Wheeling received & 230.8 & 54.8 & 13.2 & 19.6 & 4.3 & 322.7 \\
& & & & & & \\
$\quad$ Disposition of Energy & & & & & & \\
Sales to ultimate customers & $2,071.1$ & 54.7 & 90.3 & 295.6 & 201.0 & $2,712.6$ \\
Sales for resale & 385.3 & 195.7 & 150.2 & 47.3 & 220.8 & 999.3 \\
Transmissiondistribution losses & 150.0 & 9.4 & 7.0 & 17.2 & 20.8 & 204.3 \\
Source: DOE/EIA Electric Trade in the U.S. 1990 & & & & & \\
\hline
\end{tabular}

(the type that wheeled cogenerated power could displace) from short-term coordination transactions (economy or reliability sales and exchanges).

Table 3.2 shows that utility purchases by state agencies, municipals and cooperatives are targets for cogenerators. Their purchases of long-term power will generally be at full wholesale prices. For cogenerators who have found that they cannot compete by selling at the low avoided costs of the local utility, other utilities that purchase power at wholesale rates provide new opportunities for wheeling cogenerated power. The table also shows significant IOU purchases from other utilities, nonutilities, and through wheeling. Power purchased by lOUs under long-term contract presents an opportunity here, also. Current cogenerators who do not wheel can become a direct competitor when their existing power sales contracts expire or come up for renewal.
A new competitor to utility plants and cogenerators is the Exempt Wholesale Generator (EWG), a nonutility entity created by the 1992 Energy Policy Act. A discussion of EWGs is contained in Chapter 7. In some instances a cogenerator may find it advantageous to meet the competition by seeking certification as an EWG rather than as a Qualified Facility (QF) under the Public Utility Regulatory Policies Act.

Another new competitor is the "power marketer." Citizens Power \& Light Corp. of Boston was the first to receive FERC approval for marketing electricity in 1986. As of July, 1994 more than $\mathbf{4 0}$ marketers have sought, or have been granted, permission to market power at market prices. This list includes several affiliates of electric utilities.

A primary business objective of marketers is to broker, or to sell, excess generating capacity at 
"market prices." Price is mutually determined by the buyer and seller under the condition that the seller does not possess monopoly power. This generally means that transmission lines used for a power sale are available, under comparable terms, to other potential sellers of power. New competition for a cogenerator arises because the power can be sold at a price below what would be required under traditional utility rate regulation. Traditional determination of prudent rates is based upon full cost recovery of allowable capital and operating expenses. A cogenerator may therefore have to meet or beat not only a utility's wholesale power rate, but a lower rate available through a power marketer.

Power marketers are increasing their competitive position by offering additional services to electricity buyers. Such services include development of transmission and distribution access capabilities, new approaches to sourcing and managing electric generation assets, fuel supply, and risk management tools such as futures, options and swaps. The last service just cited, financial instruments, can provide buyers and sellers with fixed prices that control future costs or lock in sales prices. On the positive side for cogenerators, a power marketer can serve a useful function by finding a market for power and developing access to transmission lines.

Even with these new competitors, the utilities that own transmission lines may impede access, at least in the short run. They have a significant self-interest in off-system short term power purchases and sales that reduce costs for their native load (retail) customers. Various obstacles can be presented to cogenerators such as anti-cogeneration rates. Another example is the requirement of the Pennsylvania-New Jersey-Maryland Interconnection that all of its members approve any firm wheeling agreement.

Tradeoff between a utility's commitment to long term wheeling under firm prices (as with a cogenerator) and short term reservation of capacity for uncertain cost-saving opportunities may have to be adjucated by regulatory authorities. Over the longer term the Federal Energy Regulatory Commission is expected to create a level playing field through its new comparability standards for transmission service. This is discussed further in Chapter 8 . On the other hand, the continuing trend toward market pricing is a direct consequence of industry deregulation that can only increase competitive forces over the long term.

\section{NICHE MARKET OPPORTUNITIES}

If special interests of the parties potentially involved in wheeling are examined, market opportunities can be identified. These market niches must present benefits that outweigh the costs of wheeling to all parties involved. In general, it will seldom be possible to compete directly with utility plants that are operating (aside from those involved with power marketers). Capital costs are being recovered in the rate base, and one must compete with only their variable fuel plus O\&M cost of production. Table 3.3 lists market opportunities. These are briefly discussed in what follows. 
Table 3.3 Market Opportunities

Non-interconnected utilities with high avoided costs

Requirements utilities

Industrial plants within a requirements utility's service territory

Retail affiliate of a non-utility generator or exempt wholesale generator

Mutually beneficial situations

\section{UTILITIES WITH HIGH AVOIDED COSTS}

This is the most obvious alternative: find a utility that has high avoided costs who will pay more than the interconnected utility for electricity.

\section{REQUIREMENTS UTILITIES}

The second opportunity is with utilities that purchase some or all of their power requirements from other utilities. They are generally public, versus private utilities. Most are either municipallyor cooperatively-owned electric systems. The relevant price with which a cogenerator can compete is the utility's wholesale cost of electricity, not avoided cost. The interconnected utility, in this case, might object to wheeling power for a qualified facility if the cogenerator wanted to receive a price higher than the avoided costs of the supplier utility to the requirements utility. In this case, the cogenerator could first pursue the designation of Exempt Wholesale Generator from FERC and then request a wheeling order from FERC.

\section{RETAIL CUSTOMERS IN REQUIREMENTS UTILITY SERVICE TERRITORY}

The third option can occur when a requirements utility cannot purchase cogenerated power because of contractural arrangements with its supplier utility.
If power is wheeled to one of their retail customers, wholesale purchase requirements and peak demands decrease for the requirements utility by the amount of wheeled power. In this situation the requirements utility would lose its markup on power previously sold to the retail customer; so power savings might have to be shared between the retail customer and the requirements utility. On the other hand, the wheeling charge and standby power charge paid to the requirements utility might more than offset markup loss to the utility.

\section{RETAIL AFFILIATE OF A NON-UTILITY GENERATOR}

The fourth opportunity reflects enabling rulings by Public Utility Commissions (PUCs) in several states. An affiliate is defined as a subsidiary or other legally related industrial plant or government facility that is affiliated with the facility which desires to cogenerate. Some PUCs have mandated that power be wheeled to such affiliates.

John Anderson of the Electricity Consumers Resource Council (ELCON) has suggested two additional alternatives. First, if an industrial plant owning generation gets certified as an Exempt Wholesale Generator (EWG), it can probably wheel power to an affiliate plant under the 1992 Energy Policy Act. Because the company owns the power that it generates, no retail sale is involved. Second, if the thermal host and the company receiving wheeled power (different companies) are joint owners of the cogeneration facility, it may be possible to convince the PUC that a retail sale is not involved. 


\section{MUTUALLY BENEFICIAL SITUATIONS}

Finally, the fifth category includes many opportunities that can be exploited by innovative ideas from cogenerators. For example, a municipal utility might benefit by the ability of a cogenerator to burn municipal solid waste, thereby addressing an unrelated municipal problem. Municipalities might also be interested in cogenerated power as a way to provide lower priced electricity to local industry, either to attract new industry or to prevent existing industry from closing.

For an investor-owned utility, a cogenerator's ability to burn coal fines from a coal washing plant and thus solve a disposal problem might be sufficient to offset lost power sales from the utility's own capacity. Dispatchability of power by a cogenerator to meet a utility's peak demand could also provide a purchase price high enough to make wheeling cogenerated power economically feasible. Here, dispatchability may not necessitate real time control by the utility's power control center. It could be accomplished through telephone communication or long-term contractual conditions.

Innovation by non-utility generators has been the predominant force of change in the electric utility industry since passage of PURPA. Other market niches will, no doubt, be identified by developers.

\section{MARKET POTENTIAL}

The total potential for wheeling cogenerated power has been estimated by Resource Dynamics Corp. using several modeling techniques. Over the next decade this market is estimated at between 5,000 and 20,000 MW. These numbers compare with an installed capacity of about $45,000 \mathrm{MW}$ for non-utility generation in 1990.

In general, once the power enters the grid, the production method becomes unimportant: price and reliability are the principal drivers for power sales. To a large extent, cogeneration technologies can produce power at prices that would prove competitive in many wholesale markets. Economies of scale associated with a cogeneration facility that could wheel power might be able to compete favorably with independent power projects and with current long-term inter-utility power sales arrangements. However, all else being equal, once cogenerators have access to these markets, so will other competing electricity generators. Therefore, some of the real opportunities are associated with unique thermal and electrical demand situations. These unique niches may sometimes include retail, as well as wholesale, wheeling.

\section{Table 3.4 Regional Market Potential}

(in order of importance)

1. Western Systems Coordinating Council

2. Northeast Power Coordinating Council

3. Southeastern Electric Reliability Council

4. East Central Area Reliability Coordination Agreement

5. Mid-Atlantic Area Council

6. Southwest Power Pool

7. Electric Reliability Council of Texas

8. Mid-American Interpool Network

9. Mid-Continent Area Power Pool 
Figure 3.1 North American Electric Reliability Council Map

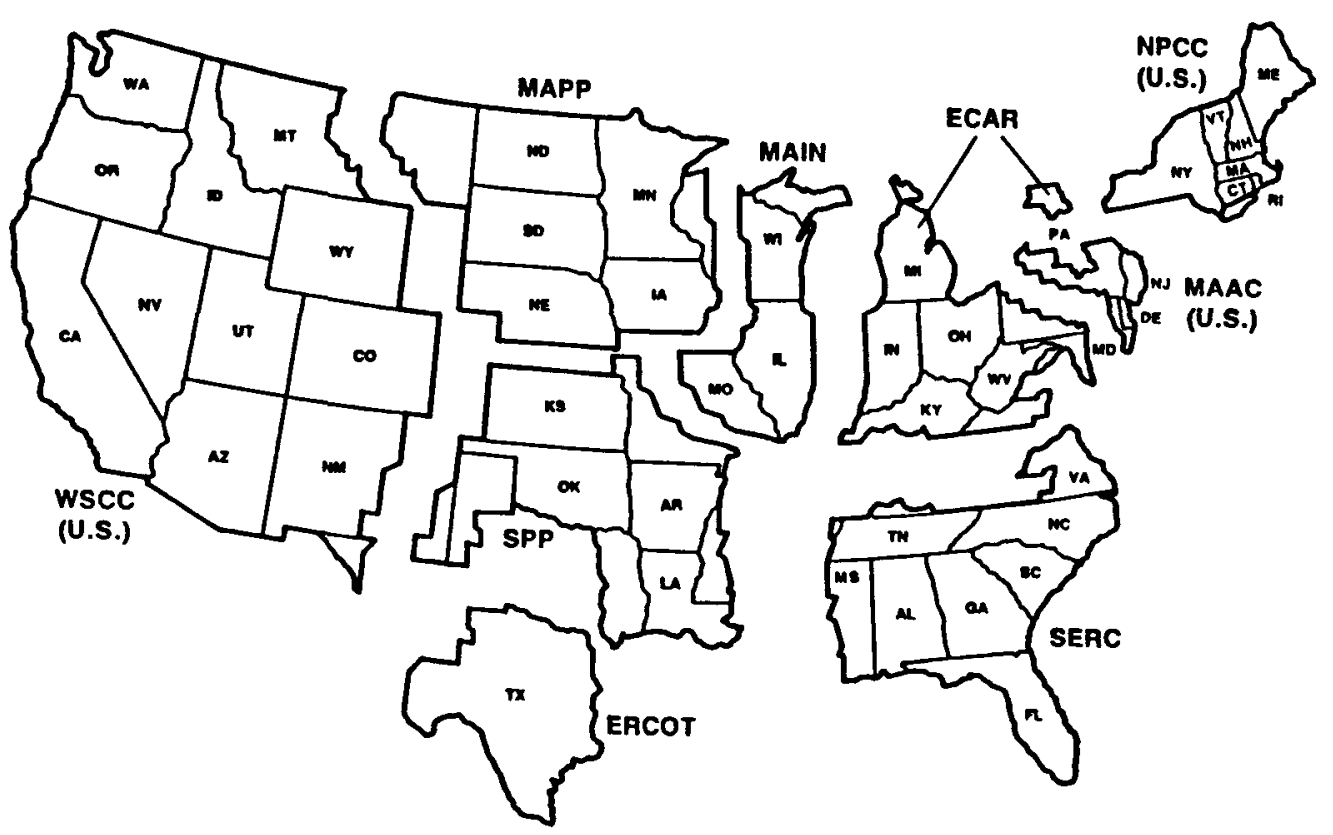

Market opportunities, of course, differ by region of the country. Table 3.4 ranks this potential by electricity reliability council region, as shown in Figure 3.1. The largest potential is in WSCC, NPCC, and SERC regions. However, market opportunities may not comprise an entire region. In SERC, for example, the major market is in states on the Atlantic coast, not in Tennessee, Mississippi or Alabama.

Current data on utility prices are helpful in identifying market opportunities. Three price categories are useful: avoided costs, wholesale prices, and retail industrial and commercial prices.

Utilities' avoided costs are published quarterly in Independent Power Markets Quarterly. Those with high avoided costs are obvious targets.

Wholesale prices are not assembled and published in any convient source. However, average wholesale prices may be found in many utilities' annual reports. Some libraries maintain a collection of utilities' annual reports. Afternatively, a phone call to a utility can provide a company's wholesale demand charge, energy charge, and monthly fuel adjustment adder. Average retail industrial and commercial prices are published in Energy User News on alternate months for over 150 utilities. Companies can be targeted that have industrial prices of at least $5.3 \mathrm{q} / \mathrm{kWh}$. Most of their utilities already have many cogenerators in their service territory.

Aside from any favorable economic situations that can be identified by cogenerators, market opportunities can be negated by those utilities that are fundamentally opposed to wheeling. However, innovative ideas from project developers can possibly reduce the reluctance of certain utilities to 
wheel power. The innovation shown by non-utility generators since passage of PURPA can result in identification of opportunities for greater wheeling of cogenerated power. Projects should be structured to be in the interest of the interconnected utility and the purchaser of power.

\section{INFORMATION SOURCES}

Electric Prices

Electric Statistics

Electric Utilities

Markets

Power Marketers
Energy User News; Chilton Publications (industrial and commercial prices).

Independent Power Markets Quarterly; McGraw-Hill (avoided costs).

Capacity and Generation of Non-Utility Sources of Energy - 1991; Edison Electric Institute, \#01-92-08.

Statistical Yearbook of the Electric Utility Industry / 1992; Edison Electric Institute, \#01-93-05.

"U.S. Electricity Statistics;" Public Power; Jan/Feb 1993, pp 64-67, 71-155.

Electrical World Directory of Electric Utilities - 1993; McGraw-Hill.

Electric Trade in the United States - 1990; DOE/EIA-0531 (90), Dec 1992.

"Markets for Wheeling Cogenerated Power;" R. G. Tessmer, Cogen, Winter 1994.

"Retail Wheeling in the Electric Utility Industry: It's Working;" R. J. Dingle, Cogeneration \& Resource Recovery, JulAug 1992, pp 10-13.

"Tapping the Public Power Market;" H. D. Baker, Independent Energy. Oct 1990.

Wheeling Cogenerated Power - Phase / Report; DOE/CE/40942-1, Sep 1993, pp 4-22 to 4-29, 5-2 to 5-33.

Power Marketing Association, Alexandria, VA, 703-998-3522. 


\section{CHAPTER 4.}

\section{DECOUPLING ELECTRICAL \& THERMAL POWER PRODUCTION}

The ability of a cogeneration facility to separately follow thermal and electrical load patterns is critical to widespread adoption of WCP. This chapter addresses three prime considerations. The first is flexibility of fuel supply and consideration of alternative fuel sources that will enhance decoupling. Secondly, mechanical system design considerations are examined. The mechanical prime movers that are looked at include steam turbines, gas turbines and diesel engines. Finally, flexibility of operation is addressed as a consideration in designing a facility that decouples thermal and electric power production.

\section{FUEL FLEXIBILITY AND SUPPLY}

Cogeneration systems use a wide variety of fuels. The selection of a fuel or fuels is not in any way restricted by the fact that cogeneration technology is being used. Certainly fossil fuels (coal, oil, gas) in their many forms are the fuels of choice. Many process wastes are also attractive for cogeneration fuel. Waste to energy plants utilizing municipal solid waste (MSW) to cogenerate are numerous throughout the world. Many applications for cogeneration also exist where waste heat is available in bulk. Waste-fueled are usually the easiest cogeneration plants to justify economically.

Project advantages are possible when the primary boiler can burn multiple fuels in varying proportions.
Burning of waste fuels such as MSW, tires, and coal fines in combination with, say, coal can provide important environmental benefits. Stoker-fed boilers and rotary kiln combustors are especially suitable for this purpose.

Consideration should be given to the fuel used in backup boilers as well. Backup boilers insure the availability of steam to the process host when the main boiler or the primary fuel is unavailable. They can also be part of the system design that decouples steam and electrical output. If backup boilers are not used very often, premium price fuels may be preferred for use in lower-first-cost backup boilers.

\section{CHOICE OF FUEL}

Reliable system operation usually dictates the need for some diversity in fuel burning capability. In particular, fossil fuels are subject to interrupted availability for numerous reasons. Coal is plentiful and usually available from many independent suppliers. It is not normally subject to short supply or wide price swings. Coal, however, is subject to delivery problems associated with weather, and it is not uncommon for extended winter storms to curtail delivery long enough to impact coal users. Historically, labor strikes in the mining and trucking sectors have interrupted the supply of coal to large parts of the United States. 
Burning coal in an environmentally acceptable manner requires air pollution control systems. Baghouses or electrostatic precipitators are normally required for particulate removal. Under the 1988 Clean Air Act, flue gas scrubbers are often necessary for the removal of pollutant gases such as sulfur dioxide and the oxides of nitrogen. Besides having a negative impact on the cost of operation, scrubbers require bulk chemicals for injection which are necessary for operation.

Fuel oil is a product of the international petroleum industry and is subject to all the political and economic forces of world events. There have been periods of short supply in recent history, but the main risk to users has been volatile prices. Low sulfur oil has commanded premium prices as the requirement for its use to reduce sulfur dioxide emissions has become more common. Fuel oil is one of the most expensive cogeneration fuels.

Natural gas is a relatively clean burning fuel and often does not require air pollution controls. Where available, natural gas is the fuel of choice for combustion turbines. Delivery is reliable since it is transported via interstate pipelines. However, natural gas for boiler fuel and combustion turbines is often subject to interruption from weather affecting off-shore platforms and from delivery capacity shortages during extremely cold weather.

In large regions of the United States the natural gas market has both firm gas and interruptable gas available with the reliability of supply reflected in the cost. However, firm gas is sometimes not delivered in lieu of shipment to residential customers during extreme winter weather. Natural gas, while not usually the least expensive fuel, is arguably the most convenient to use and is applicable to most cogeneration technologies.

It is important to consider having an independent fuel supply provide backup for the primary fuel source. While this backup supply can take the form of on-site inventory of the primary fuel, the capability to use a second fuel will give additional protection. For example, it is common to use gas or oil as a backup for a coal-fired plant. Light fuel oil is commonly used as a backup fuel for gas-fired combustion turbines. But extreme winter weather can disrupt availability. Local supplies can become exhausted, and tank trucks licensed for interstate shipment may not be available. Liquified natural gas, propane and other liquified gases can be used as a backup for natural gas. Process waste and municipal waste fired plants have successfully used fossil fuels as backup.

The ability to supplement the primary fuel with additional heat input from a secondary fuel source is important as a method to boost output during peak load demand. It can also be economically attractive to use a more expensive supplementary fuel to substitute for less expensive main fuel that is temporarily unavailable in order to meet contract demands and load peaks.

\section{STORAGE AND INVENTORY OF FUEL}

The primary fuel can be inventoried on-site in most cases. To assure an adequate supply, coal, fuel oil, 
and most waste fuels are commonly stored nearby in sufficient amounts to supply the plant through any reasonable shortage. It is not unusual for a cogeneration facility to store one month's supply of fuel measured at full load conditions. Risk management and a full consideration of the cost involved in a fuel-shortage-induced outage must be considered. An alternate fuel capability can reduce inventory requirements dramatically by providing a fuel not subject to the same risk as the primary fuel. Natural gas can be liquified, but the investment in this capability is seldom economically feasible. Municipal waste and other waste fuels have a shelf life which restricts the time period during which inventory can be held before it is consumed. Municipal waste held more than a week becomes an environmental and health problem for plant workers and neighbors. These problem fuels invariably demand a more friendly backup fuel.

\section{MECHANICAL SYSTEM DESIGN}

Basic cogeneration systems usually have the electrical power generation and the thermal process load coupled in a serial as opposed to a parallel arrangement. In other words, cogeneration is the sequential production of electrical power and heat. In some cases (called bottoming cycles), the cogeneration system can use the recovery of thermal energy for power production. In any case, the power generation and thermal loads are arranged so that the exhaust of one is the input to the other. This is precisely what gives the cogeneration cycle the advantage of efficiency over utility generating plants which must condense steam or vent waste heat from gas turbines and engines.
Unfortunately, the nose to tail relationship between electrical generation and thermal energy production causes the output of one to be directly proportional to the other. It is a very dependent relationship. When power generation is increased in a topping cycle, delivery to the thermal host is increased in a proportional amount and vice versa. This would be fine if the thermal host and the electrical power consumer had simultaneous load requirements. Unfortunately this is seldom, if ever, the case.

To separate the production of thermal and electrical power, designers use decoupling techniques. These techniques provide varying degrees of independence to the thermal host and to the electrical power customer.

In general, these designs involve the use of auxiliary or supplementary fuel to boost the production of electric power or heat to the process. Other techniques involve the addition of condensing turbine generators which run parallel and can substitute for the process host as a thermal load. Almost all of these techniques require the addition of installed capacity: additional boilers, auxiliary burners, additional turbines and generators, or some combinations of these. The added flexibility of operation translates into additional equipment and increased cost.

\section{TOPPING CYCLES}

Steam Turbine Cycles - In order to discuss the more common decoupling techniques, each must be considered in the context of the overall cycle. The most common is the topping cycle which uses a 
Figure 4.1 Basic Steam Topping Cycle

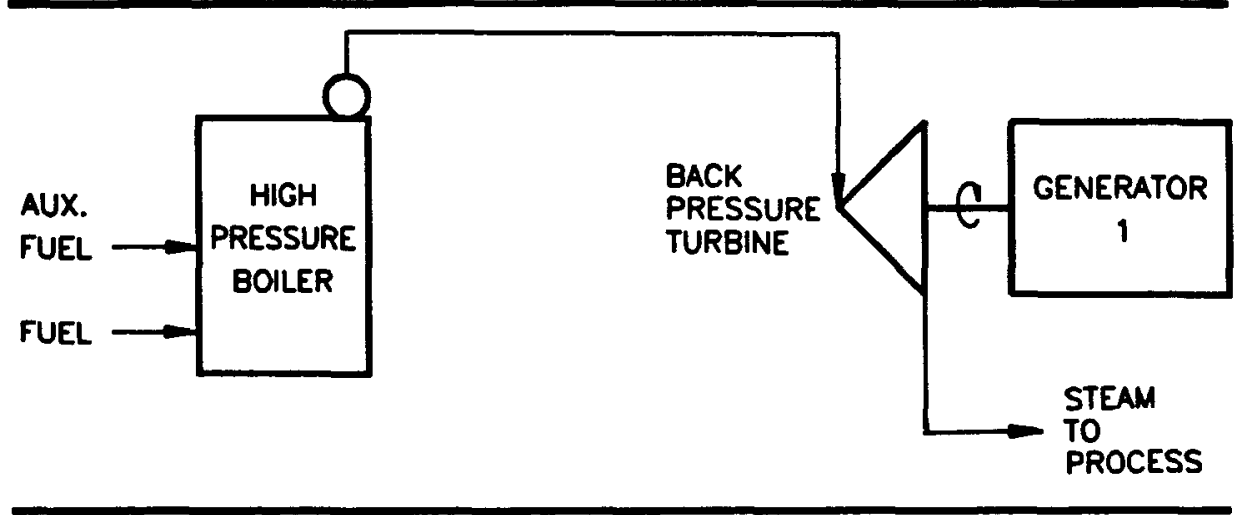

Figure 4.2 shows the addition of a pressure reducing valve and desuperheater to bypass steam flow around the turbine. This relatively inexpensive modification permits the load to be shifted from generation to the process host either backpressure steam turbine, and discussion shall begin there.

Figure 4.1 shows the basic steam topping cycle. In this cycle a boiler is fired with coal, gas, oil, or some other fuel. The steam passes through a backpressure turbine and then exhausts to the host thermal process. In this basic cycle all the steam flow to the process host must pass through the turbine. Therefore, the electrical generation and steam to the process may not be varied independently.

Figure 4.2 Steam Topping Cycle With Steam Bypass

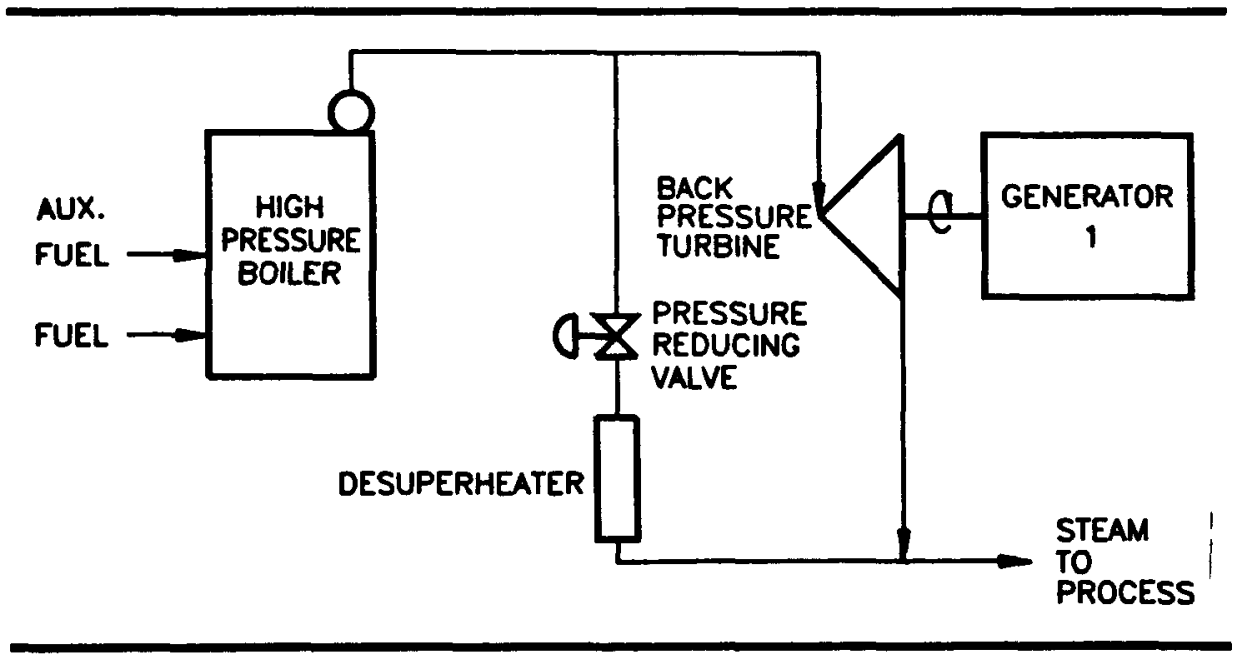

partially or completely. The process load can now be met completely independent of electrical generation. The opposite is not true.

Figure 4.3 adds a condensing turbine generator in parallel flow to the process host. With this arrangement, steam can be sent to the condensing turbine generator, in all or in part. Electric power can now be generated completely independent of the process host. Since the condensing turbine is relatively large and will require a condenser and cooling water system to support it, and since the generator will require additional synchronizing switchgear, this is a very expensive option. The added equipment could well double the cost of the plant.

If short periods of process load curtailments are expected, a much less 


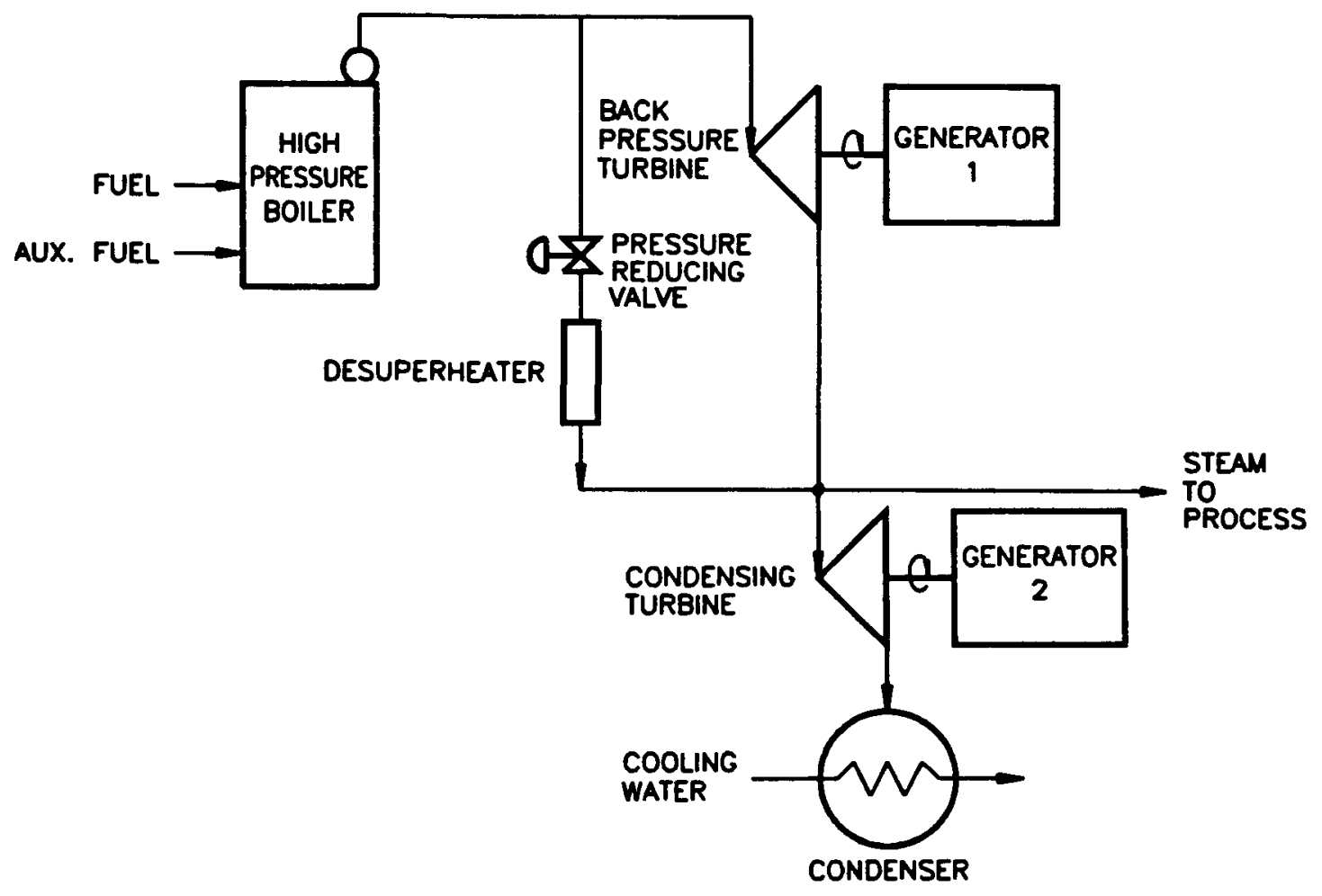

expensive steam condenser may be substituted for the condensing turbine generator. In this case the cooling water system will still be required, and the energy of the steam will be lost.

For very short periods of process load interruptions a simple steam blow off to atmosphere with a sound attenuation muffler may be used in lieu of the turbine or condenser. This inexpensive solution should only be considered for short and infrequent use. Not only is the energy of the steam lost, but the steam condensate which is lost must be replaced by the boiler feedwater makeup system.

With either of these decoupling schemes in place, the original steam generation system may not be adequate to support independent operation. This will require additional boiler capacity, either a larger boiler or an additional boiler. If the primary fuel source is limited, additional capacity may require an auxiliary fuel source.

Figure 4.4 shows a cogeneration system which includes all of these options, providing complete decoupling of the electrical generator from the process host. Since this design now has a noncondensing turbine and a condensing turbine, the designer may need to consider replacing both of these with a single condensing turbine which has interstage extraction at the process pressure. Economically this would be a wise choice since the single condensing turbine with extraction would be 
Figure 4.4 Complete Decoupling In Steam Turbine Facility

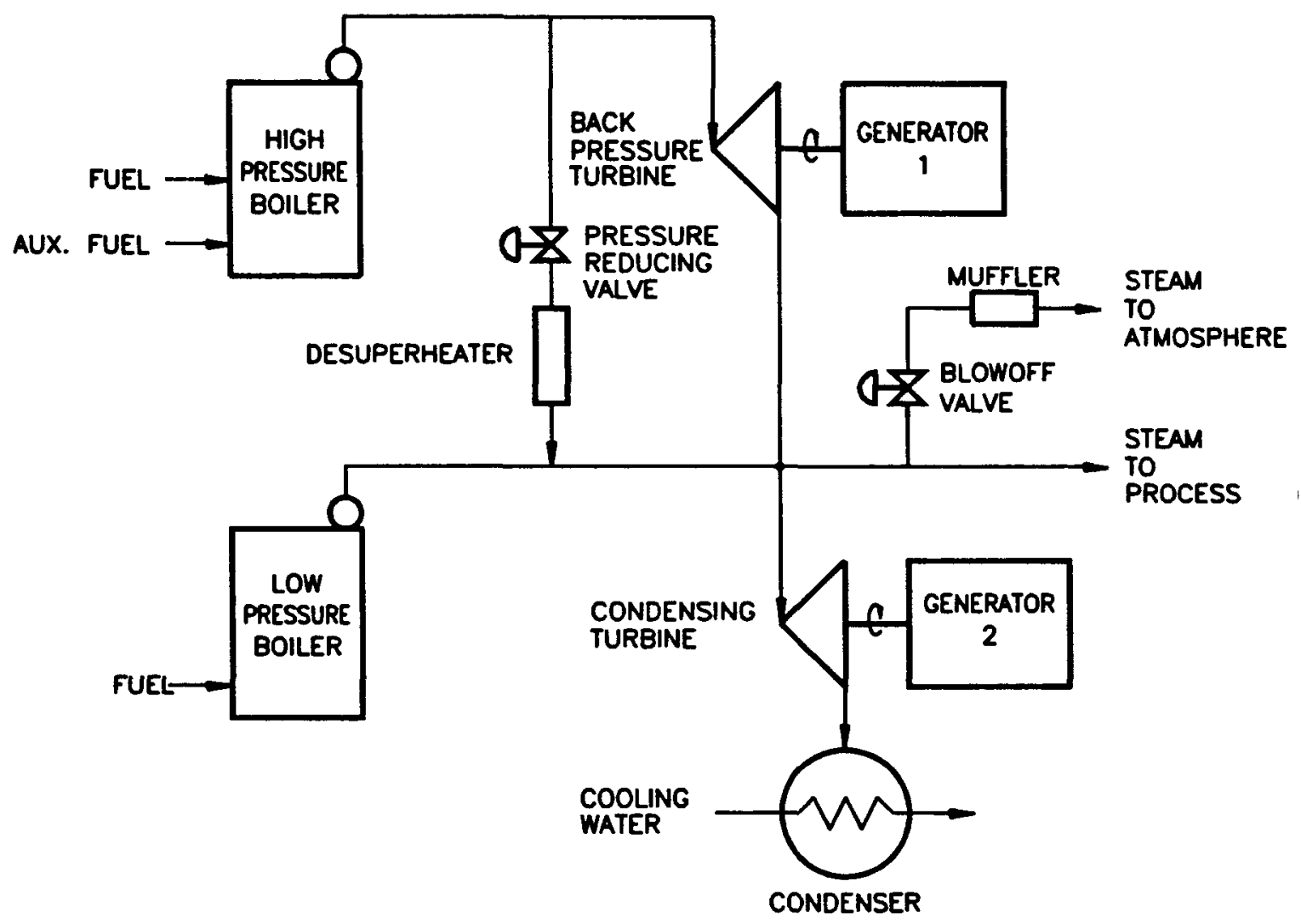

less expensive than the two it replaces. This alternative has the added benefit that it would need only one generator. This avoids the addition of electrical switchgear, protection, and synchronizing equipment required by the second generator. This design would be as shown in Figure 4.5.

Gas Turbines \& Combined Cycles - A simple combustion turbine based cogeneration system is shown in Figure 4.6. Usually, natural gas or light oil is used to fuel a combustion turbine. This highly reliable engine is commonly used on turbo-prop aircraft and many other aircraft. It is called an aeroderivative, having been modified for use as an industrial combustion turbine. The shaft horsepower of the combustion turbine is connected through a gear reduction unit to an electrical generator. The hot exhaust gas is ducted to a heat recovery steam generator (HRSG) where steam is produced for the process host.

One will notice that with this arrangement the electrical generation and steam generation are close coupled, dependent, and directly related. To increase steam for the process, the combustion turbine firing rate must be increased, which results in more electrical generation, more exhaust heat, and thereby more steam to the process. Likewise, 
Figure 4.5 Decoupling With Extraction Turbine

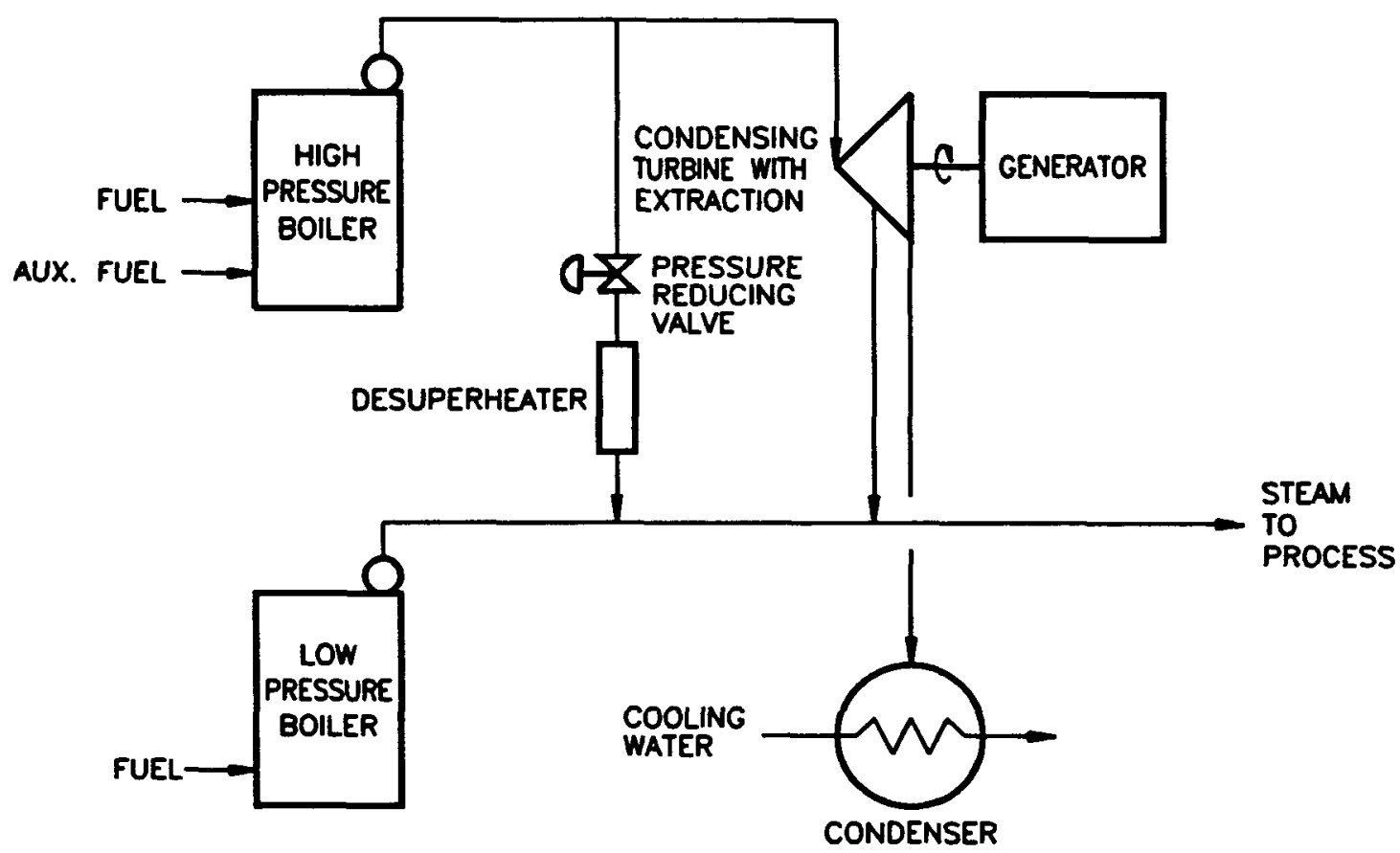

Figure 4.6 Basic Gas Turbine Cycle

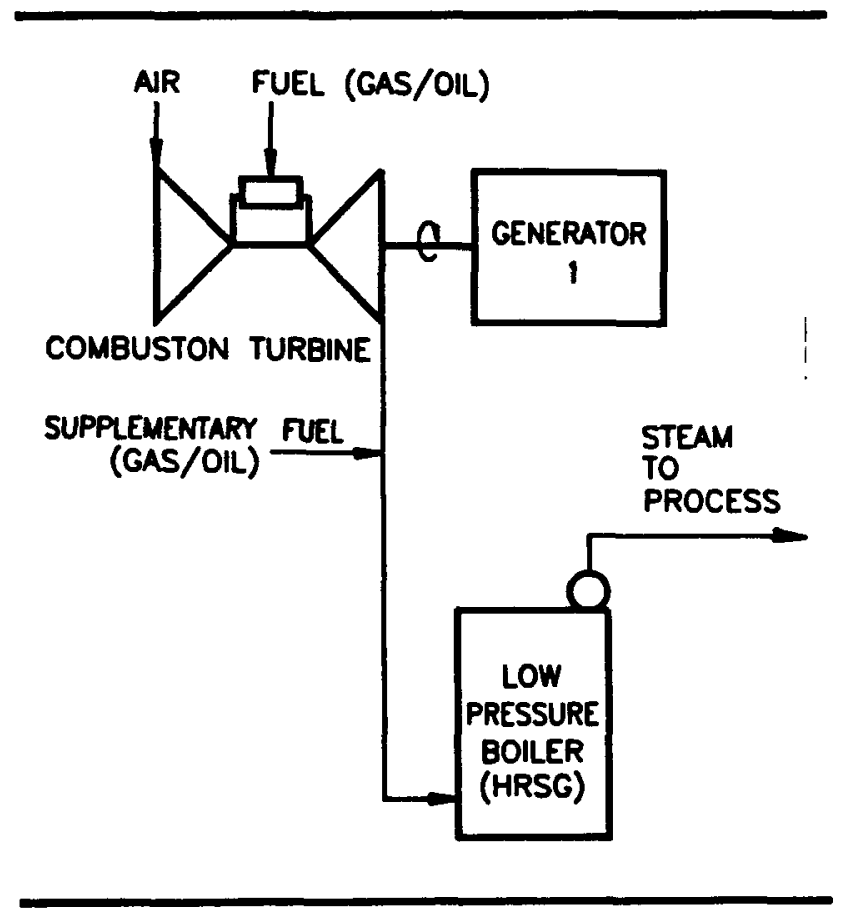

the only way to increase electrical generation is to increase fuel flow, exhaust heat, and steam flow to process.

A relatively inexpensive decoupling technique can be employed which allows the steam flow to the process to be increased independently of the electrical generation. By addition of supplementary firing of fuel into the combustion turbine exhaust duct, the heat to the HRSG can be increased. Steam flow to process can be doubled or even tripled. The additional fuel is utilized very efficiently since the turbine exhaust gas is essentially preheated combustion air. Steam produced from the supplementary firing can require $20 \%$ less fuel than a typical gas- or oil-fired power boiler. 
Figure 4.7 Basic Gas Turbine Combined Cycle

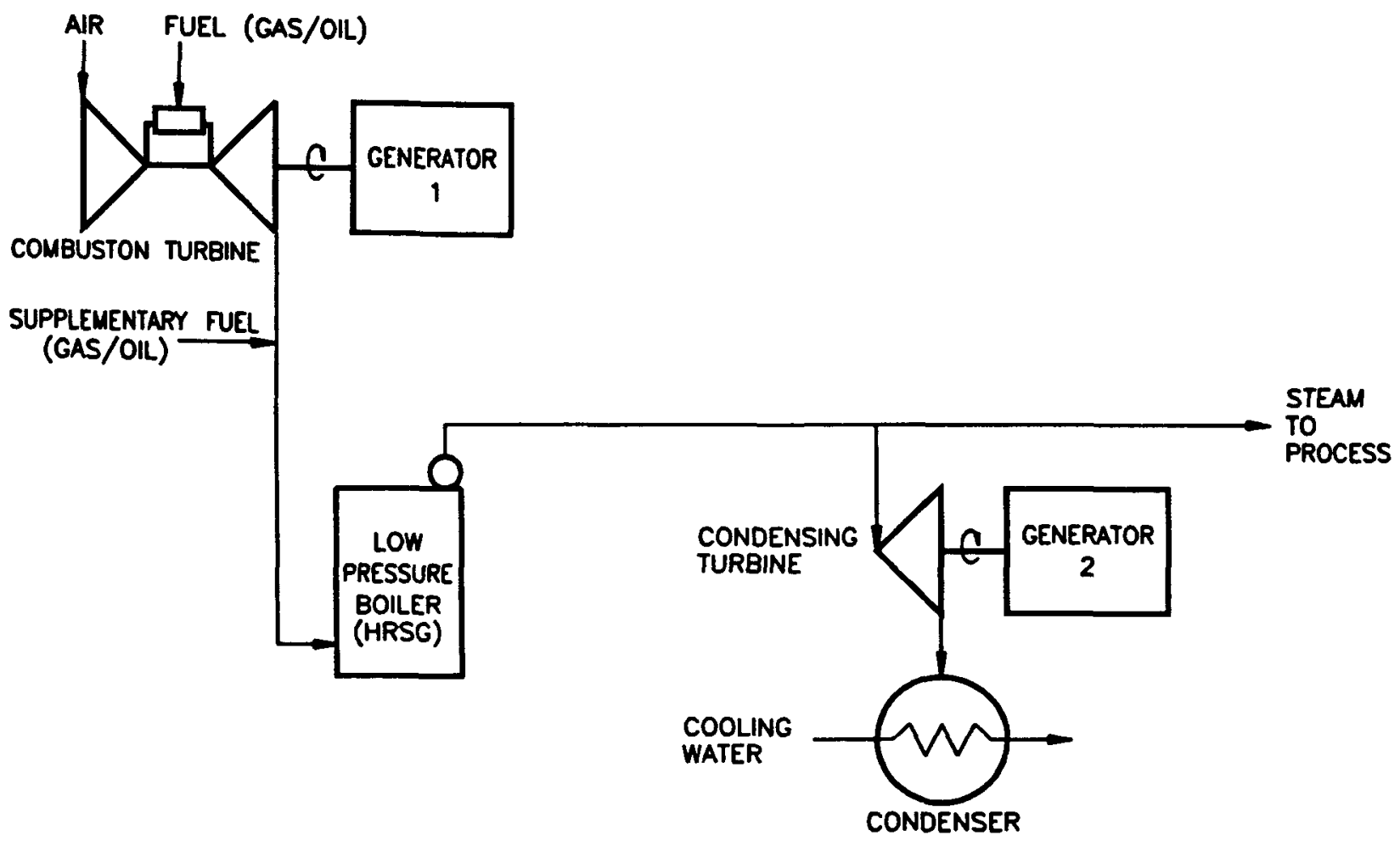

In order to provide increased electrical generation without providing more process steam the cogeneration system can be modified as shown in Figure 4.7. The addition of a condensing steam turbine generator essentially transforms this example into a combined cycle, which is the combination of a combustion turbine and a steam turbine cycle. The condensing steam turbine provides an alternate use of the steam to provide electrical generation in lieu of steam to process. Often the process steam pressure requirements are low enough (150 PSIG or less) to enable the use of a second, higher pressure steam cycle. In this scenario the HRSG normally requires supplementary firing to produce superheated steam at 400 PSIG, 650 PSIG, 900 PSIG or even higher pressures. The higher steam pressures and temperatures can drive a backpressure steam turbine before being exhausted to the process at the lower pressure. The multipressure boilers are normally close coupled so that the hot gas enters the high pressure end of the HRSG and exhausts from the low pressure end. This improvement in the efficiency and flexibility of the design is shown in Figure 4.8.

Similar to the discussion of the steam turbine topping cycle, interstage steam extraction and atmospheric steam blow off valves may be added for additional flexibility of operation. It should be noted 


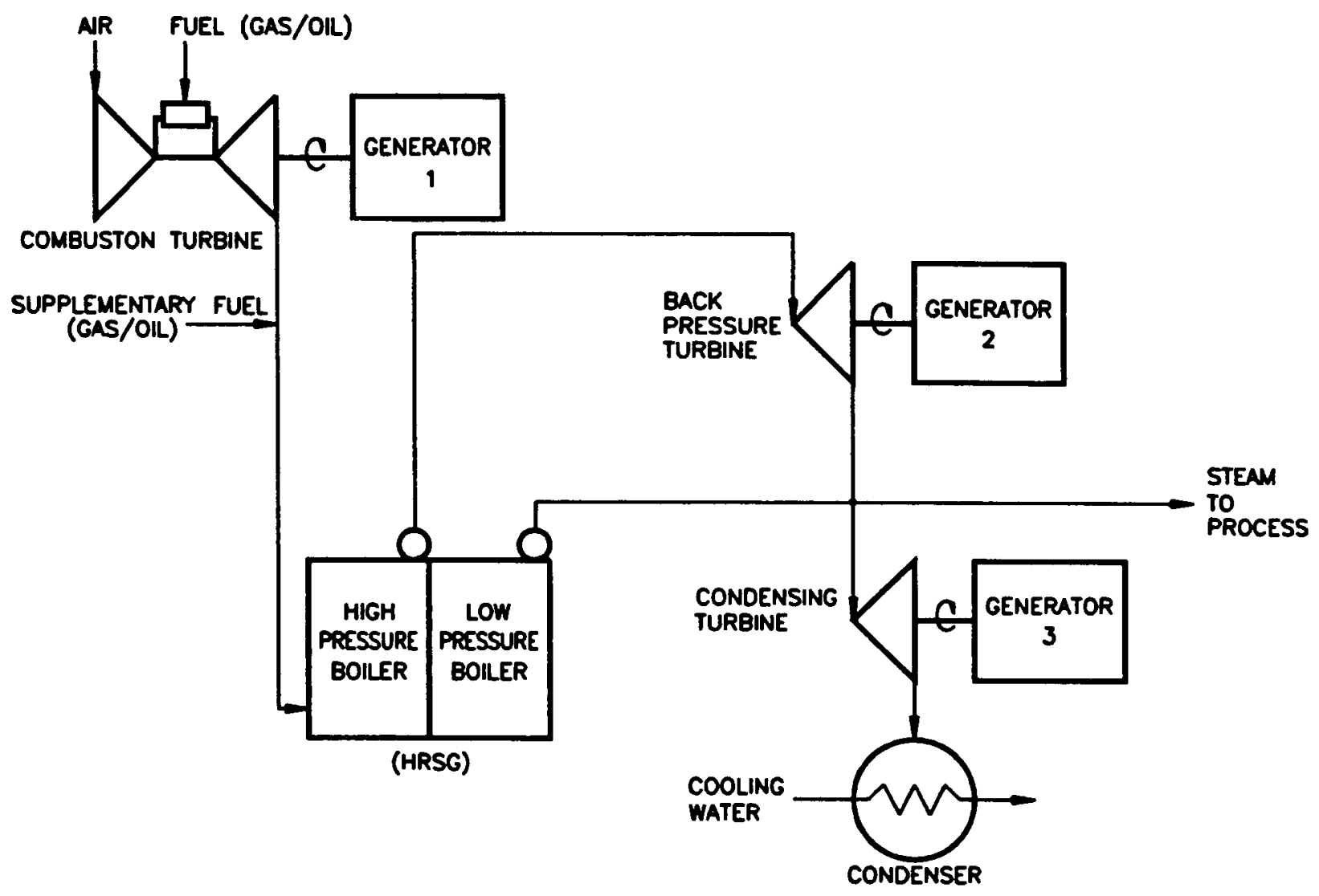

that many combined cycle plants avoid the addition of a second generator by coupling the shaft horsepower of the steam turbine directly to the same generator which serves the combustion turbine. This works well for a cycle dedicated to electrical generation but does impose limitations on the flexibility of operation to process steam applications. Addition of these alternatives is shown in Fig. 4.9.

Special note is made here concerning the effect of atmospheric pressure, ambient temperature and humidity upon the performance of combustion turbines. Like any air breathing engine, the performance of a combustion turbine will be affected by changes in the mass flow of air into the intake of the engine. Although high intake air temperature is the main problem, high humidity and low atmospheric pressure are also significant performance factors. Together these factors can combine to reduce power output by more than $20 \%$. Fortunately, most process steam load occurs during the colder winter months when the output of the combustion turbine is at its highest. Temperature is usually a problem in the hot summer days during a utility's peak period when electric power is at a premium and rates are the highest. The 


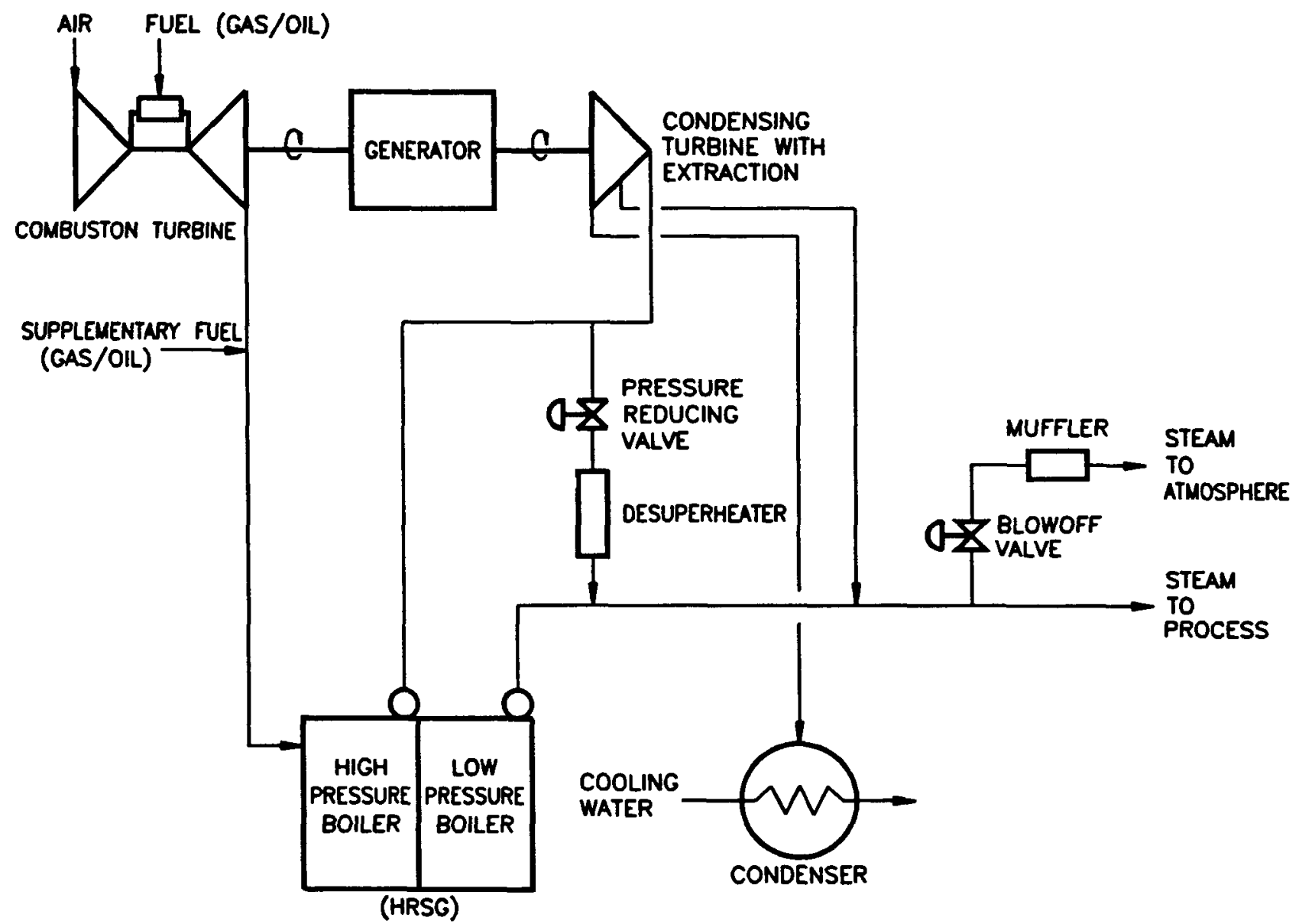

problem must be taken into consideration in setting contract demand for the utility's peak hours.

There are other design alternatives which are available for the combustion turbine system, the details of which are best left to the system designer and the manufacturer. They are mentioned here to acknowledge their possible use. Inlet cooling devices like evaporation coolers or refrigerated chillers can reclaim performance loss due to high ambient air temperatures. Steam or water injection into the compressor discharge, which is commonly used for control of nitrous oxides emissions, can also increase output $10 \%$. This increase of output is usually at the expense of increased maintenance and more frequent inspection intervals. Likewise, operating the combustion turbine and/or generator above normal temperatures may be allowed for intermittent and for peak operating periods. This can be done with the approval by the manufacturer of a peak rating. Again, this requires shorter inspection intervals and increased maintenance expense. Sophisticated reheat cycles can also be implemented to optimize cycle efficiencies. 
DECOUPLING

Gas Turbine With Thermal Storage - Recent research at Pacific Northwest Laboratory indicates that the addition of thermal energy storage (TES) to a simple cycle gas turbine can completely decouple thermal and electrical power production. Electricity can be economically generated for, say, eight or twelve hours per day if the peak price paid for electricity is at least $6 \mathrm{c} / \mathrm{kWh}$. Heat from the turbine exhaust is transferred to either an oil/rock or molten nitrate salt storage tank. Process heat is then produced by sending the hot oil or salt through a steam generator that operates 24 hours/day. and potassium nitrate mixture freezes at $464^{\circ} \mathrm{F}$, systems must operate above $550^{\circ} \mathrm{F}$. These systems typically use separate hot and cold salt tanks. Field demonstration has already been shown for solar thermal power generation.

An oil/rock TES system is less expensive than molten salt, but it is limited to low temperature applications, typically below $570^{\circ} \mathrm{F}$. A low cost filler such as river rock is used in a single storage tank. Hot oil is maintained at the top of the tank and cold oil at the bottom.
Figure 4.10 Gas Turbine With Thermal Energy Storage

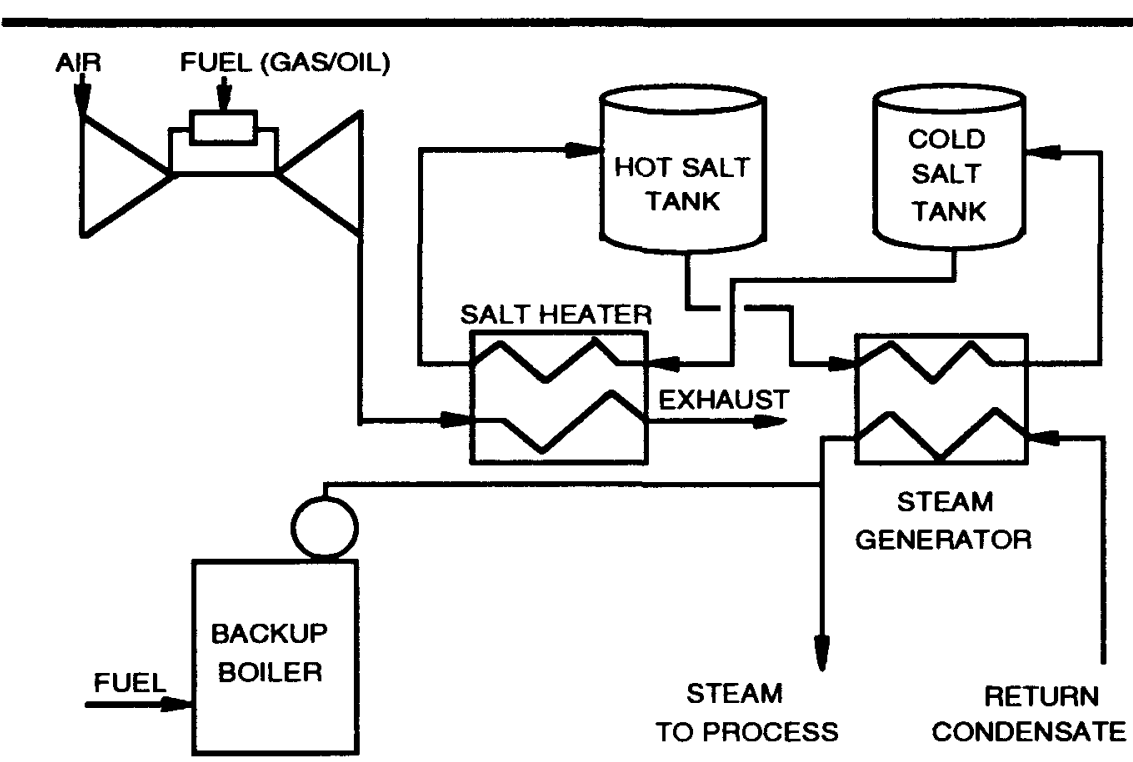

A TES system can also be more economical than a combined cycle (CC) plant designed for peak power production. The CC system, in this instance, would employ a condensing steam turbine and have a supplementary boiler for production of thermal energy during off-peak hours.

\section{Diesel/Coal Combined}

Cycle - A new cycle for decoupling thermal and electrical production has been developed by Energy Resources and Logistics, the diesel/coal

A simple schematic of a salt storage system is shown in Figure 4.10. Molten nitrate salt is an excellent storage medium for high temperature TES applications at up to $1050^{\circ} \mathrm{F}$. Since the sodium combined cycle. Diesel engine generator sets with inherently high efficiencies are used in combination with a conventional steam cycle. Electrical load variations of up to 2 to 1 and steam load variations of 


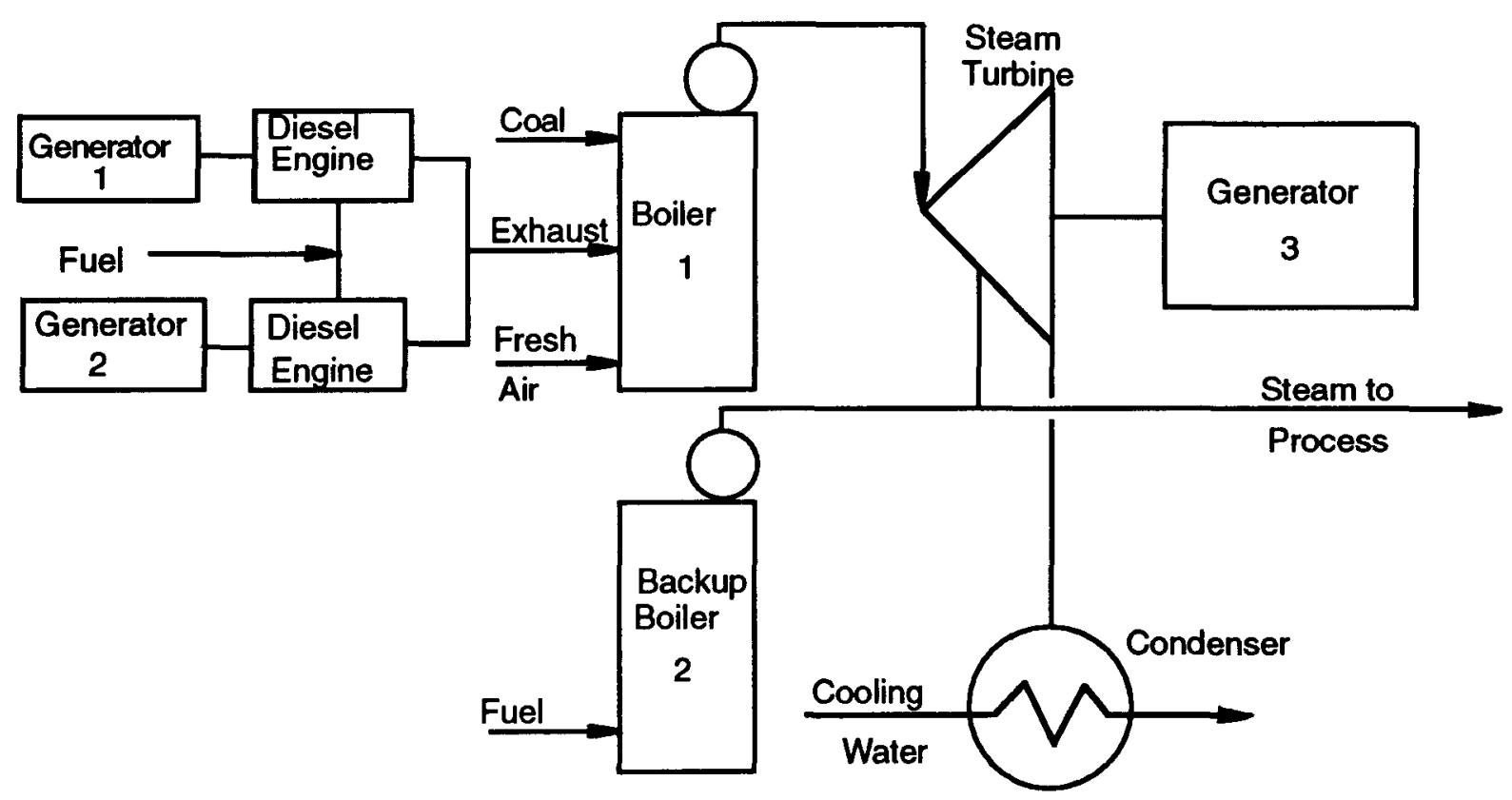

up to 10 to 1 are possible with lower loss of combined cycle efficiency than with a combustion turbine combined cycle.

Exhaust gas from the diesel engines, as shown in Figure 4.11, is used as preheated air in a micronized coal-fired boiler. The boiler operates under limited oxygen conditions by admitting only enough fresh air to achieve stable combustion. Because of the preheated air and reduced gas losses with the lower oxygen levels, very high boiler efficiencies are achieved. With appropriate use of a scrubber and baghouse, emissions are reduced considerably over a conventional diesel generating plant.
Electricity production relative to process steam is increased by raising diesel generation and adding more coal and fresh air input to the boiler. Because a diesel engine exhibits an efficiency curve that is almost flat over its range of operation, the overall cycle efficiency varies little with load.

A major advantage of this cycle over natural gas-fired systems is lower fuel cost when firing with high sulfur oil or coal. Also, diesel engines do not suffer the large decrease in output under high ambient air temperature that turbines do. Good efficiency at high electrical to thermal output can make this an attractive option for increasing peak electric sales. 


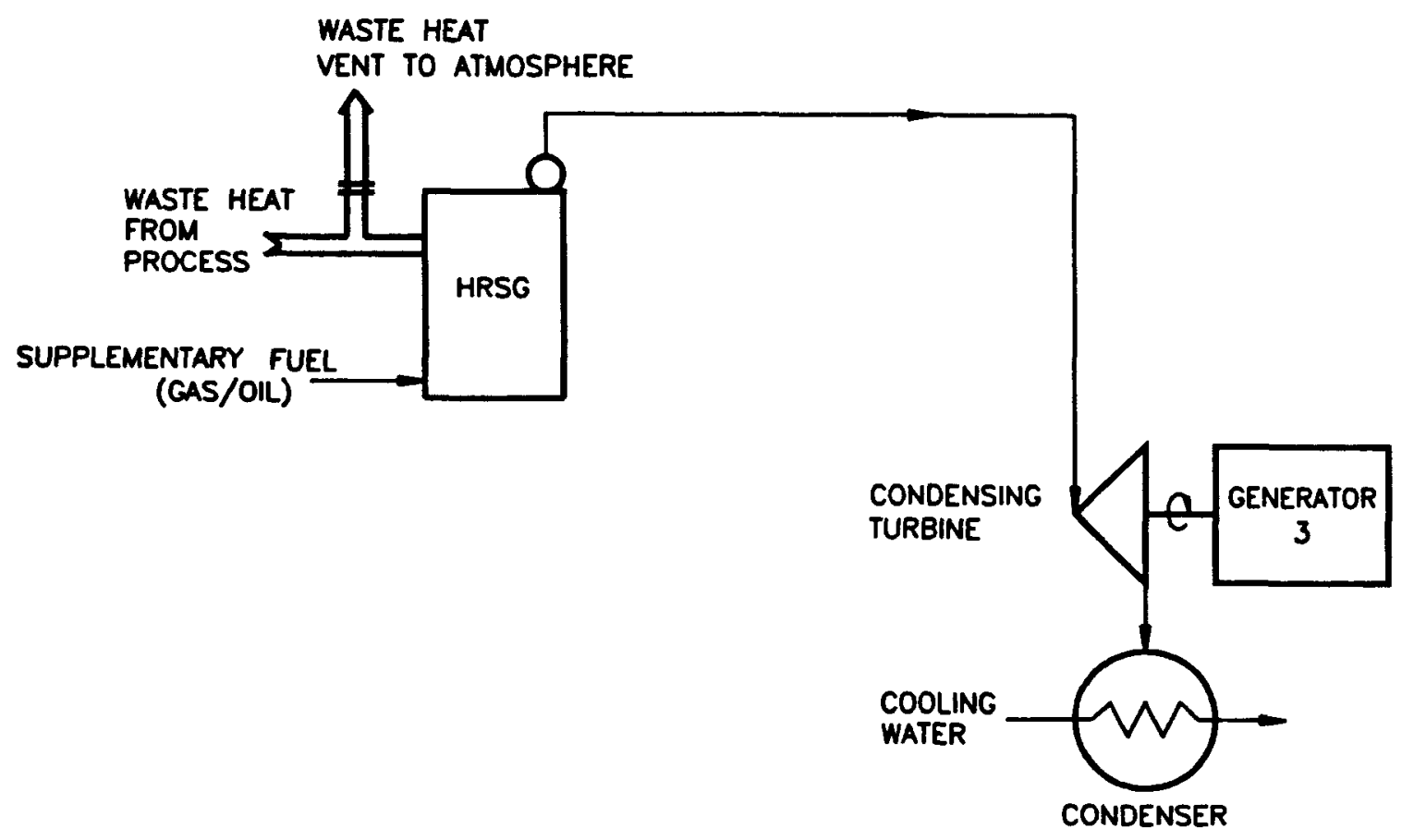

\section{BOTTOMING CYCLES}

Waste Heat Recovery Types - The bottoming cycle cogeneration system is less common than the topping cycles just discussed. However, where the host process has waste heat available and the bottoming cycle can be employed, the economics are usually very attractive. Figure 4.12 sketches a simple application. Waste heat from the process is ducted to a heat recovery steam generator where steam is produced and delivered to a condensing turbine generator. In this cycle power generation is a byproduct of the host process and is completely dependent on this heat source for power generation. Obviously, the addition of supplementary fuel to the HRSG can provide additional power generation during periods where the process heat output is reduced or curtailed. This provides decoupling of the power generation from the process heat. Although the additional capital cost is modest, the operating cost of the plant will increase dramatically due to the cost of fuel. This alternative may be attractive for meeting peak generation demands and increasing availability which improves the overall economics by avoiding contract penalties.

Almost every waste heat recovery cycle will require a mechanism to limit the heat flow to the HRSG. This is necessary to protect the HRSG and safeguard the steam generating system by providing a means to quickly reduce or stop the heat flow to the steam generator in case of overfiring, operation outside safe operating limits, loss of boiler feedwater or other emergency conditions. The control of the 
Figure 4.13 Decoupled Waste Heat Recovery System

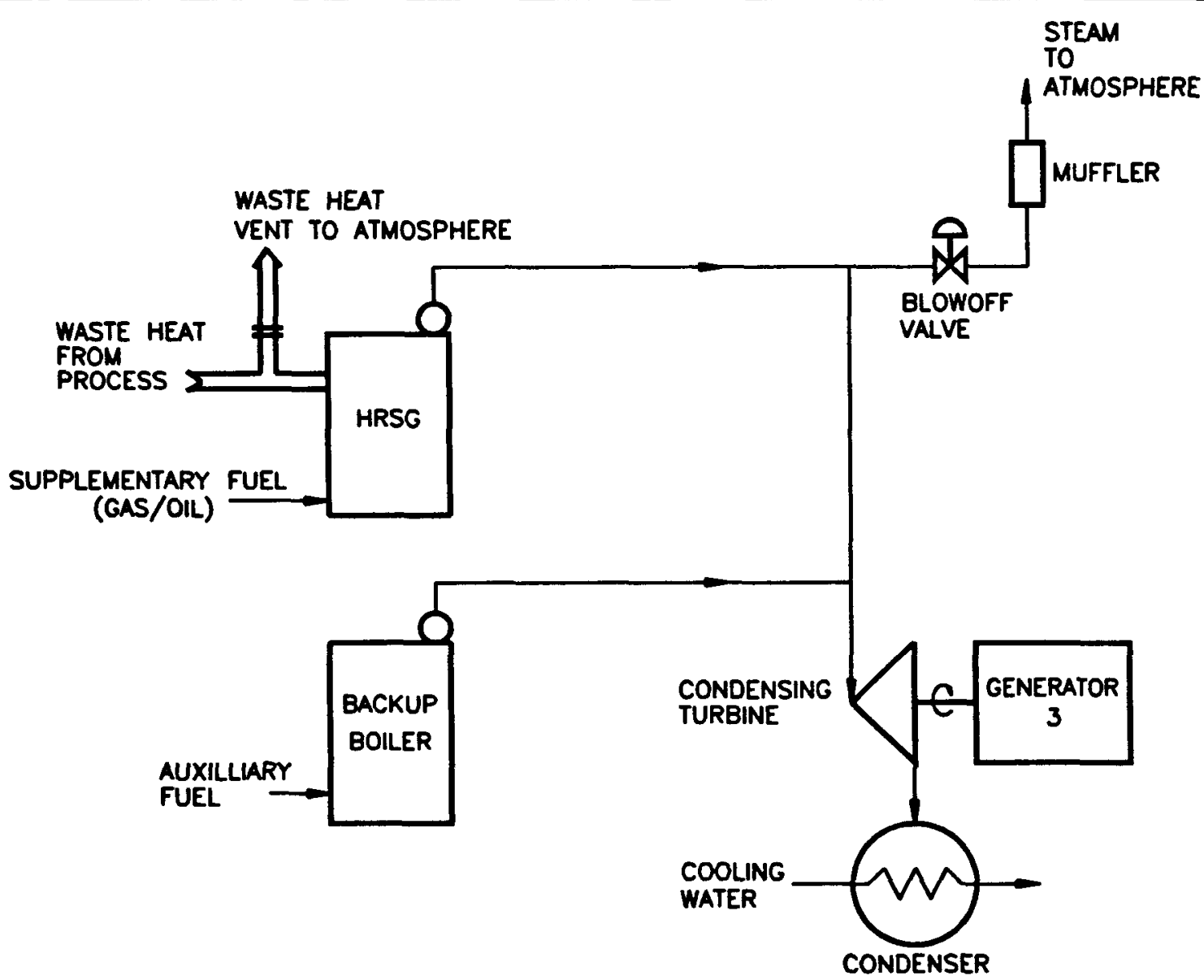

heat input to the boiler can be as simple as a vent to atmosphere, or bypass around the HRSG. However, the temperature of the waste gas and the need for air pollution control may dictate more complicated and much more costly answers.

It should be noted that a waste heat recovery cogeneration cycle usually makes air pollution control easier and less expensive than without heat recovery since lower temperatures are more compatible with the air pollution control systems popular today. Likewise, the addition of a back-up boiler fired with an auxiliary fuel will protect the WCP producer from outages due to failures of the process heat source and the associated HRSG. Atmosphere relief of steam through a blowoff valve and muffler can prevent turbine-generator trips from upsetting the thermal process and can expedite an orderly restart. This is normally a very inexpensive option to install. The fully equipped waste heat recovery system is shown in Figure 4.13.

Waste-Fuel-Fired Types - Many processes have a byproduct which can be used as fuel for a bottoming cycle. A good example of this is the black liquor of the paper manufacturing process. Black 
liquor is sprayed into a specially designed boiler where it is burned to produce steam. From there the cycle is similar to Figure 4.13 with one notable exception. The steam can be returned to the paper manufacturing facilities where it is used for process heating. This is a decoupling technique which is also applicable to the waste heat bottoming cycle.

While there may be some paper mills with simple cogeneration systems, modern paper mills have their process needs and cogeneration systems closely integrated. The Champion Paper Mill at Courtland, Alabama uses both topping and bottoming cogeneration cycles, gas turbines, backpressure and full condensing steam turbines, multiple interstage steam extraction, and waste-fuelfired boilers with a gas/oil-fired boiler back up. There is little doubt that the paper manufacturers are today's leaders in cogeneration.

Other processes generate a combustible waste product which can be successfully burned in a properly designed boiler. These processes can be coupled with a bottoming cycle cogeneration plant like that shown in Figure 4.13 with necessary changes associated with the waste-fuel-fired boiler and waste fuel delivery system. Of course, each waste fuel has its specific emission problems and applicable control requirements. Ash disposal is also a consideration.

\section{FLEXIBILITY OF OPERATION}

A well designed cogeneration system will provide maximum flexibility of operation within the limits of the project budget. Flexibility of operation gives the opportunity for continued profitable operation in the event of equipment failures, loss of fuel supply, and change in the demands of the thermal host, interconnecting utility, or electric load. In short, system flexibility helps the cogenerator meet the challenges of operating in an ever changing world.

\section{DESIGN FOR ALTERNATE MODES OF OPERATION}

The profitability of the cogeneration plant often depends upon its ability to produce. To produce, the cogeneration system must stay on line and under load. It is often system design constraints that prevent a cogeneration system from staying on line or loading up to capacity. The cogeneration system shown in Figure 4.1, a simple non-condensing back pressure steam turbine generator, has only one mode of operation and little flexibility of operation. If either the thermal host or the electrical load is lost, the cogeneration system must be shut down.

If the system had some of the features of Figure 4.2, the system could stay on line even if the electrical load was lost, operating in a non-cogeneration mode. This would allow for continued operation, thermal energy sales to the thermal host and increased profitability.

Figure 4.3 adds the opportunity for operation in the full condensing, total power generation mode. This system can remain on line producing power to meet the electrical demand even when the host steam load is lost.

Similar arguments can be made for alternative modes of operation and system flexibility in 
combustion turbine cycles and waste heat bottoming cycles. The ability to continue operation of the cogeneration system during upset conditions, thermal and electrical customer outages and utility blackouts will enhance the usefulness of the system to its customers. The reliability of the cogeneration system will translate into increased revenues and higher profitability. The specifics of the individual system will require a cost-benefit analysis to justify capital-intensive system additions.

\section{TURBINE AND ELECTRIC DRIVES FOR AUXILIARY EQUIPMENT}

The cogeneration plant is like any other power producing facility in that it must consume steam, electricity and other utilities to produce thermal and electric power for its customers. Depending upon the efficiency of the system, 15 to 25 percent of the plant's capacity may be consumed by the plant's own equipment. Thus, to some extent, the cogeneration plant creates its own load. It is useful to consider the cogeneration plant from this perspective when designing for flexibility of operation.

Since fans and pumps can be driven with either steam turbine or electric motor drives, there is the opportunity to use the cogeneration auxiliary equipment to balance the electrical and thermal loads. Designers call this an energy balance. A good design will allow the plant operator flexibility in matching the auxiliary equipment power to plant load demands. To provide this flexibility, both turbine and motor driven auxiliary equipment are often provided. Dual drives are sometimes used to allow either steam turbine or motor drive of a single pump or fan. The flexibility of operation made possible by using a combination of drive types can improve the efficiency of the plant, increase plant reliability, and permit profitable operation under a wide range of thermal and electrical load conditions.

\section{DUMP MODE}

In several of the cogeneration systems described, including those of Figures 4.4 and 4.9, there are provisions for dumping steam. One might question the wisdom of purposefully wasting energy. Certainly the practice is not something which should be encouraged. The purpose of the blowoff valve and muffler is to provide for continued operation during major upsets of either the thermal host process or the electrical delivery system. Used only as the last resort and for short periods of time, the dump mode can react swiftly when the thermal host process stops taking steam. This can happen for several and various reasons, some of which are unique to each thermal host. Commonly, process steam flow may be curtailed under emergency trip conditions, or when equipment failures force the process to be shut down.

The dumping of steam can allow the cogeneration plant to stay on line during these steam interruptions, to generate electricity, and quickly resume delivery of steam to the thermal host when conditions return to normal. Otherwise, the cogeneration plant may well be forced to shut down, usually under less than controlled conditions. Here, the utility tie will be lost, and the boilers or gas turbines will trip. Restart may be difficult and time 
consuming. Importantly, it is not only energy sales that are lost. Most contracts provide for very unfavorable terms for loss of capacity, especially during peak demand periods and for stand-by power costs. Economically, it is very important to minimize outages of the electrical generation system.

It should be emphasized that the dump mode should not be used for prolonged operation but rather considered as a short term solution to an energy balance problem. Whereas the use of the dump mode may be very profitable for short periods of time, it is certainly cost prohibitive for longer periods. Not only is the energy loss expensive, but the steam condensate is also lost and must be replaced with relatively expensive chemically treated make up water. Cost will vary, but for a cogeneration system similar to that shown in Figure 4.1, dumping steam could add five cents or more to the cost of each kilowatt hour of electricity produced.

Some cogenerators have found that dumping is necessary and feasible for longer periods of time. The economics can be improved by adding a steam condenser to the system to recover the condensate from the condensed steam for return to the system. In some cases, with proper design, the condenser serving a condensing turbine generator may be used to condense dump steam. This avoids the cost of an additional dump condenser.

The pressure reducing valve and desuperheater, shown in Figures 4.4 and 4.9, are a bypass for steam around the back pressure turbine generator. This bypass can also be considered to be a dump mode of operation and should be used with proper consideration of its cost and benefits. The bypass will allow the cogeneration plant to remain on line supplying steam to the thermal host process if the utility tie is lost or in the event of a failure to the backpressure turbine generator. The bypass provides a reliable source of steam for the thermal host when the electrical generation system is under upset conditions and when the electrical utility is under black out. The bypass allows the cogenerator to recover from an electrical outage quickly and minimize the downtime.

Although the bypass is not as wasteful or expensive to utilize as the steam blowoff to atmosphere, the opportunity to generate electrical power with the backpressure turbine generator is missed and the advantage of cogeneration is lost. Therefore, economics dictate that use of the bypass should be minimized.

\section{INFORMATION SOURCES}

Decoupling

Mechanical System Design
"How a Cogeneration Plant Can Meet Utility Needs," S.W.Shor, Electric World, 9/88.

"Applications of the Diesel Coal Combined Cycle," T.P. Davis and F.M. Shelor, Paper presented at the Florida Cogen Roundup, Tampa, FL, 1/24/94.

Cogeneration Systems - Gas Turbine Power Plants, 1-50 MW, Solar Turbines, Inc. San Diego, CA, 93. 
Gas Turbine Systems for Generator Applications, Solar Turbines, Inc., San Diego, 93. GE Aeroderivative Gas Turbines - Design and Operating Features, H. Fogg, General Electric Co., Cincinnati, OH, 91.

GE Gas Turbine Performance Characteristics, F.J. Brooks, General Electric Industrial and Power Systems, Schenectady, NY, 92.

"Integrating Thermal Energy Storage in Power Plants," Somasundaram, Drost, Brown and Antoniak, Mechanical Engineering, pp 84-90, 93.

Steam Turbines for Industrial and Cogeneration Applications, F.G. Baily, R. Peterson and R.T. Gentner, General Electric Co., Schenectady, NY, 93.

Steam Turbines - Their Cost and Application to Industrial on-Site Generation, J.B. McCullum and J.O. Stephans, Westinghouse Canada, Hamilton, ON, 87. 


\section{CHAPTER 5. COGENERATION SYSTEM OPERATIONAL LIMITATIONS}

As seen from the perspective of the cogeneration plant owner/operator, the goal is to maximize revenue from the sale of thermal and electric power and to minimize the cost of manufacture and delivery. It is incumbent upon the cogeneration plant owner/operator to assure that the plant is capable of meeting its contractual obligations. In other words, the performance limitations of the plant must be well understood by the cogenerator so that the resulting contract includes reasonable performance requirements within the capability of the cogeneration system design.

\section{PERFORMANCE LIMITATIONS, RATINGS, AND RESTRICTIONS}

The performance characteristics of the cogeneration plant, including the electrical and thermal power delivery systems, will determine the plant's ability to meet its contractual obligations. Ultimately, this will be a major factor in the overall success or failure of the WCP system.

The most obvious performance rating of the WCP plant is the electrical output capacity, usually expressed in kilowatts (kW) or megawatts (MW). The tendency is to accept the nameplate ratings of the generator (or generators) as the capacity of the plant. One should use caution, however, since plant capacity may be dependent on other factors. As will be discussed later in this chapter, several system design decisions can limit the maximum generation available at any time. Outside temperature can markedly influence output capacity of a combustion turbine driven system or, to a lesser extent, a condensing turbine driven generator. Simultaneous delivery of thermal energy to the host can either increase of decrease the capability to generate electric power depending on the system design. The point here is to use caution when offering capacity guarantees, and to take into consideration other factors which may limit output below generator nameplate rating.

It is important to recognize that the WCP plant is a system of interdependent parts and pieces of equipment, each with its own rating and limitations. The performance envelope of the total plant likely will not permit operation of all subsystems to their maximum capacity simultaneously or under all conditions. The total plant performance may not be a simple sum of the parts. Therefore, WCP producers should be careful to keep plant performance guarantees within the plant's overall performance envelope.

\section{SYSTEM RESPONSE TIMES}

The load demands of both the thermal host and the electric power consumer are usually variable with time. The thermal and electric loads may increase and decrease dramatically throughout the day, week, or season. The ability of the WCP system to 
meet these demands depends on the WCP plant's system response times.

Power generation equipment is physically large and often is required to operate at temperatures well above ambient. This normally requires a controlled warm up period prior to being placed in service to allow for thermal expansion, thus avoiding thermal stress, fatigue and other damage that might occur. The larger the temperature difference and more massive the equipment, the longer the time required for warm up.

Start up time requirements vary with the design of the equipment. Typical boilers require four to eight hours to place on line from a cold start. Smaller heat recovery steam generators used in conjunction with combustion turbines may take less than an hour. Combustion turbines take very little time to put on line, and special peaking units designed for frequent cycling can be generating power minutes from a cold start. Large multistage steam turbines and their generators can require several hours of start up preparation and gradual load increase. These start up times may require the plant operator to anticipate the actual need by several hours. Once on line, WCP plants can typically respond to thermal and electrical load changes of $10 \%$ per minute when fired with coal, gas, or oil. A waste fuel plant's response depends upon the specific fuel characteristics, but is typically much slower than common fuel-fired systems. Load changes for municipal-waste-fired systems are especially difficult to make unless the design provides for load swinging enhancements.
Thermal hosts who use a batch operation place unusual demands upon the WCP system. These batch operations operate either off or on and place an instantaneous demand on the WCP plant. Such customers are usually very accomodating because of the pressure and temperature variations which their demands create.

Electrical loads which have characteristically large instantaneous changes (high horsepower motor starting loads and electric arc furnaces among them) are also troublesome. WCP systems are seldom able to handle these demands because the load swings can be half of the generation capacity. In these cases, the utility must provide their relatively infinite capacity to augment the WCP system. The terms of the contract will provide a reasonable compensation to the utility for furnishing this service.

\section{MAXIMUM AND MINIMUM RATINGS}

The developer needs a basic understanding of the cogeneration system's performance limitations, equipment ratings, and operating restrictions. Sometimes this is referred to as the performance envelope. By far the most important limitations are the maximum system ratings. And perhaps the rating which most concerns the developer is the maximum electrical power output, usually rated in kilowatts. Larger units are rated in megawatts (MW) which are equal to 1000 kilowatts (kW). Ratings for combustion turbine generators are at a standard ambient pressure and temperautre. Operation at lower pressure or higher temperature will decrease maximum output. 
To be precise, it is necessary to specify the power factor or kilovoltamps (kVa) in addition to kilowatts, to accurately characterize the output. Generators are normally rated at a specific power factor. Power factor is the ratio of $\mathrm{kW}$ (real power) to the total $\mathrm{kVa}$ (apparent power). Power factor is that factor by which apparent power $(\mathrm{kVa})$ must be multiplied in order to obtain the real power $(\mathrm{kW})$.

A typical synchronous generator may have a nameplate rating of $10,000 \mathrm{kVa}$ at 0.9 power factor, $9,000 \mathrm{~kW}$. The same generator could not be expected to deliver $10,000 \mathrm{kVa}$ at 0.95 power factor because this would require about 675 more shaft horsepower input which may not be available. The same generator would also not be capable of generating $9000 \mathrm{~kW}$ at $0.95 \mathrm{pf}$ because of higher current flows and winding temperatures.

When stating generator outputs and ratings, at least two of the three output variables must be given to fully specify the power output. Persons unfamiliar with these concepts are cautioned not to confuse the generator apparent power rating in $\mathrm{kVa}$ with the real or true power rating given in $\mathrm{kW}$. The contract terms should clearly define the characteristics of the power at the metering points.

Maximum thermal energy is also an important rating to be considered. Delivery of thermal power to the host can be in many forms but most commonly is made as steam flow in pounds per hour. Boilers and heat recovery steam generators are typically rated at a maximum delivery in pounds per hour at a specific pressure and temperature. For example, a WCP plant may have a boiler rated at $100,000 \mathrm{lbs} / \mathrm{hr}$ at 600 psig and $750 \circ \mathrm{F}$. This boiler would produce 100,000 pounds of steam per hour. The steam would be at a gage pressure of 600 pounds per square inch and would be at a temperature of 750 degrees Fahrenheit. These conditions would be guaranteed at the boiler outlet. Other conditions may be specified at the delivery point. There, BTU meters which measure pressure, flow, and temperature are sometimes employed which calculate the flow of energy in British Thermal Units per hour.

Like the generator, the boiler output might be limited at times by other factors such as fuel availability, fuel quality, emission limitations, or auxiliary equipment availability. In the case of a bottoming cycle or a combustion turbine cycle, the waste heat available from the thermal host or combustion turbine exhaust may be limited at times and under certain operating or ambient conditions.

In a simple system, the maximum power output may be the nameplate rating of the generator itself, but this is not necessarily so. The developer should recognize that the WCP system may be limited by almost any of its parts including the fuel supply, the heat recovery steam generation system, the turbine, the electrical system, the emissions control system, or even the host process. It is the designer's task to integrate individual systems and equipment components to create an overall design where isolated component overcapacity is avoided and the capacity of each component system can be fully utilized. A designer's success can be 
measured by how well he has coordinated individual components of the WCP system to avoid oversizing equipment while simultaneously preventing the potential bottlenecks caused by undersized components.

It should be noted that the WCP system performance can also be limited by outside factors. Environmental permits for air and water quality and solid waste disposal are often stated in terms of maximum allowable system capacity. The permit restrictions are imposed to protect the environment and limit pollution by allocating emission discharge capacities. The environmental laws effectively force the WCP developer to minimize the plant's emissions by either limiting the plant's capacity or by adding relatively expensive emissions control systems. Either way, the tendency is to provide financial disincentives to increased capacity.

After the WCP system has been designed, it is then possible to talk in terms of plant or system ratings without concern for individual component limitations. For simple topping cycles, maximum power generation and maximum thermal energy delivery to the process host usually occur simultaneously. For instance, a back pressure turbine generator must exhaust more steam to the process host in order to generate more electricity. It must be noted however, that for other cycles or more complex designs using condensing turbine generators or combined cycle gas turbines, this may not be the case. In fact, some designs have an inverse relationship between steam flow to the process host and electric power generation. The steam may be directed to electric power production only at loss of steam flow to the process host. This must be taken into consideration.

\section{MINIMUM LOAD OPERATION}

Whereas the impact of a maximum rating may be obvious, it is operation at very low loads, at the minimum rating, that often causes the most difficult problems. For example, the boiler will require a minimum firing rate in order to establish stable combustion. A turbine generator can require one fifth of its maximum steam throughput just to overcome windage and friction losses. The governor and throttle valves may not allow the unit to turn down below 25 percent of its maximum nameplate rating. Likewise, the complete cogeneration system will take on the characteristics of its individual components such that one will find the total WCP system will have a minimum operating rating below which successful operation is not possible.

This minimum rating becomes extremely important during curtailments or outages of the thermal process host. This is especially true when the load reduction is temporary or unexpected. The ability of a cogenerator to operate at very low loads, thermal or electrical, can keep the plant on line when the electrical system or host thermal demand is interrupted or reduced. The ability to remain on line avoids costly shut down/start up cycles, contract penalties, and demand charges. It also allows the WCP system to better meet the needs of the thermal host, the wheeling utility and the electrical load client. 
UTILITY VS. COMMERCIAL GRADE EQUIPMENT

Historically, there has been a tendency to categorize power generation equipment into utility or commercial grade. Perhaps this distinction reflects the past purchasing decisions of utilities more so than an intentional market segmentation by the manufacturers. At any rate, utility representatives associate quality equipment with reliability and dependability and often encourage the use of preferred equipment by the cogenerator. Contract terms certainly reflect the utility's demand for high availability and severely penalize unreliable operations and unscheduled outages. The growing cogeneration and independent power production markets and increasing number of non-utility generation systems have been met with an enthusiastic response by the power equipment industry. High quality power generation and electrical equipment are now available at competitive prices on systems rated as low as $\mathbf{2 0 0 0}$ kilowatts. It is not at all unusual for the cogenerator now to report better availabilities that the interconnecting utility.
GENERATION WITHOUT INTERCONNECTION - UTILITY BLACKOUT

If the cogeneration system has the capability to operate independently after a loss of service from the utility grid, the process host will enjoy the distinct advantage of increased reliability and uninterrupted operation. This is especially true if the process host can avail itself of the electrical power generated by the cogeneration system as well as the thermal energy. This can be very important in remote locations where the electric utility system is unreliable or where the process host faces severe financial loss from an interruption of power. The ability to operate independently of the utility grid is called asynchronous generation. This can be an attractive option available to the cogenerator and process host. Of course, this option does not come without cost. The additional automation, electrical interconnection, and fast response times which are required increase the complexity and cost of almost every major system. Value engineering and cost benefit analysis should be applied to the decision to determine if independent operation is feasible.

\section{INFORMATION SOURCES}

Limitations and Ratings Cogeneration Application Considerations, R.W.Fisk and J.M. Kovacik, General Electric Industrial and Power Systems, Schenectady, NY, 92.

"Gas Research Institute: Cogeneration Forced Outage Rates," D.J. Smith ed., Power Engineering, 2/93.

"Making Interconnnection Work," J. Reason, Power, 6/82.

The Impact of Energy Legislation on Electric Generation Choices, M.M. Schorr, General Electric Industrial and Power Systems, Schenectady, NY, 92. 
5- 6 


\section{CHAPTER 6. \\ UTILITY TREATMENT OF WHEELING COGENERATORS}

The entity most crucial to development of a successful wheeling contract is the interconnected utility (ICU). The technical characteristics of the utility's transmission system and the operational responsibilities of the utility will, in large part, determine the costs of interconnection and service. Understanding utility operations is necessary in order to negotiate a mutually beneficial wheeling contract.

An overview of transmission system operations is presented first. This section describes operational procedures that are needed to ensure high system reliability. The mechanism whereby power is actually transferred across utility boundaries is also described. Potential capacity constraints on wheeling are presented next, as well as methods to eliminate them. Because power loads are constantly changing, along with the generation to meet those loads, power system stability is discussed next. This is followed by the topic, transmission system security. This utility concern entails design and operation such that outages and faults on a transmission system will not propogate into neighboring systems. This leads directly to the last section on system protection requirements. These requirements determine what specific equipment items must be installed in order to protect the ICU, the cogenerator, and the personnel who must operate and maintain the transmission system.

\section{TRANSMISSION SYSTEM OPERATIONS}

Cogenerators who wish to wheel power to a remote customer will probably use the transmission facilities of an electric utility rather than some other third party. If this is the case, project developers should understand some of the constraints under which utilities operate. As a general rule, individual utilities do not operate independently. Each is connected to its neighbors for purposes of increasing reliability, decreasing capital investment in generating equipment, and improving economy among other things. This mode of operation forces the utilities to pay particular attention to the effect their operation has on each other and certain possible events that can affect neighboring systems.

Interchange of power between interconnected utilities has been a common practice for many years. During a particularly cold day in November 1965, utilities in the Northern U.S. were experiencing high demands for electricity. Power was being imported from Canada to meet part of this demand. It was flowing over four transmission lines. One of the lines was tripped when the current in it exceeded the setting of a protective relay. This action caused overload of the remaining three lines, and they tripped. This resulted in the overloading, and subsequent tripping, of other lines in the system. In a matter of minutes New York, Massachusetts and parts of other states experienced total power failure. 
Following the event the President, Lyndon Johnson, directed the Federal Power Commission to determine actions required to prevent the event from being repeated. The utilities of the country were convinced that the problem was technical in nature and that its solution could not be effected by regulation alone. The North American Electric Reliability Council was the product of the solution. Through NERC, the industry is now committed to maintaining and improving reliability of service. It does this by developing and enforcing a set of planning and operating guidelines governing the bulk power system of North America. It is this commitment to minimize the possibility of cascading outages that governs operations and planning.

\section{INTERCONNECTED NETWORKS}

The utilities of North America are grouped in four interconnections. Within each interconnection, the generators operate at the same frequency through a transmission system that spans neighboring utilities. Ties between interconnection groups are by direct current systems or through alternating current systems of limited capacity. Direct current ties allow transmission between utilities whose alternating current generation is not synchronized.

The largest, both in terms of geographical size and generating capacity, is the Eastern Interconnection. It covers the United States and Canada east of the Rocky Mountains except for Texas and Quebec. They have their own individual interconnections. The fourth interconnection comprises the western states and the Provinces of British Columbia and Alberta.

\section{CONTROL AREAS.}

Large utilities or groups of utilities operate as units, or control areas, within these interconnections. Their function is to plan and operate their portion of the network in a reliable and economical manner. The control areas look at both the second-bysecond condition of the network and the hour-byhour generation patterns.

The control area seeks the most economical solution for each of four objectives on a continuous basis. These are:

- Determining the optimum mix of generation to meet the connected load and transmission losses within the control area;

- Adjusting the generation to supply or absorb power from utilities outside the control area on a prearranged schedule;

- Operating the system in such a manner that it can survive credible contingencies; and

- Participating in the control of frequency within the interconnection.

The fourth objective is one that does not involve cogenerators and is only mentioned for the sake of completeness. The other three are vitally important to cogenerators.

Given the objectives above, the control system needs to look at the actual vs. scheduled power exchanges with other control areas in the interconnection and the deviation from scheduled frequency of the generation within the interconnection. This control scheme is used because utilities cannot adjust connected load within the 
control area, nor can they control the path over which the power flows.

When using this scheme, the control area must develop the generation to supply losses which are the result of power flowing in the transmission system within the area. If a cogenerator is wheeling power through the control area, losses in excess of those caused by the control area are going to occur. The generation to supply these losses represents real fuel expenditure as well as generation capacity that is no longer available to supply connected load within the control area or to sell to another utility within the interconnection. Prudent business practice dictates that some means be provided to compensate the utility for the loss in capacity and the extra production cost.

\section{CONTRACT PATH FLOWS}

Transmission lines between control areas allow for the interchange of power during emergencies as well as during normal operations. Exchange during normal operations is usually for the mutual benefit of both control areas.

Power is transferred between utilities, not by switching, but by the simultaneous adjustment of the generation level in the two control areas. For instance, take the simple situation of two interconnected utilities - $A$ and $B$ in Figure 6.1. Control Area "A" wishes to sell 100 megawatts to Control Area "B". At a precise time, say 1:00 PM, the operators at "A" and "B" will adjust the output of their generators, " $A$ " increasing its by $100 \mathrm{MW}$ and " $B$ " decreasing its by a like amount. This will result in
$100 \mathrm{MW}$ flowing between the two. Prior scheduling of the net interchange level in both control areas is necessary in order to get this accomplished.

\section{Figure 6.1 Power Transfer Between Control Areas}

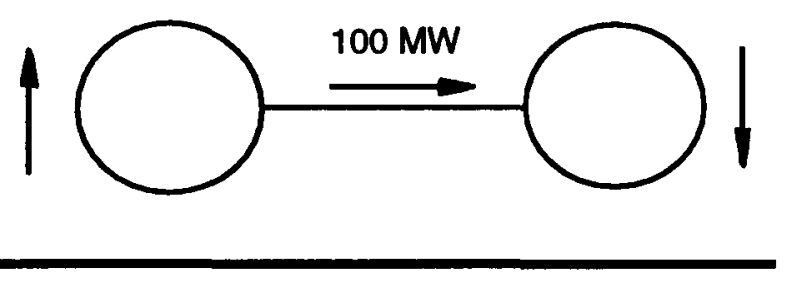

In the three-control area interconnection shown in Figure 6.2, when " $A$ " sells to " $C$ ", " $A$ " and " $C$ " make the adjustment in generation and " $B$ " makes no adjustment. However, "B" incurs extra losses and the portion of his control system that monitors losses will raise generation within his area.

Figure 6.2 Wheeling Through Control Area

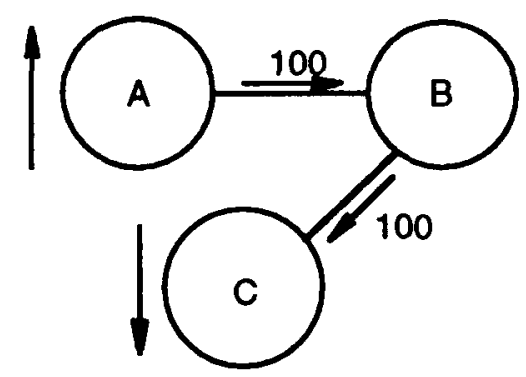

Historically, the manner in which losses due to wheeling have been handled is similar to that shown in Figure 6.2, allowing that more that one utility or control area might be involved as a third party. The wheeling parties pay some compensation to the third parties along some assumed (more or less 
direct) path that the flow is going to occur. This has come to be known as the contract path. This convention ignores the reality that the flow takes place over all possible paths between the contracting parties.

\section{LOOP FLOWS}

In a large interconnection there are many tie points between several utilities. When " $A$ " sells to " $B$ ", the flow is not directly between the contracting parties but over all the network regardless of control area boundaries. This is shown in Figure 6.3. The division of flow among the lines changes with changing load and generation patterns within each of the control areas of the interconnection as well as any topology change of the transmission network.

Figure 6.3 Loop Flows

100

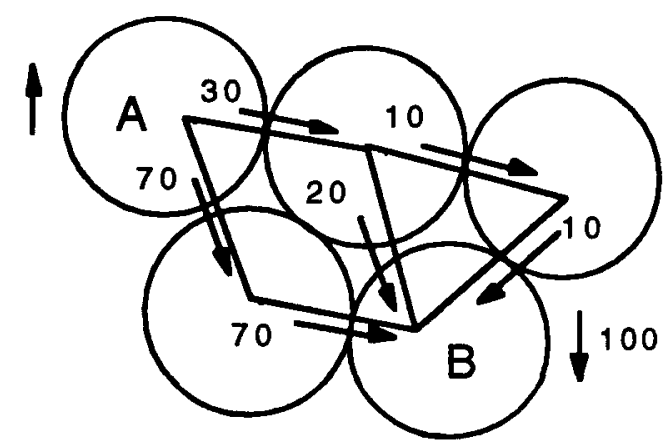

With the increase of wheeling sales within an interconnection, flows along the parallel paths, or loop flows, are recognized as being non-negligible quantities. Cogenerators who are planning to wheel through the utility to which they interconnect are going to exacerbate the problem.

\section{WHEELING TRANSACTIONS BY COGENERATORS}

Wheeling for cogenerators can be roughly subdivided into two groups: those wheeling operations which take place within a control area and those which cross the boundary of a control area.

Within a control area several types of transactions are possible. The first is the transaction wherein the cogenerator sells all output to the utility to which it is connected. The second is a wheeling transaction wherein a wholesale transaction is made to another utility (within the control area). The third is a retail wheeling transaction which is made to a customer which may be connected to the same utility or another utility within the same control area. The principal feature of either of these types of sales is that inter-area flows are not involved and scheduled transactions between control areas are not affected.

There are also several forms of inter-control area transactions. These are sales to utilities on a wholesale basis or retail sales to customers within utility boundaries. These sales are more complicated than those of the previous type. In all of these cases, the flow out of the cogenerator's control area and an equal flow into the customer's area must be scheduled at least one hour in advance. The contract should be designed such that once the transaction begins, the control systems of both areas treat the transaction as a firm sale. This means that, should the cogenerator fail to deliver the contracted power, generators within his control area will act to deliver the difference between actual output and scheduled output. 
Likewise, if the cogenerator delivers power above the scheduled amount, the generators within the control area will lower their output to maintain the scheduled net flow over the tie lines connecting the control areas.

The control area in which the cogenerator's customer is located will take a similar set of steps to ensure that the scheduled interchange is met. If the customer reduces his load, either totally or partially, generators in his control area reduce the output levels a corresponding amount. Likewise, if the customer's load exceeds the schedule, generators within the control area supply the excess.

As cogenerators develop contracts with interconnecting utilities they should consider three situations:

- The contract with the control area should include terms in which, once scheduled, the power to be wheeled through the control area should be made firm by the control area;

- The sale of power should be for an integral number of megawatts since a single megawatt is the lower limit that can be scheduled in current control systems; and

- Wheeling policies being developed are going to account for loop flows in some manner, and compensation payment schedules will be determined by the interconnected utilities within a region. The cogenerator will probably be afforded the same treatment as any utility seeking to wheel over the facilities of another.

\section{TRANSMISSION SYSTEM CAPACITY CONSTRAINTS}

As more and more cogeneration facilities are added to an existing grid, transmission line flows can be additive or subtractive in any transmission line segment. Where they are additive, a section of transmission line may exceed its thermal capability. When this occurs a utility has the following immediate options to reduce the overload conditions in the short term:

- Reduce generation that would mitigate the problem;

- Increase generation to mitigate the problem;

- Restore transmission lines that parallel the overloaded line segment; or

- Reduce load.
Figure 6.4 Cogeneration Distant from Load

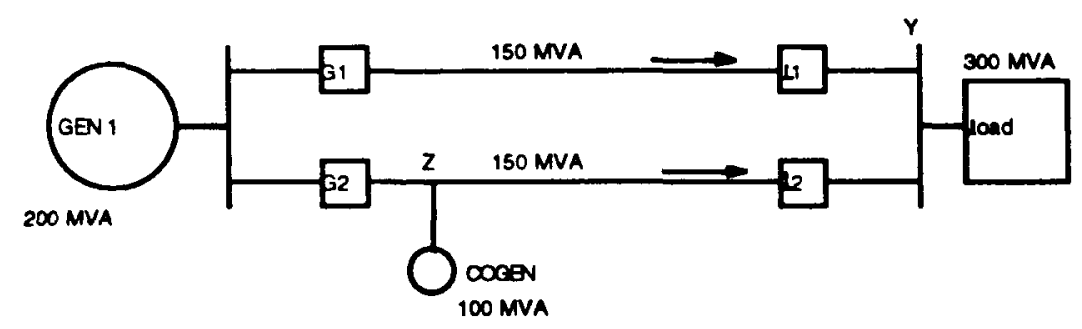

The short term options can best be described by referring to Figure 6.4 which depicts two trans- 
mission lines within a network from Bus $X$ to Bus $Y$.

For simplicity the utility generation (GEN 1) is depicted as entering at Bus $X$ and the total load is aggregated at Bus $Y$. A cogeneration facility (COGEN) injects power close to Bus $X$ on the line between breakers G2 and L2. Assuming each line is constructed in a similar manner and has a normal rating of 150 MVA, and that the load at Bus $Y$ can vary between 150 and 300 MVA, a nondispatchable 100 MVA unit (COGEN) injecting power at Point $Z$ (close to Bus $X$ ) would limit GEN 1 to 200 MVA serving a 300 MVA load at Bus $Y$. This is true because each line would load to its capability of 150 MVA: 200 MVA from GEN 1, 100 MVA from the COGEN.

These restrictions are a direct result of the line loading limitation between $Z$ and L2 (150 MVA).

Examination of Figure 6.6 shows that one solution to supply the original 300 MVA load would be to bring generation (GEN 2) on line at Bus $Y$. This generation might not be as economical as GEN 1 but might prove more economical than building additional transmission facilities. A detailed economic study is required to determine if the fuel cost differential is higher or lower than the cost to invest in new transmission facilities. Utilities would probably attempt to recover the fuel cost differential through charges to the cogenerator. Unfortunately, charging cogenerators for fuel cost differential would be difficult

Figure 6.5 Line Loading With Generation Near Load

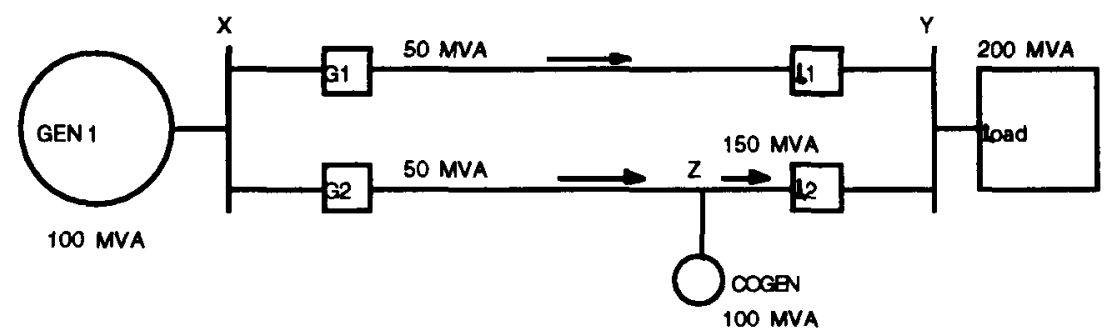
because the cogenerator and the point of current injection on the transmission system may not be well defined for all scenarios. The 100 MVA cogenerator depicted in Figures 6.4 through 6.6 can be made up of a composite of many small cogenerators that inject power in the vicinity of

The line loadings given in Figure 6.4 change as the cogenerator is located nearer Bus $Y$. As demonstrated in Figure 6.5, if the COGEN injected power close to L2, 100 MVA of its output would flow between $Z$ and Bus $Y$. The output of GEN 1 would be restricted to 100 MVA and the load would be restricted to 200 MVA. The line loading between G1 and $L 1$ and $G 2$ and $Z$ would be 50 MVA each.
Busses $X$ and $Y$. Obviously, some cogenerators would tend to reduce or aggravate transmission overload problems based on their size and point of power injection.

Communications between cogeneration facilities and utilities benefit both parties. Obviously the size of the cogenerator is a significant factor in its rela- 
Figure 6.6 Generation Solution to Line Loading Problem

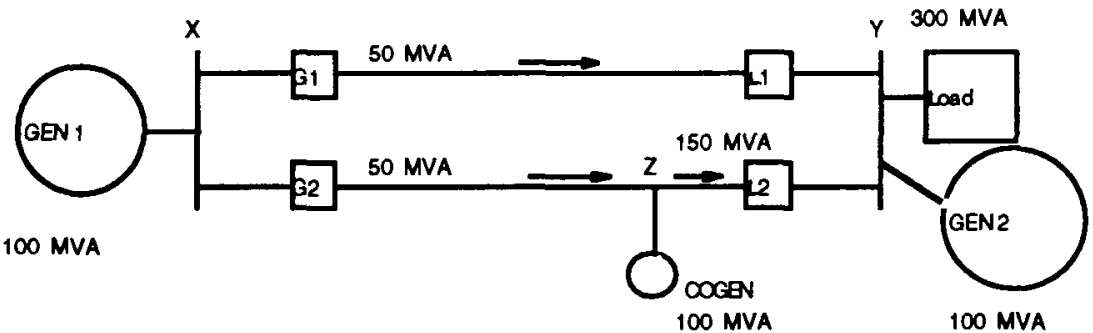

resolution to the transmission overload conditions shown between $Z$ and $L 2$ in Figure 6.6. If it is known that the injection of cogeneration at Point $Z$ in Figure 6.7 will create an overloaded transmission line, facilities that were switched out for maintenance in the network could be restored to service. tionship to a utility. Cogenerators less than $1 \mathrm{MW}$ in size would probably not require communication facilities to notify utility dispatchers when it is on-line or off-line.

Utilities frequently maintain transmission facilities during off-peak periods. Dispatchers should be aware of the existence of generation when major transmission facilities are down for repairs. Cogeneration can be extremely helpful during periods of transmission and generation maintenance; conversely, based on flow direction and point of power injection, they could aggravate transmission line overloads. Figure 6.7 depicts a

Figure 6.7 Transmis. Line Solution to Line Loading Problem

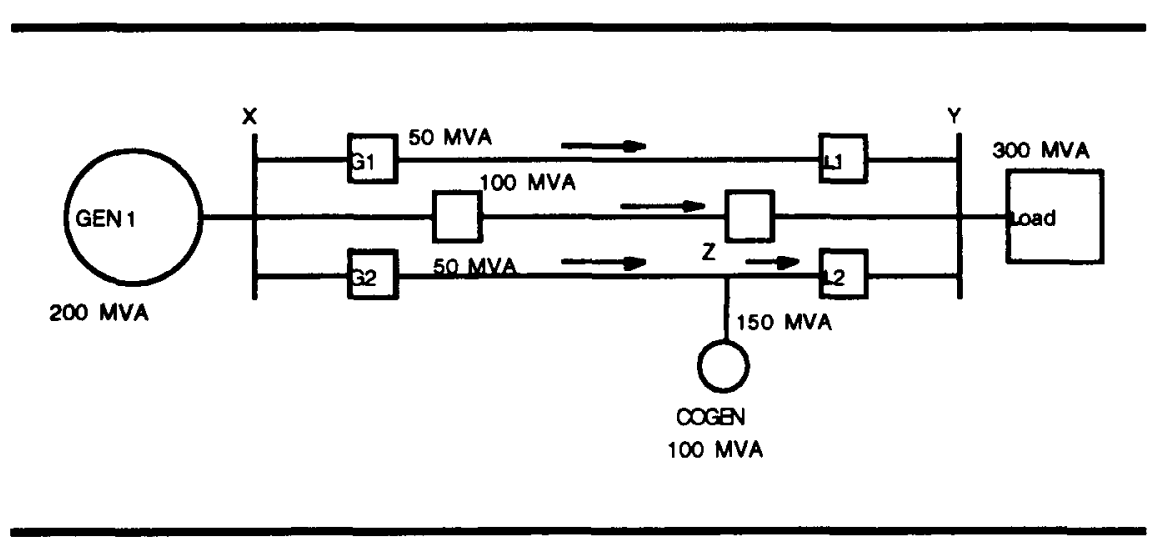

Transmission line flows vary daily and seasonally. These flows are influenced by the following:

- Flows to a utility's own customers - The primary responsibility of each utility is to serve its own customers in a timely and adequate fashion;

- The need to purchase firm power from other utilities. Conversely, when excess generation is available, utilities might find it economical to sell firm power to other utilities;

-Wheeling power flows over transmission systems. Such flows can also be divided into firm and non-firm transactions; and

- Inadvertent power flows by other utilities.
If the cogenerator installs apropriate communications facilities and uses them to give utility dispatchers enough notice, the utility can take action to alleviate anticipated overload problems.

Cogenerators could utilize the unused capacity of transmission lines by determining 
the available reserves under a variety of system configurations. Power flow studies could be run to determine an appropriate wheeling charge based on transmission line losses and the fuel cost differential to supply the losses. The power flow scenarios used to determine wheeling charges would have to include conditions that reflect, at a minimum, peak and off-peak load periods. This might suggest that wheeling charges be broken down into peak and off-peak charges, as well as firm and non-firm service.

In the long term, utilities can add facilities to the portion of the network they own. The addition of facilities might range from reconductoring the transmission lines affected, employing series or shunt capacitors, phase shifters, or constructing additional transmission lines. These actions are almost totally in the control of the utility and its regulators and can only be viewed as long-term solutions to any operating problem. The cogenerator cannot consider these as options unless they are applied to some portion of the network he owns. This alternative is only mentioned for completeness.

\section{COGENERATOR EFFECTS ON SYSTEM STABILITY}

The power system, no matter how large or complex, is made up of only three components: generators, loads, and a network connecting the two. The generators operate in synchronism. The electrical quantities (voltage or current) measured at the terminals are at the same frequency. When no changes are taking place in either of the three components, the system is balanced by having the mechanical power input exactly equal to the electrical power being consumed plus losses in the system. The network is described as being in steady state when this is achieved.

A true steady state, in which no changes are taking place, is impossible to achieve since loads are always being switched. Changes affect the stability on the system. For the purpose of description and study, three major categories of stability are used:

- Steady-state stability;

- Transient stability; and

- Hunting.

Since cogeneration projects may affect stability, it is important that developers understand concerns that certain projects may raise with utilities to which they intend to connect. The subject is best treated in the categories cited above.

One of the basic laws of electric circuits has to do with transfer of power across an impedance which is between any two points. In a typical power system the expression is approximated, with little error, as:

$$
P=\frac{E_{1} E_{2}}{X} \sin \delta_{12}
$$

where:

$\mathrm{P}=$ Power transferred from Point 1 to Point 2

$E_{1}=$ Magnitude of voltage at Point 1

$E_{2}=$ Magnitude of voltage at Point 2

$\delta_{12}=$ Difference in phase angle between $E_{1}$ and E2

$X=$ Impedance between Point 1 and Point 2. 
The effects of quantities should be noted. First, there is a maximum amount of power that can be transferred and it is reached when $\delta_{12}=90^{\circ}$. Second, raising the magnitude of voltage at either terminal improves the limit of transfer. Third, lowering the impedance between the terminals improves the limit.

\section{STEADY-STATE STABILITY}

The term steady-state stability is used to describe the behavior of synchronous machines when they are subjected to small and gradual changes in the network or the connected loads. This concept deals with processes involving generators operating near the point of maximum power transfer into the network to which it is connected. Generators operating near the maximum power transfer point are characterized by a lack of forces to dampen oscillations of terminal voltage following network or load changes. At the limit, changes result in one or more generators losing synchronism and accelerating until safety systems act to shut down the prime movers. Cogenerators located on parts of a distribution system that have relatively low fault capacity or high system impedance may find that the utility has a limit on the size of the generator that may be connected to the network.

Should steady-state stability be a consideration in determining the maximum allowable generator size, there are sevecal options available to project developers: alter the generator characteristics, lower the generator transformer impedance, or lower the network impedance. The changes that can be effected are discussed below.
Generator Impedance - The generator characteristics which affect stability are the Short Circuit Ratio and excitation system. The SCR is a measure of armature circuit saturation. As the SCR increases, the effective value of armature impedance is decreased. Decreasing impedances result in higher power transfer limits.

Excitation System - Generators with excitation systems large enough to hold constant terminal voltage regardless of system conditions have effectively increased the maximum internal voltage they may produce. This increased internal voltage also increases the maximum power transfer limits.

\section{Generator Step-Up Transformer - The} impedance of the transformer which connects the generator to the utility network has the same effect on the power transfer limit as the generator impedance. By lowering either impedance, a higher transfer limit is achieved.

Network Changes - Changes which reduce the equivalent impedance of the network between the generator and utility also increase the power transfer limit. The changes include such options as constructing parallel paths, redesign of lines for minimum impedance configuration, and installing series capacitors.

\section{TRANSIENT STABILITY}

When change occurs in an electrical network, the system moves from one steady-state configuration to another. These changes are assumed to occur in small steps or over a long period of time in problems 
associated with steady-state stability. Events that are precipitated by faults in the network and the necessary line switching to isolate the faults are a problem with more serious potential than steadystate stability problems. These are problems that require study of how the generators in a network move from one equilibrium state to the next. The condition is given the name transient stability.

The network is said to be in equilibrium when the electrical power output from the generator matches the mechanical power developed in the prime mover. The mechanical power over short periods is almost constant because steam flow to the turbine cannot be rapidly changed. On the other hand, the electrical power output from the generator can change almost instantaneously. For instance, when a fault occurs in the transmission network near a generator, the voltage at the terminals of the machine is depressed. Since the power output from the generator is directly proportional to the terminal voltage, a fault in the network results in a mismatch between the mechanical and electrical power at the generator. The generator will accelerate as long as the power mismatch is present. The acceleration forces that the generators experience is determined by the degree to which the terminal voltage is depressed and the length of time the condition exists.

The acceleration of the rotor will increase until the disturbance is removed from the network. Usually, this involves switching lines to remove a fault. Once a fault is removed, voltage is restored in the network at near the pre-fault level. The generators have retarding torques restored and begin to experience deceleration provided they have not moved too far ahead of the other generators in the network. The moment of inertia of the generator rotor determines the degree to which a machine accelerates. The phase angle oscillates until a new equilibrium point is reached. The point beyond which the rotor cannot be allowed to advance is the transient stability limit. This limit depends on many things including the length of period of acceleration, the terminal voltage during the acceleration, and the post-switching network.

The utility to which a cogenerator connects may be very concerned about the network's ability to survive events related to transient stability. The proposed addition of a generator can have far-reaching effects in the network, and the utility will carefully consider this addition. Options are available to the cogenerator to improve the transient stability limit.

Switching Time - The faster a faulted line section can be isolated from the system, the greater the amount of power that the network can transmit without stability problems. This is expressed graphically in Figure 6.8. In this figure it can be seen that the maximum generator size allowed for a network of specific fault capacity is determined by the operating time of the device connecting the generator to the network.

Types of Faults - Some utilities have recognized that three-phase faults are the most severe to which the network may be subjected. They are also the least frequent. These utilities may be willing to 
UTILITY CONSIDERATIONS

Figure 6.8 Effect of Switching Time on Transient Stability

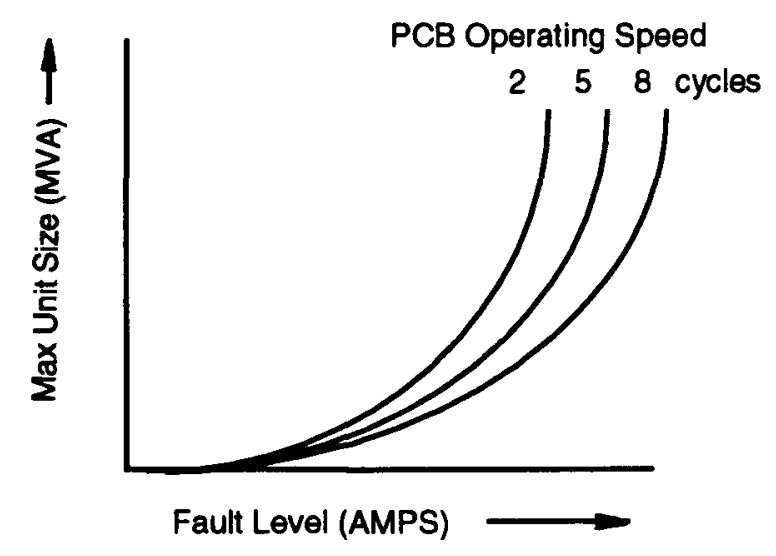

accept loss of stability for three-phase faults near a generator and base their designs on acceptable performance for most other faults.

Single line-to-ground faults are generally the least severe, and their severity may be controlled by the application of impedance in the generator step-up transformer neutral. If this becomes the design basis, careful attention is required to ensure prompt fault isolation to prevent the relatively harmless fault from progressing to another, more severe, fault.

Generator Inertia - The inertia of the generator rotor has a bearing on the transient stability limit. Use of rotors with larger inertias will increase the stability limit for first swing cases. However, the heavier rotors may be a problem for subsequent swings.

Network Factors - As with steady-state stability, network changes which lower the impedance to increase the transfer limit of the network also aid the transient stability limit. Among these are:

- Use of generators with lower transient reactances or step-up transformers with lower leakage reactances;

- Increasing the number of parallel lines between. the generator and network; and

- Use of series capacitors in the lines.

In addition to the above, several switching schemes might be employed. These involve increasing the number of sectionalizing points in the lines between the generator and network so that the post switching network has as low an impedance as is possible. The second is the use of independent pole switching. Independent pole switching is a scheme that recognizes that most faults on transmission lines are temporary in nature and only involve one phase. The scheme allows for a single pole of the circuit breaker at either terminal of a faulted line section to open, thereby deenergizing a fault. While one phase is open, the other two remain closed, allowing nearly full transfer of power from the generator. The poles remain open long enough for the fault to clear itself. After a predetermined time, the poles reclose, restoring full service.

Both steady-state and transient stability problems arise from choice of generator size. Both can be removed by choosing a machine of lower rating. If this is not possible for the proposed project, then developers will be required to examine some of the alternatives listed above. Use of the alternatives will all result in a project of slightly higher costs if their 
application is acceptable to the utility to which the generator is being connected.

Hunting - The frequent or periodic switching of large loads has an undesired effect on generators and motors that are connected nearby in the network. The switching produces fluctuations in voltage which, in turn, affect the balance of input and output torques on the machine rotors. The imbalance in torques results in additional heating of the rotor bodies and damaging stress in shafts and couplings. In addition, the voltage regulating equipment of synchronous machines may be adversely affected.

For the above reasons, the utility may not allow the cogenerator to connect to lines that have arc furnace or electric welding loads served from them. Similarly, the utility will examine the loads of the cogenerator to make sure that they do not have characteristics of this type.

\section{TRANSMISSION SYSTEM SECURITY CONSTRAINTS}

Reliability Councils within North America have generally adopted operating and planning rules that attempt to minimize the chances for recurrences of the "Great Northeast Blackout." Each Regional Reliability Council has promulgated reliability criteria for its members. These are basically anticascading measures that require each member to design and operate its system in such a manner that contingencies within its system will not cause uncontrolled outages which propagate into neighboring systems.
The generally accepted industry practice is to plan and operate facilities to meet certain contingencies which have a high probability of occurring in any power system. The contingencies which a system must survive without loss of load are:

- Loss of any single transmission line or any single generator;

- Loss of any two transmission lines which are on the same double-circuit towers for at least onefourth of the length of the shorter line;

- Loss of any one transmission line or generator with any line out of service for maintenance during spring and fall periods or during summer and winter offpeak periods. It is recognized that outages for routine maintenance will not normally be taken on heavily loaded transmission lines during peak hours; - Loss of any one transmission line or generator while any generator is out of service for scheduled routine maintenance; and

- Loss of a transformer bank or major bus at a generating plant or bulk transmission substation.

Less probable but more severe contingencies involving loss of some bulk load and/or instability of some local generation are contemplated as a practical means of analyzing the transmission system for contingencies beyond those which can be reasonably expected to occur. It should be pointed out that even these events, resulting in mayhem in a given system, may not spread beyond the borders of the system wherein it occurs.

The network is planned so that it will survive the contingencies enumerated above even though they are unlikely to occur when viewed on a 
statistical basis. Operators are forced to limit the loading of facilities during normal circumstances in order not to overstress facilities should any given contingency occur. These limits are generally viewed in two stages of reserve capacity:

- Committed transmission reserves which are reserved margins that the utility maintains for contingencies; and

- Uncommitted transmission reserves which are reserved margins that are availiable for other uses.

Determining limits is no trivial task. The bulk transmission system is a network of multiple paths over which power flows from generators to loads. Should an event occur that requires the removal of a line, the power redistributes itself over the remaining lines. The first stage of determining if a power system can survive contingencies is to see if the steady state flows which are the result of a particular contingency overload the equipment. This type of simulation does not consider the effects of generator dynamics in the determination of acceptability. Machine behavior during network disturbances greatly affects the ability of the network to survive and reach an acceptable operating state. The only way that these determinations may be made is through the progressive application of a list of contingencies to computer simulations of the network in near real time.

Given the requirements of Reliability Councils, a utility is required to operate the network in a secure manner. Operating limits are conservative because of the complexity of the process of determining the level of security. Continued service to its customers and commitments to other utilities will be high priorities in the operations of networks and in the use of network capacity. Wheeling operations involving other utilities or non-utility generators that reduce the security of the network will have much lower priority in the utilization of network capacity.

Cogeneration installations might be able to utilize committed transmission reserves and uncommitted transmission reserves under some arrangements that would not jeopardize the utility's transmission grid. Such an arrangement might necessitate instantaneous removal of the cogenerator for transmission abnormalities that require the immediate use of the transmission reserves. Under such an arrangement both the utility and the cogenerator might profit.

\section{SYSTEM PROTECTION REQUIREMENTS}

\section{UTILITY CONNECTIONS}

Cogeneration installations can be connected to distribution or subtransmission lines. Distribution lines are usually radial and subtransmission lines can be radial or connected in a mesh network.

Distribution circuits in the United States are normally connected in a three-phase, 4-wire, multi-grounded configuration. A typical substation transformer is shown as connected in Figure 6.9. The upper diagram shows wiring for all three phases. The lower diagram condenses this into what is termed a single line diagram. The delta connection is shown on the left, and the wye connection is shown on the right. The phase-to-phase voltages on distribution circuits range from 4.16 to $34.5 \mathrm{kV}$. It is 


\section{Figure 6.9 Four-Wire Distribution Substation Transformer}

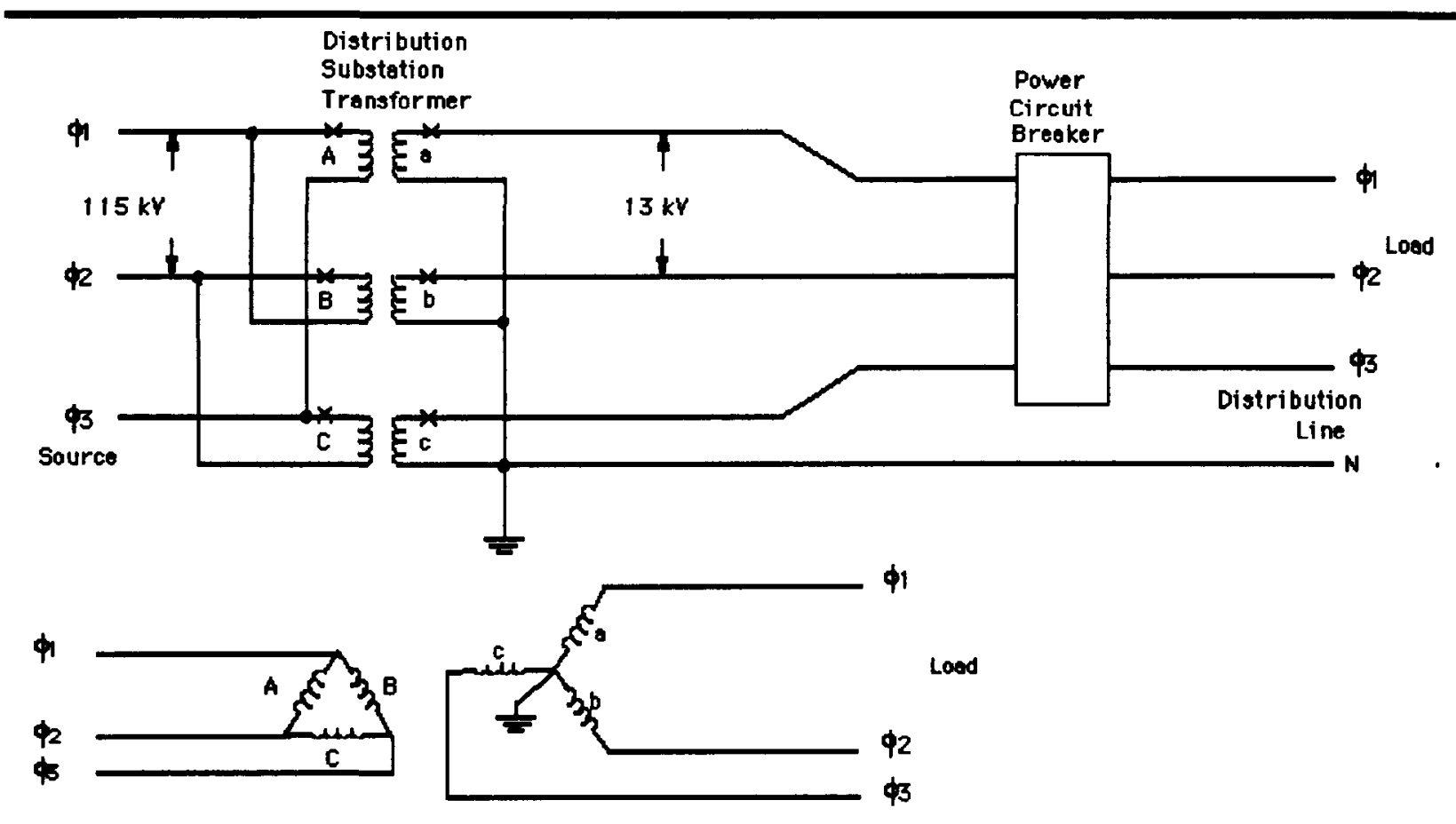

important to note that the substation transformer connection blocks the flow of zero sequence currents on the subtransmission system for phaseto-ground faults on the distribution system. Threewinding transformers are used where three separate voltage levels are required (for example, $230 / 115 / 13 \mathrm{kV}$ ). Under these conditions the distribution winding (13 kV) is normally connected in delta and the two high voltage windings in grounded wye. To obtain a 4-wire system at $13 \mathrm{kV}$, a zigzag or grounded wye-delta transformer must be connected to the $13 \mathrm{kV}$ bus. This is shown in Figure 6.10.

Typically, the loads on distribution circuits consist of single-phase distribution transformers connected between one phase and the neutral wire. The neutral conductor is connected to earth at the substation and at frequent intervals throughout the length of the circuit. With single phase loads connected throughout the network, it is impossible to exactly balance the load between the three phases. Therefore, it is not uncommon for ground current to flow continuously in the neutral of both the distribution circuit and transformers. This unbalance must be accounted for in setting ground relays.

Cogenerators connected to a distribution circuit would be connected through a three-phase transformer. Some of the more common methods of connection are given in Table 6.1.

The type of connection used significantly affects the type of circuit protection required. For example, transformers connected with grounded wye primary 
UTILITY CONSIDERATIONS

Figure 6.10 Three-Voltage Distribution Substation Transformer

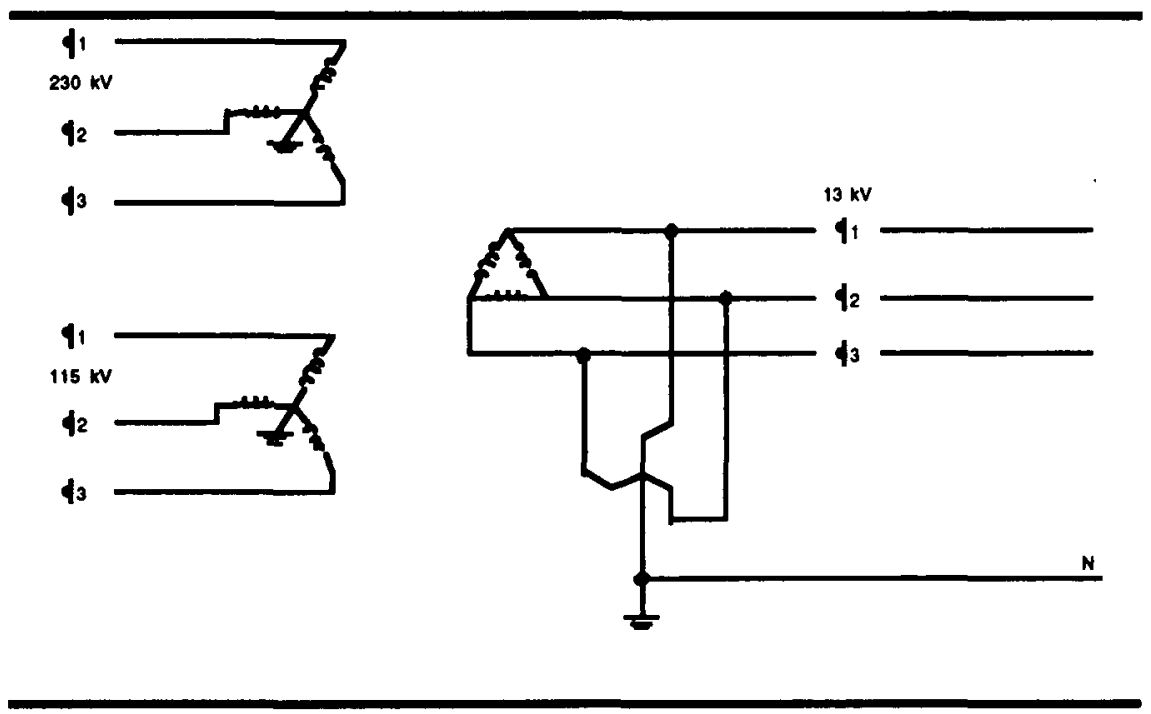

primary fuses. This will usually result in higher current settings on some of these devices and thereby reduce their sensitivity.

In addition, three-phase transformer banks will energize broken phase wires that are grounded on the load side if the transformer bank is located on the same side as the grounded conductor. This condition is shown in Figure 6.11. While these protection problems are of great concern, most of the methods presently employed in the United States permit overhead distribution customers to install cogeneration facilities if the equipment is properly designed and constructed.

Overhead Circuits - A considerable number of branch circuits are built with small conductors such as 1/0 aluminum and No. 6 copper. These lines have limited current capability and tend to anneal and melt quickly when subjucted to high currents. For this reason they are normally protected by small fuses that will coordinate with distribution transformer cutouts. These circuits also vary considerably in length from one to two miles in densly populated urban areas to $\mathbf{2 0}$ miles or more in sparsely populated rural locations. Clearly, cogenerators connected to these circuits will be limited to a relatively small capacity. Someone wishing to install a small hydroelectric unit (up to $1 \mathrm{MW}$ ) would be faced with the expense of paying the 
Figure 6.11 Transformer Energizing Broken Phase Line

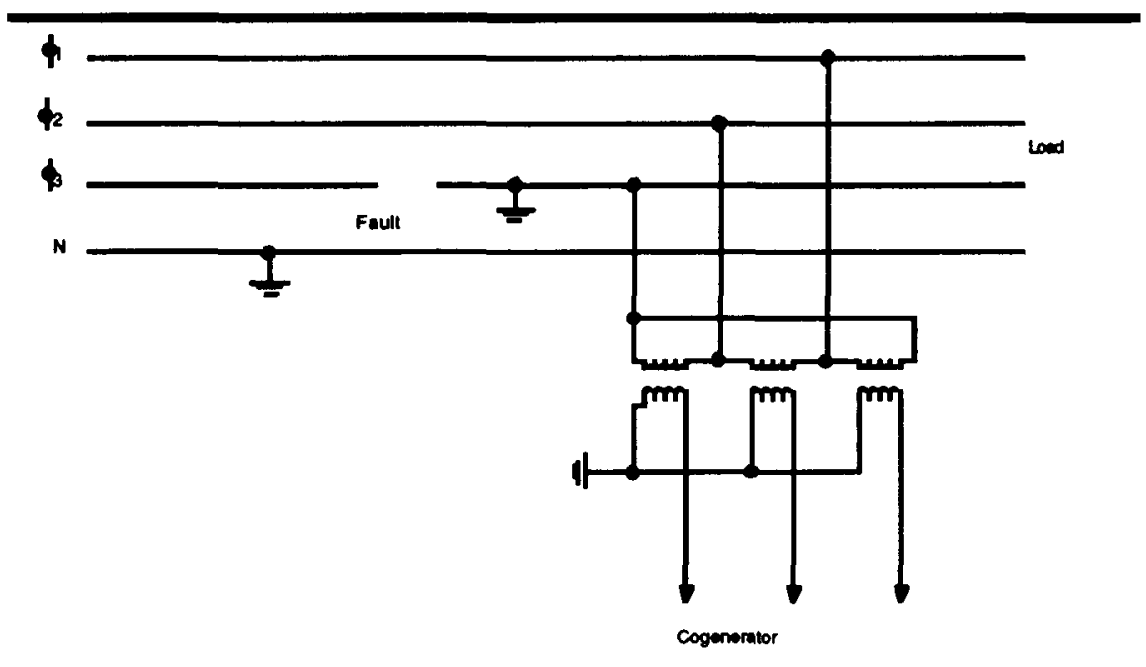

3 Benk koepe broken phese enorgizod

utility with which it wishes to connect to extend three-phase service over a considerable distance.

\section{Underground Circuits - Where utilities employ} radial underground distribution circuits, the protection for cogenerators becomes even more complex. Such cogenerators may have difticulty maintaining continuous parallel operation with the utility because underground network transformer secondary circuit breakers are usually equipped with sensitive network protective relays. These devices will not permit reverse power flow. Thus, slight excesses of generation over load would cause tripping of the network protectors resulting in total disconnection of all customers, even under normal steady-state no-fault conditions.

\section{FAULT CURRENTS}

Fault currents vary widely depending, among other things, on the nature of the disturbance. In general, phase currents will be maximum if a phase wire contacts another phase wire. They will be minimum if a phase wire contacts sand, concrete, or other high-impedance materials. High fault currents clear quickly; low fault currents clear slowly. Some high impedance (low fault current) ground faults may not be cleared except by manual disconnection of the circuit. This is of prime concem when connecting additional sources of generation on distribution networks because its contribution to the fault current may be small, but potentially very dangerous.

\section{SYNCHRONOUS VS. INDUCTION GENERATORS}

A synchronous generator is one in which its rotational speed is in synchronism with the system frequency. Field excitation is supplied separately. This makes the synchronous generator somewhat unique in that it can supply power to a load without being connected to a utility's system. The separate excitation means that the unit can supply sustained fault current until it is isolated from the fault. The synchronous generator requires more complex protective equipment to isolate it from faults.

An induction generator requires an external source to provide magnetizing current necessary to establish the magnetic field across its air gap. This 
means that an induction generator cannot apply electric power without always being connected to the utility or connected to a capacitor of sufficient size to supply its reactive requirements. Many utilities are required to install capacitors to reduce losses in their systems. These capacitors could supply an induction generator with sufficient excitation to continue to supply connected loads in an islanding situation. Conversely, if the reactive requirements of an induction generator are sufficiently high to cause the utility to incur power factor penalties, the utility may require that the cogenerator supply sufficient capacitors to offset its reactive requirements.

The rotational speed of an induction generator is determined by the prime mover and is slightly higher than system frequency. While the induction generator does not require special procedures or equipment to synchronize with the utility, potentially damaging inrush currents and associated shaft torques can occur when they are reconnected to the utility at below synchronous speeds.

\section{UTILITY REQUIREMENTS}

Normally, utilities have a number of generating units operating in parallel, and they have complete control over how they function in a parallel environment. All generators must be designed to accommodate system disturbances such as transmission line faults, equipment failures, sudden loss of generation or load, and variations in line current flows. The same attention to detail must be considered when a cogenerator expresses an interest in parallel operation with a utility system.
Detailed information on the design of the interconnection may be found in the IEEE Guide for the Interconnection of User-Owned Substations to Electric Utilities.

The utility must address the following concerns when it considers the parallel operation of a cogenerator:

- Personal safety;

- Damage to the cogenerator;

- Damage to the utility; and

- Problems for other customer-connected loads.

In general, small cogenerators will not present a significant problem for utilities. However, large cogenerators or large concentrations of small cogenerators may cause operational and control problems for some utilities.

\section{DISTRIBUTION PROTECTIVE DEVICES}

Fault Detection - Typical protective devices in a distribution network are shown in Figure 6.12. This figure is a single line diagram depicting a circuit supplied through a single power circuit breaker at the source substation and subsequently divided into zones of protection by automatic sectionalizing devices. The protective devices are arranged so that a fault in any section is isolated without causing interruption to other portions of the circuit. A fault close to the circuit breaker will cause it to operate and de-energize the entire circuit.

Normally, overcurrent relays are connected to detect phase and ground faults on the three-phase circuit from the substation to the first reclosers. The 
Figure 6.12 Distribution Network Protective Devices

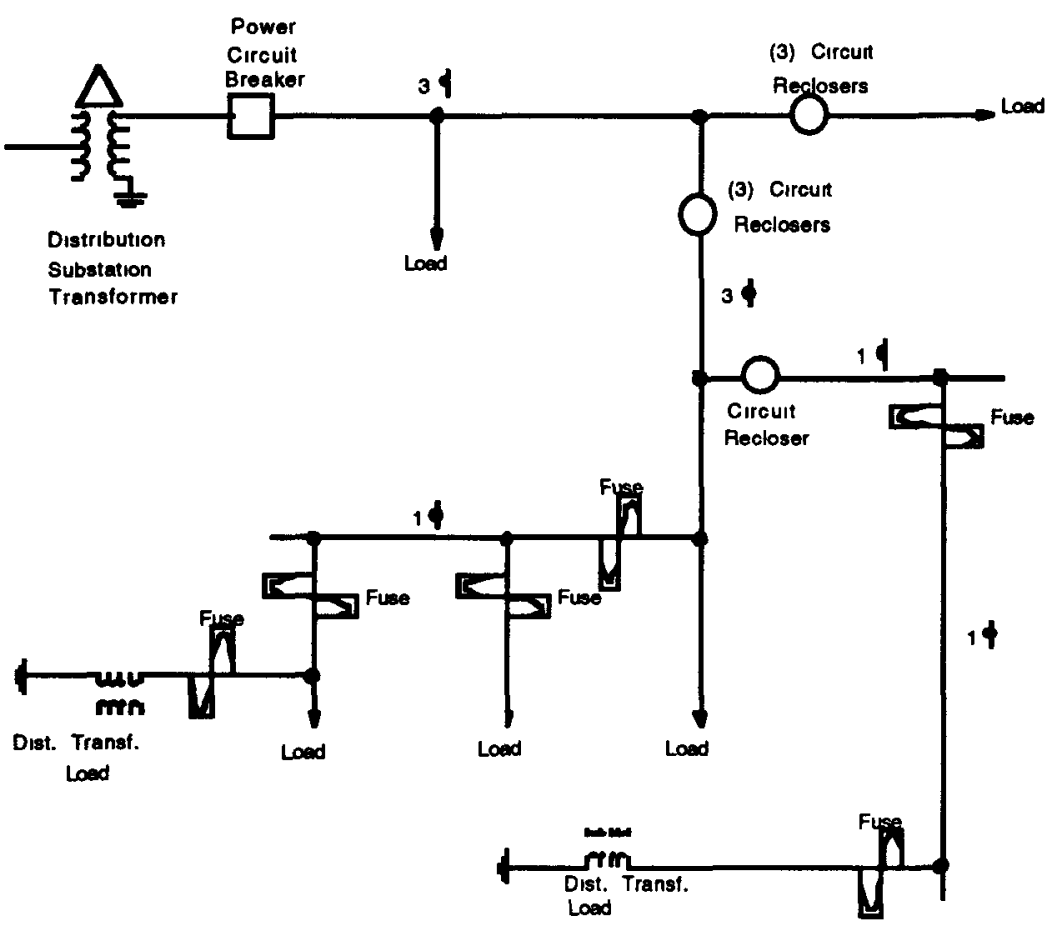

However, their sensitivity is still limited by the amount of load current that they must carry and the operating characteristics of other protective devices further down the line.

The installation of a cogenerator on a distribution circuit will tend to degrade the ability of protective relays on the source breaker to detect line faults. This is particularly true if the cogenerator is connected to the distribution system through a delta-wye bank with the wye-side connected to the distribution network. Under these conditions any phase-to-ground fault currelays are connected as shown in Figure 6.13. The phase relays must be set above the maximum anticipated load and therefore are considerably less sensitive to phase-to-ground faults. It is not uncommon for phase overcurrent relays to be set as high as 1200 amperes. Ground relays can be set considerably lower if the three-phase circuits are reasonably well balanced. However, ground relays must be set high enough to accommodate load imbalance when a fuse or single phase recloser operates. Also, all phase and ground relays are subjected to inrush currents upon load restoration. The sensitivity of protective devices on branches of the main feeder line is much greater, and they will operate at considerably lower fault current levels. rent will be divided between the two sources. The closer the phase-to-ground fault to the cogenerator, the less current flow in the source breaker. Protection will be further degraded if a recloser or fuse has to be removed to permit the cogenerator to function. This problem can be eliminated by connecting the cogenerator transformer in delta on the utility side. However, once the station breaker opens to clear the fault from the source, the circuit is no longer effectively grounded and the two unfaulted phases will be subjected to full line voltage by the cogenerator. If this condition is allowed to exist, damage could occur to connected equipment. Protection solutions to these problems will be addressed in later sections. 
UTILITY CONSIDERATIONS

Figure 6.13 Overcurrent Relay Protection on Distribution Network

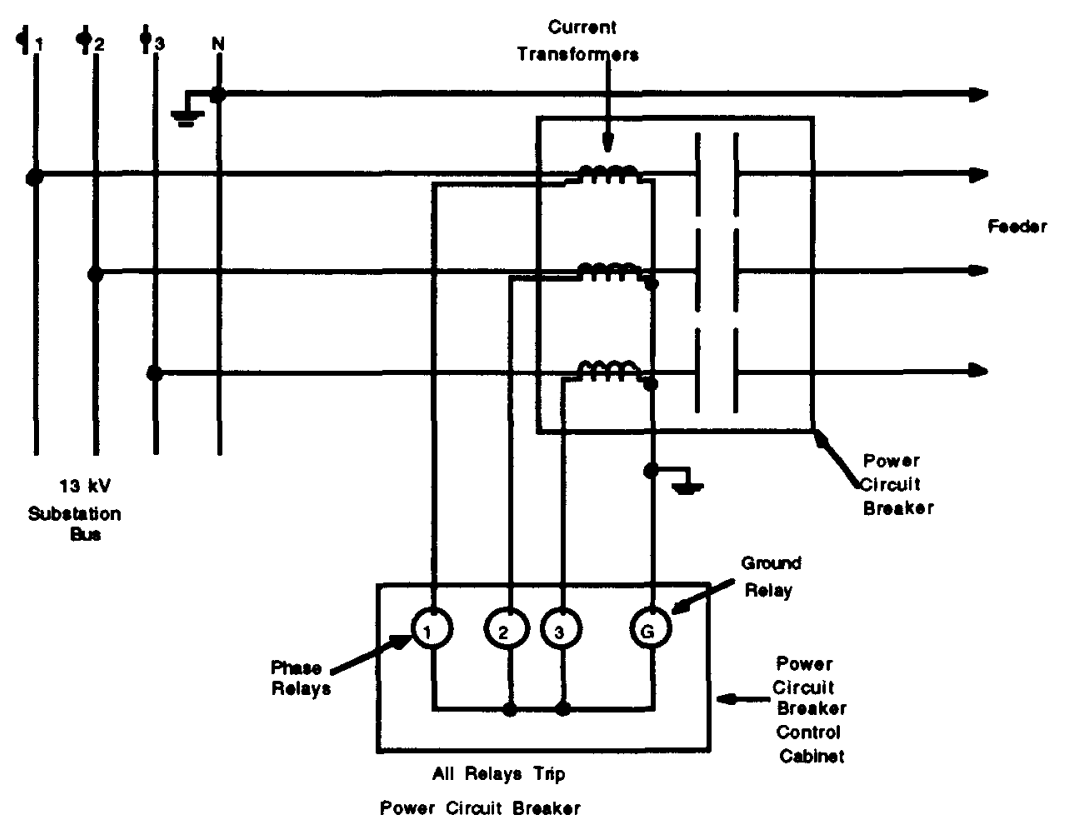

between the cogenerator and the source station. Solutions to these and other reclosing problems will be discussed below.

In general the sizes of cogenerators connected to the utility distribution system are 5 MW or less. Cogenerators in excess of 5 MW are normally connected to a utility's subtransmission system. As one might suspect the larger the cogenerator, the more complex the protection provided by both the cogenerator and the utility. In general it is extremely important to isolate the cogenerator from any fault in the transmission line segment to which the

Reclosing - The normal practice is to have a circuit reenergized at least once following breaker operation. This is an attempt to reestablish service after extinguishing temporary faults. However, there may be as many as four attempts to accomplish this restoration. If the automatic features fail, restoration is done manually. A utility's reclosing practice may have to be altered dramatically with the advent of a cogeneration facility. With the introduction of a cogenerator, a utility that previously employed automatic 4-shot reclosing may have to eliminate reclosing. High-speed reclosing would not be fast enough to prevent damage to the cogenerator if it is still on line. Similar considerations would have to be employed on a recloser installed cogenerator is connected. It would be the responsibility of the cogenerator to resynchronize after the source voltage is successfully reestablished.

\section{PROTECTION OF COGENERATORS}

Personal Safety - Most distribution systems are designed for radial operation. This means that power flows in only one direction from the substation. There is no provision to accommodate continuous reverse flow from cogenerating equipment. The addition of a cogenerating unit to a radial distribution line will require that the utility modify its operating procedures to accommodate the cogenerator. For example, when maintenance 
is performed on distribution lines it will be necessary for the utility to properly identify and disconnect all cogeneration before line crews can work on distribution lines. Line crews are accustomed to working between visible break points from all sources to prevent deenergized distribution lines from becoming inadvertently energized.

Islanding - It is not uncommon for distribution substations to be momentarily isolated when a source breaker trips to clear a fault. Under these conditions a cogeneration facility will attempt to supply the isolated load. The cogenerator could also continue to supply fault current to the fault. If the fault is sustained by the cogenerator, even for a few cycles, this may adversely affect the ability of the source breakers to restore service through high speed reclosing.

Also, the potential of the cogenerator to continue to supply the connected load would raise concern for the type and quality of electric service during periods of isolation. It is important that a utility maintain service limits of voltage, frequency, flicker, harmonic distortion, and proper short circuit protection of the connected system. It is doubtful that this responsibility will ever be delegated to a cogenerator. However, it is quite conceivable that, if it has sufficient size, the cogenerator may be able to serve connected loads while the facility is not in parallel with the utility system. This would probably require more sophisticated equipment to be installed by the cogenerator for which it would receive few benefits under most contract conditions.
Figure 6.14 depicts a 30 MVA distribution transformer supplying loads via breakers $B, C$, and $D$. The cogenerator is served by breaker $D$ together with other connected loads. Note that a fault on the 30 MVA bank will trip breakers $A, B, C$, and D leaving the cogenerator supplying load connected to breaker $D$. A fault on the 115-kV transmission line may leave the cogenerator connected to all loads on feeders B, C, and D plus any other load connected to the transmission line at other locations. There are other scenarios that would have to be evaluated, but it is evident that both the utility and the cogenerator must explore and evaluate all the potential operating conditions.

Protection Examples - Most islanding problems can be alleviated by installing protective devices at the cogenerator/utility interface that will quickly disconnect a cogenerator from the utility when it becomes isolated. Fault current levels on any circuit, such as breaker $C$ in Figure 6.14, will be increased by the addition of a cogenerator on circuit D. The additional fault current must be evaluated because it may exceed the interrupting capability of breaker C. Another consideration is the time/current coordination of the overall circuit protection as a result of the installation of a cogenerator that was not envisioned when the circuit was first designed.

A system must be designed to protect the generator from damage due to faults on the utility network and conversely to protect the utility and its customers from damage due to the operation of the cogenerator. Four principles should be considered: 


\section{Figure 6.14 Protection of Potential Islanding Problems}

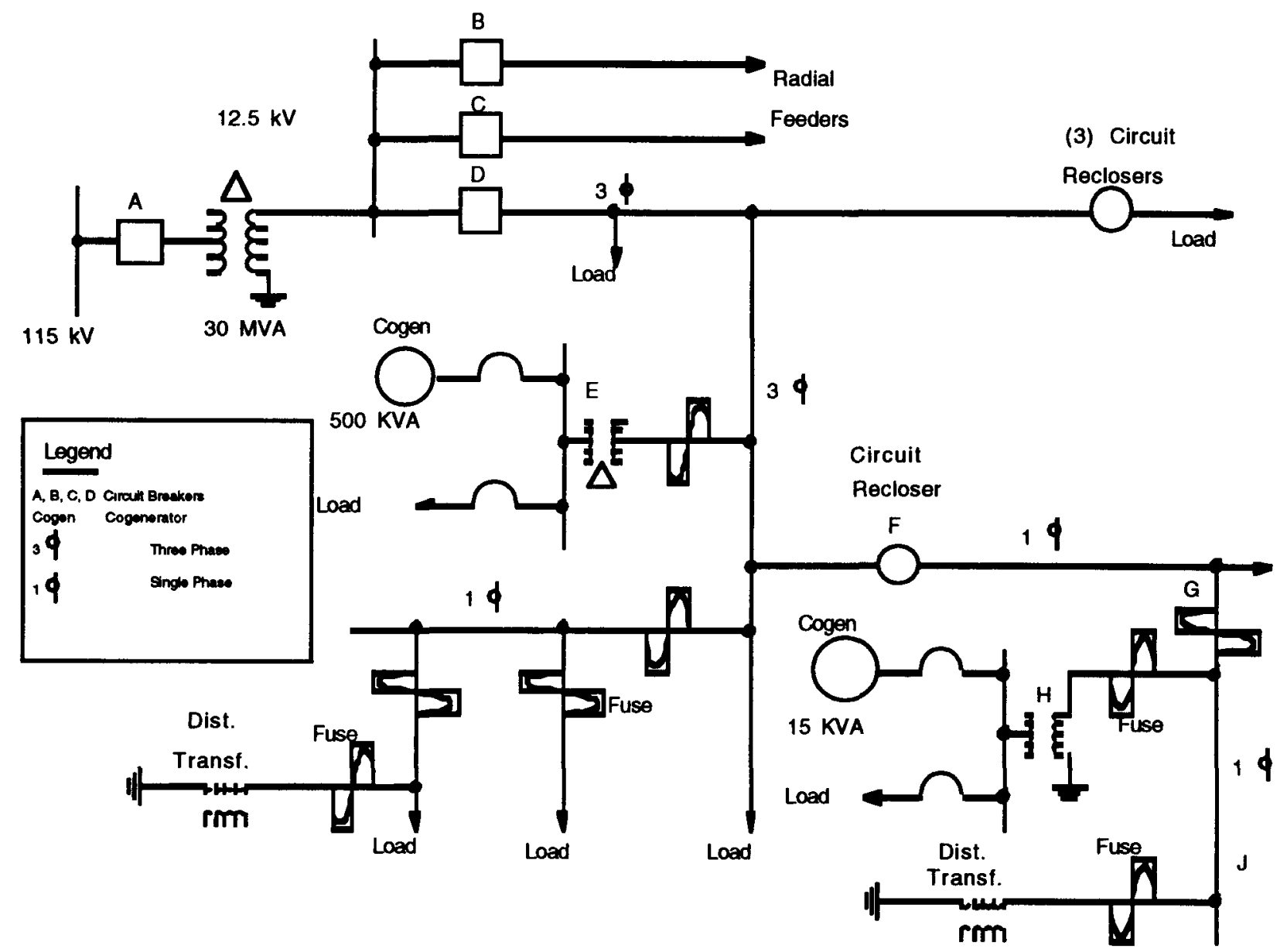

- Dependability - The protective device should have a very high probability of clearing faults that occur on the power system;

- Security - The protective device should have a low probability of interrupting the circuit unnecessarily;

- Selectivity - The protective device should isolate only the faulted area of the power system; and

- Speed - The protective device should operate as rapidly as possible consistent with coordination requirements to minimize damage.
Detailed information on the protection of a cogenerator/utility interface can be found in a report by the IEEE Power System Relaying Committee entitled Intertie Protection of Customer-Owned Sources of Generation. There are numerous protective packages that can be utilized at the cogenerator/utility interface. Detailed descriptions of these packages can be found in the IEEE Guide for Interfacing Dispersed Storage and Generation Facilities with Electric Utility Systems. 
Figure 6.15 Small Induction Generator Protection Scheme

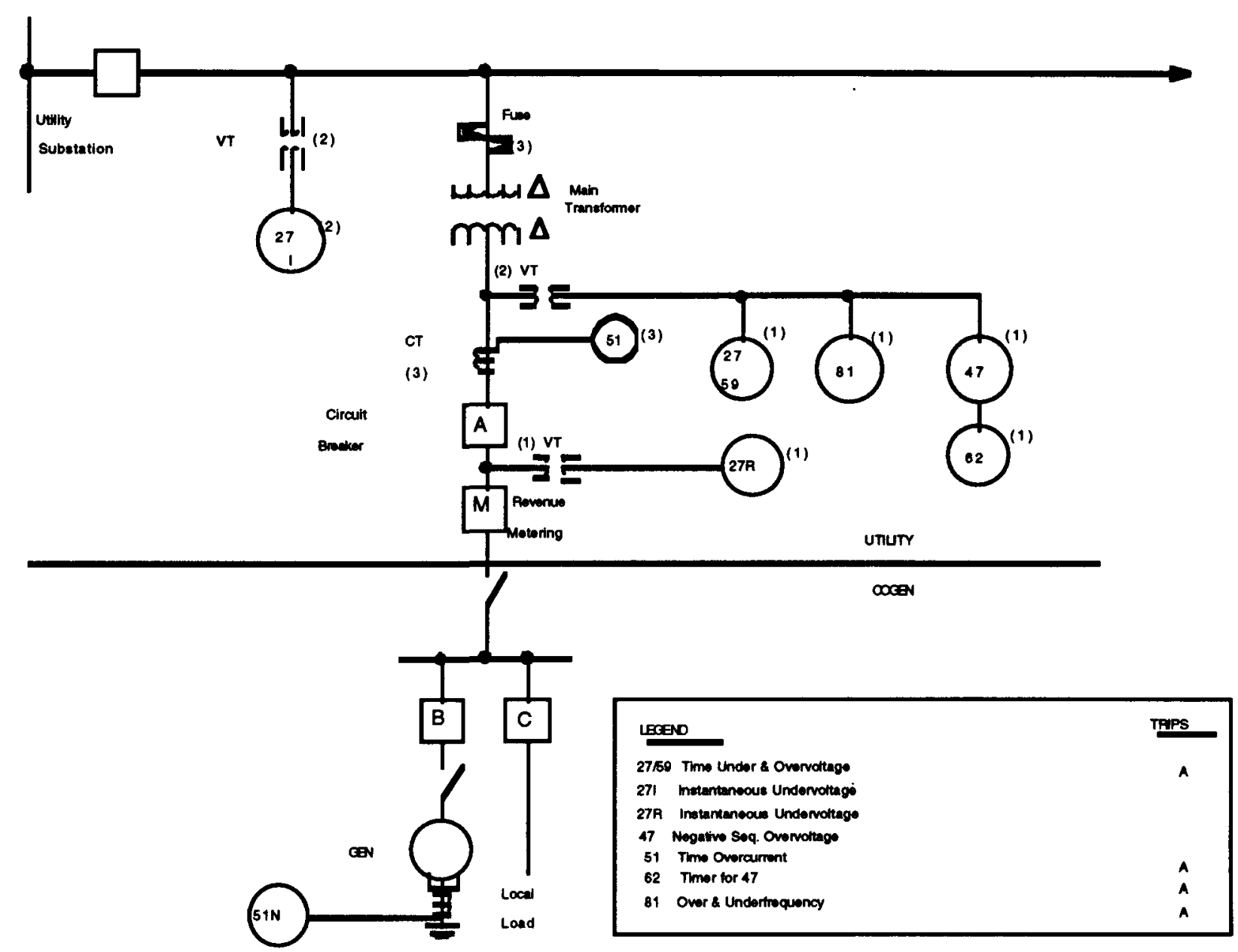

1. Small Generator Protection - Figure 6.15 shows the protection of a small three-phase generator, under $3 \mathrm{MVa}$. Note that the main power transformer is connected delta-delta. With this connection ground fault currents will not be diverted from the utility substation breaker. Thus the ground relays on the utility's substation breaker can maintain the same type of sensitivity they had prior to the installation of a cogenerator.

The high-side fuses will protect the power trans- former and all low-side connections for interphase faults. Low-side phase-to-ground faults cannot be detected with this scheme. If the cogenerator is grounded wye connected, ground faults can be detected by $51 \mathrm{~N}$ and the COGEN isolated by tripping breaker $B$. Identification numbers for protective devices, such as $51 \mathrm{~N}$ above, are listed in Table 6.2.

Islanding protection for this type of installation is provided by the $27 / 59$ and 81 relays. The $27 / 59$ is a 
Table 6.2 Identification Numbers for Protective Devices

\begin{tabular}{|c|c|c|c|}
\hline Device No. & Definition & Device No. & Definition \\
\hline 25 & Synchronizing, or synchronism check & 61 & Current balance relay \\
\hline 26 & Apparatus thermal device & 62 & Time-delay stopping, or opening, relay \\
\hline 27 & Undervoltage relay & 63 & Liquid or gas pressure, or level, relay \\
\hline 29 & Isolating contactor & 64 & Ground protective relay \\
\hline 31 & Separate excitation device & 66 & Notching, or jogging, device \\
\hline 32 & Directional power relay & 67 & AC directional overcurrent relay \\
\hline 33 & Position switch & 68 & Blocking relay \\
\hline 34 & Motor-operated sequence switch & 69 & Permissive control device \\
\hline 35 & Brush-operating device & 70 & Electrically operated rheostat \\
\hline 36 & Polarity device & 72 & DC circuit breaker \\
\hline 37 & Undercurrent or underpower relay & 73 & Load-resistor contactor \\
\hline 40 & Field relay & 74 & Alarm relay \\
\hline 41 & Field circuit breaker & 75 & Position changing mechanism \\
\hline 42 & Running circuit breaker & 76 & DC overcurrent relay \\
\hline 43 & Manual transfer, or selector, device & 77 & Pulse transmitter \\
\hline 44 & Unit sequence starting relay & 78 & Phase angle protective relay \\
\hline 46 & Reverse-phase current relay & 79 & $A C$ reclosing relay \\
\hline 47 & Phase-sequence voltage relay & 81 & Frequency relay \\
\hline 48 & Incomplete sequence relay & 82 & DC reclosing relay \\
\hline 50 & Instantaneous overcurrent relay & 83 & Automatic selective control relay \\
\hline 51 & AC time overcurrent relay & 85 & Carrier, or pilot-wire, receiver relay \\
\hline 52 & AC circuit breaker & 86 & Locking-out relay \\
\hline 53 & Exciter of DC generator relay & 87 & Differential protective relay \\
\hline 54 & High-speed DC circuit breaker & 88 & Auxilliary motor, or motor generator \\
\hline 55 & Power factor relay & 89 & Line switch \\
\hline 56 & Field application relay & 90 & Regulating device \\
\hline 57 & Short-circuiting, or grounding, device & 91 & Voltage directional relay \\
\hline 58 & Power rectifier misfire relay & 92 & Voltage \& power directional relay \\
\hline 59 & Overvoltage relay & 93 & Field changing contactor \\
\hline 60 & Voltage balance relay & 94 & Tripping, or trip-free, relay \\
\hline
\end{tabular}

time under- and over-voltage relay that can be used voltage relays come into play when the utility's to trip circuit breaker $A$. The under- and over- substation breaker trips. 
The 81 device is an over- and under-frequency one which would also be activated when the utility substation breaker trips. If a high-side transformer fuse opens, single phase protection can be provided by the negative sequence over-voltage relay (47). This is a sensitive relay and must be provided with a timer (62) to prevent inadvertent tripping for external faults. After a fault on the utility system has been cleared and the utility breaker has reenergized the line, reclosing of breaker $A$ at the cogenerator can be supervised by the undervoltage (27) relays which detect that the source voltage has been restored. It should be reemphasized that it is essential that the COGEN be disconnected (breakers $A$ and/or $B$ open) after the utility source is de-energized in order to prevent generator damage due to reclosing out-of-synchronism. The 51 time over-current relays will provide time over-current protection in both directions.

\section{Large Generator Protection - Figure 6.16} depicts the installation of a three-phase induction generator connected to a delta wye transformer. Note the delta connection is on the utility's system. Thus the ground relays on the utility's substation will not be adversely affected by the cogenerator for phase-to-ground faults on the utility's system. This installation requires a high-side circuit breaker (A) and current transformers (CT) to which over-current phase and ground relays are connected. These relays will provide protection for the transformer and the low-side bus between the transformer and breakers $\mathrm{B}$ and $\mathrm{C}$. The $51 / 51 \mathrm{~N}$ residual relay can provide sensitive ground fault protection in the high-side winding of the transformer. Note that this relay can be set quite sensitively because it does not require coordination with ground relays on the low side. Ground faults on the utility's supply circuit will be cleared by the ground over-voltage relay (59G). This relay is connected in the broken delta secondary of the high-side voltage transformers. Under normal conditions the secondary residual voltage will be approximately zero; however, when a ground fault occurs in the utility's system, this connection will produce sufficient voltage to operate the $59 \mathrm{G}$ relay.

Devices 27, 59I/T and 81 will detect out-of-limit voltage and frequency conditions whenever the cogenerator is islanded. The instantaneous units of the $59 \mathrm{I} / \mathrm{T}$ relays will provide high-speed tripping of the cogenerator under extreme over-voltage conditions which can occur if the generation in the island exceeds the load. After a fault on the utility's system has been cleared, the utility substation breaker can be permitted to reclose after the 271 relay drops out indicating that the line is dead and that all cogenerators have been disconnected. After the line has been reenergized as indicated by the operation of over-voltage relay 159l, breaker A can be closed if the cogenerator bus is not energized.

These protection examples provide a sample of the various types of cogeneration installations. However, there are many other configurations that are as good as or better depending upon the circumstances and the interface requirements. As stated in P1001, the examples described should not be considered required practice for design 
Figure 6.16 Large Induction Generator Protection Scheme

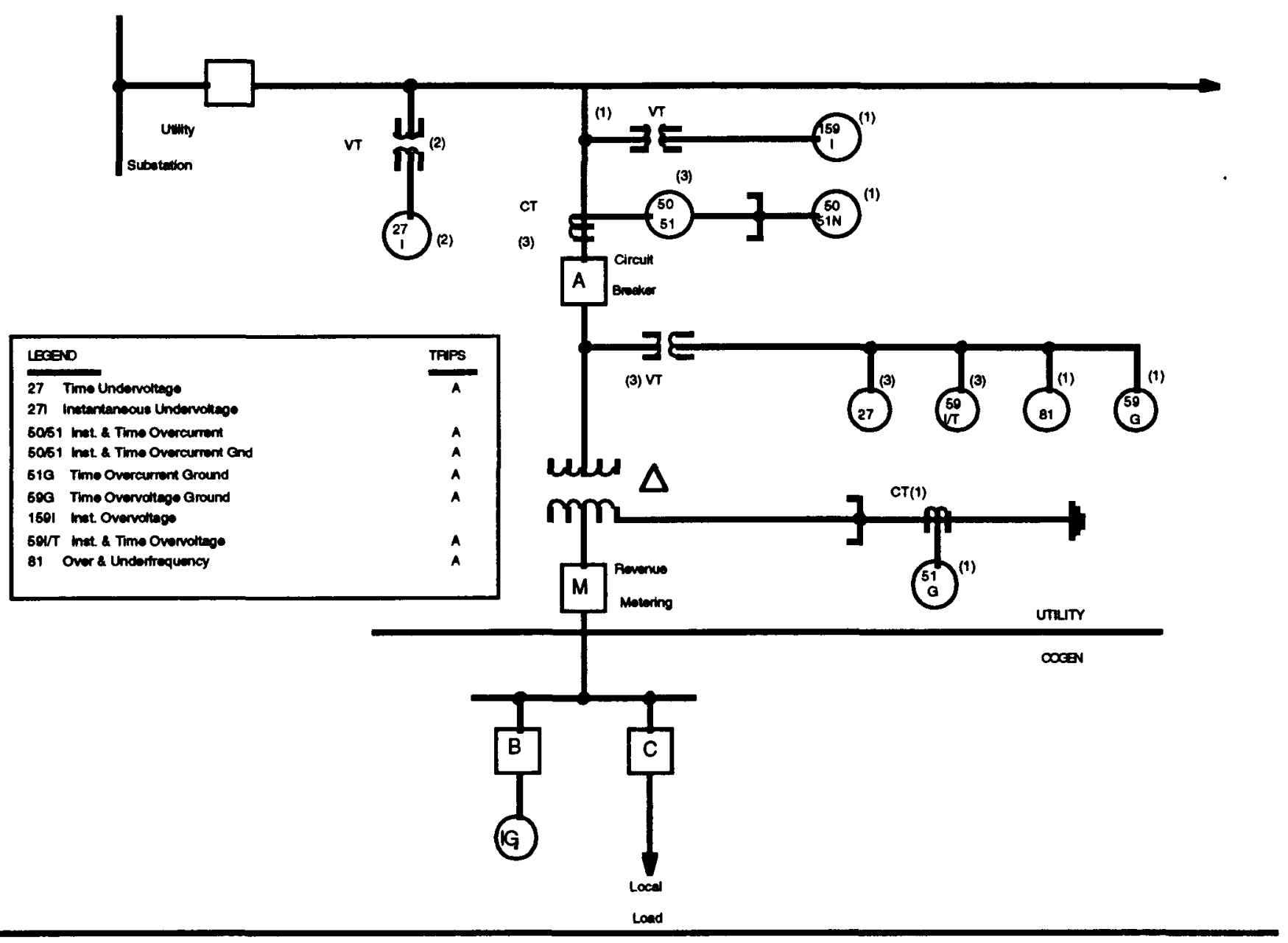

purposes. They are presented to provide information on the engineering principles involved in the protection of the cogenerator and the utility interface. All utility/cogeneration interfaces are subject to negotiation between all parties concerned.

\section{INFORMATION SOURCES}

Interconnection and Protection

Transmission Access
IEEE Guide for Interfacing Dispersed Storage and Generation Facilities with Electric Utility Systems; IEEE Std. P1001 '89.

IEEE Guide for the Interconnection of User-owned Substations to Electric Utilities; IEEE Std. P1109' 88.

IEEE Standards for Automatic Switchgear, IEEE Std. C37.2, 1987.

Intertie Protection of Consumer-owned Sources of Generation; IEEE 88TH0224-6PWR, 1988.

"Making Interconnection Work;" J. Reason, Power, June 1982, pp S1 - S24.

"Transmission Access;" R. Felak, Electrical World, June 1993. 
$6-26$ 


\section{CHAPTER 7 .}

\section{REGULATORY CONSTRAINTS AND UNCERTAINTIES}

The appearance of market competition in the construction and operation of electric generating plants resulted from two events. The first was passage of the Public Utility Regulatory Policies Act of 1978 (PURPA). This legislation facilitated construction of cogeneration and small power production facilities that could be built as cheaply as a plant built by a utility. The second event, which followed from PURPA, was the adoption of competitive bidding rules by many state regulators. Such rules recognized the possibility that non-utility entities might construct plants at even less cost than a utility. Such plants, which were indeed built, included conventional facilities that did not have the economic advantage of cogeneration at a thermal host. The term Independent Power Producer came into vogue to describe such facilities.

Competition in generation was recognized as the initial stage of deregulation of the electric utility industry. This was a term used for the airline, telephone, natural gas and petroleum industries. However, deregulation does not necessarily lead to a reduction in regulation of the industry. Regulatory oversight will continue where monopolistic market conditions exist.

In the electric utility industry monopolistic conditions will remain because utilities have a franchise for their service territory and are a sole supplier of their native load. That means that a single utility serves customers within their franchise, a monopolistic situation. Monopolistic conditions also exist in regard to most transmission and distribution facilities.

The industry is very capital intensive, and it does not make economic sense to have multiple utilities available to serve every retail customer. Since the price that retail customers pay includes all costs of production and distribution, regulation of these costs in some form or another will continue. This places constraints on development of WCP projects.

Considerable regulatory uncertainty also exists in the increasingly competitive electricity market. A major uncertainty, that of wholesale wheeling access to transmission systems by non-utility generators (NUG's), was removed through passage of the 1992 Comprehensive National Energy Policy Act (EPAct). The Federal Energy Regulatory Commission (FERC) now has authority in most of the U.S. to issue wholesale wheeling orders. Prior to this both wholesale and retail wheeling were permissable, subject to agreement by the parties involved. The problem, however, was that some PUCs would not mandate wheeling for an ICU and that FERC and the 
Nuclear Regulatory Commission would only mandate wheeling under certain conditions. FERC conditions also tended to change over time.

Regulations affect wholesale transactions as well as other aspects of a project. These areas include retail wheeling access, the pricing of transmission services, overlapping regulation, and the rights of a qualified facility versus an exempt wholesale generator. These issues are discussed in what follows.

\section{WHOLESALE TRANSMISSION ACCESS}

Section 201 of the Federal Power Act (FPA), as amended since its inception in 1920, establishes Federal regulation over generation and transmission of electric energy that is in interstate commerce. FERC has interpreted this authority broadly in recent years. It includes transmission between a buyer and seller within the same state when the affected transmission lines are synchronously interconnected with transmission lines in other states. The basis for this is that transmission lines are regularly used to transfer electric energy between states and that laws of physics, not utilities, control such power flows. Thus, they are engaged in interstate commerce.

Section 201 goes on to state that electric sales at wholesale that are in interstate commerce are under the federal regulation of FERC wherever they are not regulated by a state regulator. The exceptions, here, refer to the Electric Reliability Council of Texas (ERCOT), Alaska and Hawaii.
Utilities within ERCOT have ties of very limited capacity with neighboring reliability councils; so ERCOT utilities are regulated by the Texas Public Utility Commission (PUC). This is no problem to cogenerators, however. The Texas PUC will mandate interconnection for purposes of wholesale wheeling. (FERC's 1994 action on the merger of Central and South West Services with El Paso Electric Co., however, leaves open the possibility for FERC to order wholesale wheeling on the portion of the merged system within ERCOT.) In Alaska, on the other hand, the PUC leaves the transmission decision to individual utilities. These utilities may or may not agree to wholesale wheeling of power. Finally, in Hawaii, wholesale wheeling is just not feasible. Each of the islands has its own utility, and none are connected by undersea electrical cable.

In adddition to the exceptions noted above, FERC is not required to issue wheeling orders in the Tennessee Valley Authority's service area. This encompasses approximately a two-state area served by 160 distributors of TVA power. During the drafting of EPAct TVA argued that wheeling would present unfair competition since federal legislation prevents it from selling long-term, firm power to utilities outside its service territory.

Sale of electric energy at wholesale is defined in $\S 201$ as a "sale to any person for resale." Under $\S 211$ of FPA, as amended by EPAct, anyone generating electricity for wholesale, with the above-mentioned exceptions, can request an order from FERC for a transmitting utility to provide 
REGULATIONS

transmission service. This request connot be made until 60 days after the applicant has requested service from the transmitting utility. An order will not, however, be issued for the recipient of wheeled power if the electricity to be transmitted during any period replaces electric energy required to be provided to the applicant pursuant to a contract during that period.

Requests for orders under $\S 211$ must meet the requirements of $\S 212$ and be in the public interest. The latter requirement is not deemed excessively restrictive. A FERC policy statement issued in July, 1993 establishes standards for "good faith" wheeling requests. This has been summarized in the January, 1994 issue of Wheeling and Transmission Monthly. Orders by FERC can require a transmiting utility to include enlargement of transmission capacity necessary to provide such service. However, orders that are issued cannot "unreasonably impair the continued reliability of electric systems affected by the order."

It is probable that most utilities will contract to provide wheeling services if the transmission request satisfies the conditions listed above. If agreement cannot be reached, a cogenerator can request an order from FERC. Alternatively, it might be possible to approach PUCs in those states which mandated wholesale wheeling prior to passage of EPAct.

QUALIFIED FACILITY VS. EXEMPT WHOLESALE GENERATOR STATUS Qualified Facilities (QFs) include both cogenerators and small power producers as defined by rules in CFR (Code of Federal Regulations) §18, Part 292.201-292.209 (4/1/91). The advantage of having QF status is that utilities must interconnect with and purchase electricity from a QF at the utility's "avoided costs." These costs are the same as those that would be incurred if the utility added additional capacity itself to meet increased demand for electricity. Furthermore, QFs are not regulated as electric or public utilities, relieving them of Federal and State reporting and regulatory requirements.

\section{Exempt Wholesale Generators (EWGs) were} first written into law with EPAct. Relevant provisions have primarily been incorporated into $\S 32$ of PUHCA, and they carry over into the Federal Power Act. An EWG is defined as a person(s) owning or operating an eligible facility and selling wholesale electricity. In turn, an eligible facility is either used for generation of electric energy "exclusively for wholesale," or used for generation of electric energy and leased to one or more public utilities. Here again, the lease must be treated as a sale of electric energy at wholesale. Unlike QFs, 100 percent of an EWG can be acquired by an electric utility holding company. This is significant because it puts a utility (through its affiliate or subsidiary) on even terms with non-utilities in the construction and ownership of generation facilities that will sell only wholesale power.

Application must be made to FERC for determination of EWG status. Under $\S 2(a)(3)$ of PUHCA, an EWG is not an electric utility company, and it is exempt from PUHCA. (This 
condition removes bias that an exempt non-utility entity could otherwise benefit from.) Also, an EWG that is not part of a holding company, such as an independent cogenerator, is not considered to be a public utility. In this case, certain reporting requirements and other restraints do not apply to the cogenerator.

EPAct did not remove state regulatory authority over EWGs. PUCs are therefore free to regulate them as public utilities with potential requirements such as the following:

- A state certificate of necessity and convenience;

- Oversight of organization and finance;

- Proof of financial/management capability; and

- A contract or a written commitment for power purchase by a public utility.

Some states have already determined that EWGs will be regulated as public utilities. In others, this is still an open question.

Prior to passage of EPAct, it was common for FERC to require that a cogenerator relinquish QF status in order to wheel power. These requirements were tied to utility merger cases. More recently, FERC has allowed a QF to keep that status in cases where the host favored it. FERC also decided for admission of QFs to the Western System Power Pool. Proponents had argued that the lowest offered price on the Pool's electronic bulletin board was indeed avoided cost.

Maintaining QF status by a cogenerator who desires to wheel power has two advantages. The first is exemption from state regulation. The second is in not having to sell at wholesale the facility's entire electrical output. The thermal host, if it had a large electrical load, would almost certainly want the benefit of large electricity savings from cogeneration, even if the facility were built and operated by a third party.

Still, seeking EWG status may be a satisfactory option in several situations. First, if the electrical to steam output is high, it might be preferable to dedicate all electrical output to wholesale sales. This could be the case with a combustion turbine combined cycle plant. Second, if the cogenerator wants to sell to a requirements utility, the interconnected utility might object to a QF selling power at a rate above the avoided cost of the requirements utility's supplying utility. If EWG status were obtained by the cogenerator, the ICU would be required to wheel wholesale power. Third, if the thermal host goes out of business, the power plant might be modified for electricity production only. Operation of the facility would still be possible through wholesale power sales. Finally, if the thermal host is unavailable for an extended period, EWG status could permit electric sales for an interim period. Hopefully, QF status could be regained at the end of that period.

The drawbacks that might be imposed with EWG status are highly uncertain at this point. FERC is addressing the issue of QF vs. EWG status on a case-by-case basis. However, new opportunities may appear that permit a cogenerator to maintain QF status and to wheel part of the electrical output 
to a wholesale customer. Federal and state disposition toward increased competion in electric generation will play a major role in the evolution of QF and EWG policy.

\section{RETAIL TRANSMISSION ACCESS}

Retail wheeling has been a fact for many years, although under very limited circumstances. A New York State economic development program permits retail wheeling, primarily from two nuclear plants. Examples include Consolidated Edison wheeling to Shearson Lehman Brothers and Niagara Mohawk wheeling to ALCOA and Occidental Chemical. Examples of wheeling power to customers of the Western Area Power Administration include wheeling of electricity by Northern States Power to the University of North Dakota and the South Dakota State Penitentiary. Furthermore, FERC has even approved some retail wheeling arrangements in the past.

EPAct, on the other hand, expressly contains a "Prohibition Against Retail Wheeling" section, leaving decisions up to state PUCs. Two states, California and New Mexico, have proposed regulations that will permit retail wheeling. Nevada has passed retail wheeling legislation, but it is very limited and designed to entice only one new retail customer to locate within the state. Michigan has ordered a five-year experimental retail wheeling program for Consumers Power and Detroit Edison. These developments show that certain states are interested in wheeling as an opportunity to increase competition in the electric utility market or to promote industrial development.
Most PUCs have not yet ruled on the legality of retail wheeling. For the ten percent plus of the market where it is legal, constraints may still exist. Typical constraints restrict sales to a maximum number of customers, to affiliates of the organization generating power, or to governmental organizations. Proposals will, in general, have to be presented to the remaining PUCs in order to obtain a retail wheeling rule. However, some state PUCs might find that there are no legislative restrictions on retail wheeling or that they have no regulatory authority over such transactions, as in Tennessee.

Alternatives that have been presented by the Electricity Consumers Resource Council might also be pursued by a project developer. These alternatives generally would accomplish retail wheeling, in effect, but not necessarily entail a retail sales transaction. They may include wheeling to affiliates, joint ownership of a facility by the NUG and the distant purchaser of power, and formation of new municipal electric systems.

Given the innovation of today's law community and cogeneration project developers, other arrangements which circumvent a strict definition of a retail sale will most likely surface. If PUCs have had difficulty with prior regulation of utilities in their state, they are probably more likely to pursue retail wheeling as an option for lowering customers' electricity rates. States that already have indicated a favorable attitude toward retail wheeling by a NUG include California, Indiana, Kansas, Maine, New Mexico, Nevada and Ohio. Further, Public 
Service Co. of Indiana has indicated that it might soon file a retail wheeling tariff with Indiana regulators for its $\mathbf{4 0}$ largest industrial customers. States that do not appear favorable toward retail wheeling, that is, without regulation as a public utility, include Florida, Michigan and New York. Also, the Connecticut Dept. of Public Utility Control has issued a draft order finding that retail wheeling should not be introduced in the state until utilities need new capacity.

\section{RETAIL WHEELING PROPOSALS}

Two states have announced comprehensive retail wheeling proposals: Michigan and California. Michigan's small scale experiment would be limited to $90 \mathrm{MW}$ in Detroit Edison's service territory and to $60 \mathrm{MW}$ in Consumers Power's service territory. Wheeling would also be limited to between two and ten MW per site. Potential participants have objections, however. Potential buyers of wheeled power will have to separate and discreetly measure loads that are supplied by wheeling. For sellers of power, NUGs and out-of-state utilities must accept regulation as Michigan utilities. Thus, this experiment is but a first step toward deregulation of the retail market.

The California proposal is much broader. Wheeling is to be phased in beginning in 1997 with full scale wheeling (including residential customers) in place by 2002 . This restructuring proposal has been made by the California Public Utilities Commission, and it requires legislative approval. Wheeling would gradually allow all customers direct access to generation suppliers, marketers, brokers and other senvice providers in a competitive energy services marketplace. Issues to be addressed by the Commission include cost allocation, uneconomic utility assets, unbundling of utility services, and transmission pricing. Of particular concern to cogenerators are the magnitude of stranded costs that can be recovered in wheeling rates during the transition period and increased competition through market rates.

\section{RATE REGULATION OF THE INTER- CONNECTED UTILITY}

An important question for wheeling projects is, "Who regulates the transmission rates, terms and conditions of the interconnected utility?" This is very important because the structure and complexity of a transmission tariff can vary among different regulators, and there may be overlapping jurisdiction. In fact, tariffs may be regulated by one, two, or no regulatory body.

FERC, of course, regulates all wholesale transactions that are under its jurisdiction - both interstate and intrastate. FERC has been most agressive in exploring alternative pricing concepts and questioning just what elements of cost should be included in a transmission tariff. In this regard, FERC is making rate determinations that may be followed by PUCs in the future. FERC has requested, and received, public comments on the appropriate determination of transmission tariffs. Subsequent to two public meetings in April, 1994, FERC may amend its current policy on transmission pricing. A detailed discussion of 
alternative methodologies for determining transmission rates and appropriate cost components is presented in Chapter 8.

The next obvious question is, "Which wholesale transactions are not regulated by FERC?" As noted in the section on wholesale transmission access, FERC does not regulate wholesale wheeling in ERCOT, Alaska, Hawaii, and the TVA Power Service Area. Although TVA is a nonregulated utility, cogenerators who wish to wheel through or out of TVA's area have access to dispute resolution by FERC under $\S 206$ of FPA.

Most generation and transmission cooperatives are not regulated by FERC. Only when they camy no Rural Electrification Administration debt are transmission tariffs, among other things, regulated by FERC. Otherwise, the REA has jurisdiction.

Finally, the Pike County Doctrine, which refers to a Pennsylvania Commonwealth Court decision of 1987 , asserts the right of a PUC to review the prudence of wholesale purchases by utilities within their jurisdiction. This, in essence, establishes multiple state and federal tariff jurisdiction over wholesale wheeling transactions. It is this sort of anomaly in current regulation that may introduce complications into the successful conclusion of a wheeling agreement.

\section{REGIONAL TRANSMISSION GROUPS}

This is an idea that almost made it into EPAct. The RTG provision would have allowed an entity that was subject to, or eligible to apply for, a $\S 211$ wheeling order to join such a group. Members would have an obligation to provide transmission service, to enlarge capacity as needed, and to coordinate transmission planning regionally.

Subsequent to passage of EPAct, FERC requested and reviewed public comments on the concept of RTGs. In August, 1993 FERC issued a generic policy statement on RTGs, rather than formal rules. (FERC does not have authority to certify RTGs.) A necessary condition of their policy is that an RTG agreement include voluntary dispute resolution procedures. It is hoped that this will reduce cases brought before FERC. A second element requires consultation with state regulators. An RTG agreement should also specify terms and conditions under which transmission services will be offered. Thus, an RTG would have to determine, to the extent practicable, transmission tariffs. This might be viewed as an entirely new level of regulation. On the other hand, RTGs might be able to resolve differences between state and federal pricing policy. This would remove a certain amount of uncertainty now faced by developers. At any rate, RTGs could probably determine additional conditions and constraints that would have to be adhered to by a project developer.

The Western Regional Transmission Association filed an RTG application with FERC on May 20, 1994. Others that may apply include the South West Regional Transmission Association, Western Association for Transmission System 
Coordination, and the Southwest Power Pool. New England Electric System has also published a proposal for a regional transmission group that would replace the Regional Transmission Arrangement described below. Tariff structures are not to be submitted until FERC determines its final pricing policy.

\section{REGIONAL TRANSMISSION ARRANGE- MENT (RTA)}

One such related regional proposal resulted as a condition of the Northeast Utilities (NU) / Public Service of New Hampshire (PSNH) merger. FERC required NU to submit a proposed Regional Transmission Arrangement to the New England Power Pool (NEPOOL) after consultation with other NEPOOL participants. NU did this on February 23, 1993 and stood ready to support its adoption.

During the week of April 26 the NEPOOL RTA unraveled. Member utilities realized that locking themselves into a single wholesale wheeling tariff under the RTA could limit future pricing flexibility in regard to retail wheeling. Although the RTA would not have established another regulatory layer, it would have resulted in highly complex transmission pricing rules, with some charges established after-the-fact.

\section{INTERREGIONAL TRANSMISSION COORDINATION FORUM}

This group represents a second approach to regional coordination and dispute resolution among utilities and NUGs. Although it is not a regulatory body, decisions can be reached that could affect the cost of wheeling.

ITCF is a group of owners and users of transmission services east of the Mississippi River. Members subscribe to a written set of principles respecting owners' and users' rights and obligations and who agree to exert good faith efforts to resolve disputes through the forum before resorting to other avenues of dispute resolution.

The organization has had a number of successes to-date. Actions taken have generally responded to technical problems arising from interutility power transfers. ITCF has been officially recognized by FERC through acceptance of organizational materials, but not as an RTG.

\section{INFORMATION SOURCES}

Legislation Compilation of Selected Energy-Related Legislation; Committee on Energy and Commerce, U.S. House of Representatives, Committee Print 103-E, March 1993. (FPA, PUHCA, \& PURPA)

Regional Transmission "FERC Clarifies its New Authority;" Wheeling \& Transmission Monthly, Groups January 1994.

Regulation PUR Guide - Regulation; Public Utility Reports, Inc., Cptr. 10, April 1992.

"Regulations Under Sections 201 and 210 of the Public Utility Regulatory Policies Act of 1978 With Regard to Small Power Production and Cogeneration;" Code of Federal Regulations $\S 18$, Part 292. 


\section{CHAPTER 8.}

\section{CONTRACTING CONSIDERATIONS}

A successful WCP system must meet its contractual obligations. The thermal host, the wheeling utility and the electrical energy purchaser each have their own unique and exclusive requirements to place upon the cogenerator. The contractual agreements between these parties must recognize the performance limitations of the WCP system. Stated from the developers viewpoint, the cogeneration system design must support the contractual requirements. Otherwise, the cogenerator would be subject to costly penalties, unfavorable rates, and ultimate financial disaster.

During the development of a WCP project, the agreement between the principal parties is negotiated. The facility owner/operator, the thermal host, the electric power customer, and the interconnecting utility (or utilities) establish the terms and conditions under which they are willing to participate in the WCP system. Government agencies, including the Federal Energy Regulatory Commission and Public Utility Commissions, impose rules and regulations upon participants which partially dictate the character of the WCP system and set the criteria for the sale of cogenerated power, the wheeling of power, and the sale of standby power. The Environmental Protection Agency sets forth air emissions limitations and performance standards which are ultimately reflected as performance limitations on the cogeneration plant itself.
Ultimately, all of these constraints must be acknowledged by the WCP participants and addressed in a contractual basis upon which all parties can rely. To these negotiations each party brings an agenda aimed at improving its own position in the deal.

\section{CONTRACTING WITH THE ELECTRICITY PURCHASER AND} THERMAL HOST

Either the thermal host or a third party can develop a cogeneration facility. In both cases the needs of the thermal host are similar to those of the distant electricity purchaser. Table 8.1 lists these needs.

\section{Table 8.1 Special Interests of the Thermal and Electricity Hosts}

$$
\begin{gathered}
\text { Energy Savings } \\
\text { Dependable Energy Supply } \\
\text { Administrative Simplicity } \\
\text { Operational Simplicity } \\
\text { Minimal Investment } \\
\text { Reduction of Uncertainty } \\
\text { Lower Environmental Risk }
\end{gathered}
$$

The paramount need is sufficient energy savings to offset the effort and inconvenience that results from planning, building and operating associated facilities. Long term savings are necessary; so contracts must be ten years or more in length. 
Dependable electricity and energy supplies are also needed that will not shut down the energy hosts when the cogeneration facility experiences planned or unplanned outages. This generally requires backup boilers for the thermal host and standby power contracts with the interconnected utility. For the latter, the utility will require both a fixed monthly payment to reserve backup generation capacity and a payment for electricity actually taken.

Standby electricity contracts must be long term, but they are usually subject to periodic rate rivisions. The cogenerator's contracts for energy sales should reflect and pass through these future rate increases. Likewise, escalation of fuel and other operating costs of the cogenerator can be passed through in sales contracts when there is substantial uncertainty over future costs. Escalation clauses tied to particular price indexes are a common method for accomplishing this.

Simplicity is a desirable goal for all parties in regard to contracts, metering and acounting, coordination, and facility operation. Contracts for sale of thermal and electrical power need not be more than two dozen pages. The simpler the contract, the more easily it can be understood and adhered to by the managements of all parties and the facility operator. Latitude in facility operation is desirable when completely unforeseen events occur, as they will.

Third party cogeneration developers become important when a thermal host either lacks necessary technical expertise or does not wish to supply its own capital investment funds. Project developers can capitalize on this by securing outside investment capital and reducing project risk through their own specialized expertise. Such knowledge can span a wide range - from technical to legal to regulatory. With appropriate contracting, risk can be transferred from the thermal and electricity purchasers to the third party owner. This can even include responsibility for environmental emissions compliance.

The major contracting issues regarding thermal and electricity sales in a wheeling project are listed in Table 8.2. Multiple metering and dual load following are the two major items that can occur in a wheeling arrangement versus a conventional cogeneration facility.

Table 8.2 Contracting Issues With Thermal and Electricity Hosts

Load Following

Multiple Metering

Thermal Pricing

Electricity Pricing

Backup Electric Power \& Heat

Risk \& Reliability

\section{CONTRACTING WITH THE INTER-} CONNECTED UTILITY

Issues that will arise when negotiating with the ICU are listed in Table 8.3. Relay and protection, system security, and loop flow have been discussed in detail in Chapter 6 . The metering requirements under a wheeling contract are usually specified by the ICU with actual equipment selection left to the 
Table 8.3 Contracting Issues With The Interconnected Utility
Wheeling Price
Standby Power
Metering
Relay \& Protection
System Security
Loop Flow

project developer. In and out metering at the cogeneration facility will be required as well as metering of electric use by the thermal host and distant electricity purchaser. New metering at the transfer point between utilities should not be an issue. Electricity transfers and their metering are already part of normal inter-utility operations.

The actual number of megawatts injected into the grid by the cogenerator will be delivered to the customer. The ICU will provide the power needed to make up for line losses. The wheeling charge will therefore include a cost component that remunerates the ICU for supplying line losses.

Contract terms for standby power and for the actual wheeling arrangement will be specified by the ICU. However, determination of wheeling charges can vary widely among utilities. Their determination may even be uncertain if FERC or a PUC has not yet approved an appropriate wheeling tariff. An understanding of wheeling tariffs is especially important because of uncertainty and evolution in the current regulatory treatment of transmission service pricing.

\section{PRICING OF TRANSMISSION SERVICES}

The Federal Energy Regulatory Commission is focusing much current attention on pricing, both for utilities and non-utilities who wish to wheel power. The Commission's interest in pricing began with authority it had prior to October 1992 under which voluntary wheeling orders could be issued in regard to utility mergers and utility requests for marketbased electricity prices. FERC's recent search for a uniform pricing policy resulted in a statement of three general principles relating to the Northeast Utilities (NU) / Public Service of New Hampshire (PSNH) merger proceedings. These three principles were fully applied in the so-called 'Penelec' case. Before examining this price ruling, however, it is useful to examine the basic economic principles that can justify different pricing policies.

\section{EMBEDDED (AVERAGE) COST}

This is the most common method by which utilities determine rates for long-term, firm wheeling arrangements. Here, a fixed mark-up is added to average, system-wide capital and operating expenses. The concept is well understood by utility regulators, and it is a conservative, full-cost-recovery option when the transmission lines required for wheeling power will not be capacity-constrained. Since the same price applies to everyone wanting to wheel power, it is often called a postage stamp rate. For large utilities this is a simple way to reecover full embedded cost. One does not have to be concerned with the actual, and constantly changing, power flows throughout the transmission system. 
A variation of this is $\mathrm{MW}$-mile (or contract path) pricing under which price goes up as distance between the NUG and the electricity purchaser increases. This is an alternative when the path of actual power flow is fairly certain. It accounts for added capital facilities and increasing line loss as transmission distance increases. A pricing scheme of this type has been introduced by the MidContinent Area Power Pool.

\section{MARGINAL COST}

Marginal costs enter the picture when the transmission capacity needed to wheel firm power is, or will be, constraining. Here, the added cost of a marginal increase in capacity, either through upgrading existing capacity or by adding new transmission capacity (incremental cost), must enter into the pricing of transmission services. This allows the utility to recover expenditures for increased service. The larger the utility, the less the importance of marginal costing unless new facilities are to be dedicated to specific customers.

\section{OPPORTUNITY COST}

Since the early 1980's, many utilities have had excess generation capacity. A large market has therefore developed for economy power transactions between utilities. If someone else can supply power more cheaply, the purchasing utility can effect cost savings by short term power purchases. This has led to extensive use of transmission lines for power exchange. Many utilities feel that long term wheeling contracts with NUGs will limit their ability to purchase such low cost economy power when it is available. An economist terms any such foregone savings opportunity costs. That is, they are lost opportunities for providing lower cost power to their own (native load) retail customers.

In the NU/PSNH merger case two different examples of opportunity costs were identified. The first was transmission line constraints that, when a utility was wheeling power for a NUG or EWG, prevented economy purchases being made from another utility. The second was when wheeling prevented the wheeling utility from dispatching its own generating capacity on the most economic basis. This is termed operation of generation units out-of-rate-base.

Opportunity cost pricing introduces a future cost uncertainty to wheeling cogenerated power that could inhibit project financing unless contractural conditions require that opportunity cost payments made by the cogenerator be reimbursed by the purchaser of wheeled power.

\section{MARKET-BASED PRICE}

In a perfectly competitive market, economists assume that prices are determined by the interaction of supply and demand. With competitive wheeling, the price agreed to by the seller and purchaser would be unregulated. The electric utility industry is moving in this direction for pricing of generating capacity, but application to wheeling is probably out into the future. As an aside, in recent utility requests for market-based pricing of generation FERC has required utilities to provide open access to its transmission system. This 
ensures that the utility cannot act as a monopoly by charging a monopoly rent for its generation.

\section{THE PENELEC CASE}

FERC's current transmission pricing rules were spelled out in a ruling for a wheeling application to FERC by Penntech Papers, Inc. and Pennsylvania Electric Company. This is termed the "Penelec Case." Here, FERC ruled that the utility could charge the higher of either embedded, or incremental cost of expansion (including, presumably, any variable cost), but not both. Stated more simply, FERC allowed average cost pricing or marginal cost pricing, whichever was higher, but not the sum of the two.

Figure 8.1 illustrates the relevant pricing concepts. Average cost is shown by the solid line in Figure 8.1. It rises somewhat in the year 1995 when new transmission capacity is brought into service and the capital cost is spread over all ratepayers. This cost-of-service pricing recognizes that entry and exit of individual customers and suppliers are unpredictable and that cost averaging minimizes electricity price disruption and revenue fluctuation over time. Average cost is what FERC terms embedded cost in the Penelec Case.

The dashed line in Figure 8.1 shows marginal cost. Prior to installation of new capacity, it consists of variable cost (mainly line losses) plus any foregone opportunity cost (shown in 1994). In 1995 marginal cost increases substantially when new transmission capacity is brought into the rate base. FERC is therefore providing a utility the option of a cost path that varies very little over time, average cost, to a cost path that is lower in the short term and much higher in the long term, marginal cost. From inspection of Figure 8.1, it is clear that no economist at FERC could be comfortable with the Penelec proposal, average cost plus marginal cost.

One possible reason for so much misinterpretation of FERC's ruling lies in the wording of the Penelec pricing proposal. They proposed to charge full embedded cost plus opportunity costs, but with the latter capped at the cost of enlarging the transmission system. Incremental cost of expansion
Fig. 8.1 Transmission Service Price

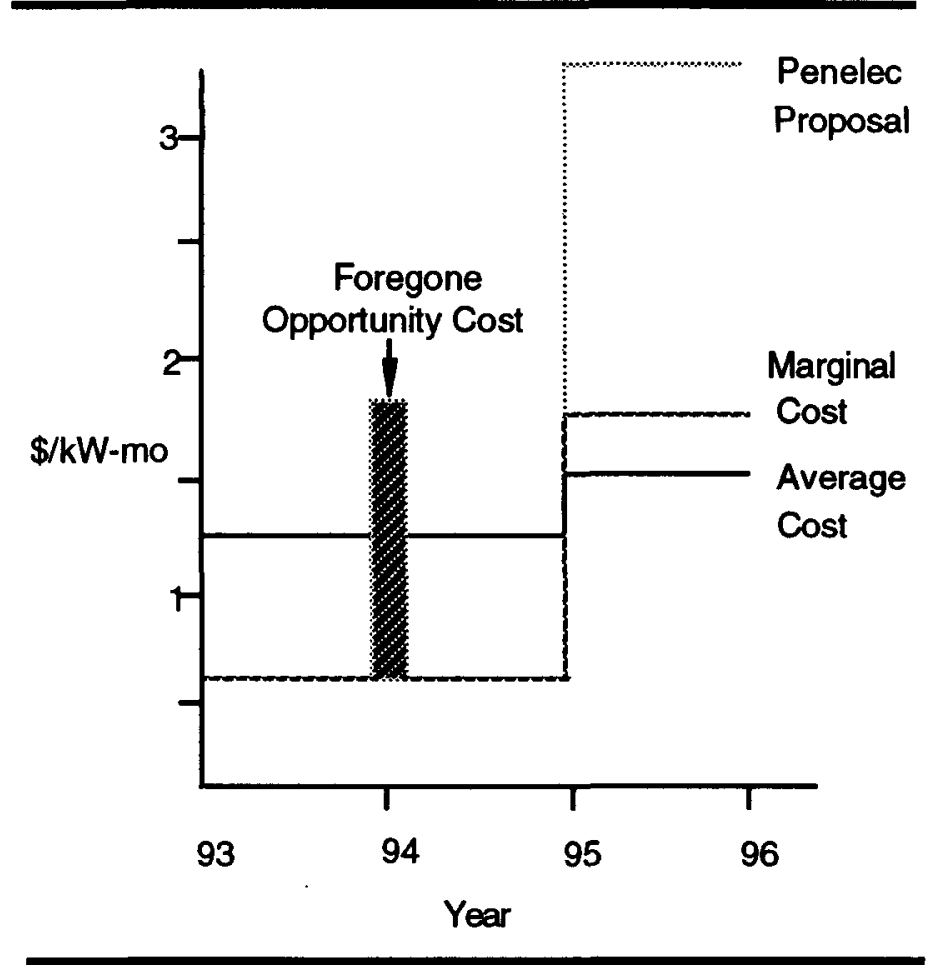


was therefore implicitly presented as an example of an opportunity cost. In fact, the two economic concepts are very different. Also, there is no reason that opportunity costs should equal incremental costs at the time of system expansion. Incremental expansion costs are a capital cost which must be recovered over the life of the capital asset using an appropriate discount rate. Opportunity costs, under the traditional economist's definition, generally account for short term, foregone opportunities.

Pricing issues have not been completely resolved by FERC or PUCs. Two public meeting were held by FERC in April, 1994 on transmission service pricing. The timing of any change in FERC's pricing policy is uncertain, but is most likely to occur in 1995. State PUCs and ERCOT are expected to follow FERC's lead where they have jurisdiction. Relevant FERC decisions on comparability of service and its forthcoming stranded investment policy rulemaking are discussed in the next section.

\section{WHICH COST ELEMENTS TO INCLUDE}

In addition to the question, What is the appropriate pricing basis?, embedded, marginal, etc., there is a question as to which elements of cost should be included in transmission prices. The issue of opportunity costs (assuming that they can be succinctly defined) has already been discussed. But should they be included in an embedded cost rate as well as a marginal cost rate? And should opportunity costs be capped at incremental cost of expansion?

FERC added an additional element of cost to the pricing issue in a 1992 decision relative to
ENTERGY Corp. FERC ruled that ENTERGY could charge a wheeler for stranded investment. That is, if wheeling removes retail load served by the utility, the value of generating capacity built to serve that load can be recovered in the wheeling charge associated with that load. Stranded investment is a major concern in regard to long term utility contracts with requirements utilities. It becomes less of an issue with shorter term retail sales contracts because the utility is not committing itself to supply of capacity beyond the contract term. In fact, it may be a non-issue in regard to residential sales because contracts are not involved with such sales.

Recovery of stranded investment costs is a prime objective for utilities. In the 1980s many of them had some of the costs of excess capacity (following escalation of utility rates) declared imprudent. Shareholders as well as all ratepayers shouldered the burden. Recognition of stranded investment, now, would permit generation costs to be recovered from individual customers that left a utility's system.

The Entergy decision on stranded investment has been successfully challenged in court on the basis that it is anticompetitive. However, FERC is of the opinion that several of the problems identified by the Court were taken care of by its 1993 comparability decisions and good-faith rulemaking. ("Comparability" means that a utility must offer to third parties the use of its transmission system at costs, terms and conditions that are comparable to its own use of the system. "Good faith" standards for wheeling requests, issued in July, 1993 ensure 
that requesting parties negotiate fairly prior to requesting FERC intervention.) FERC also maintains that any other Court concerns will be satisfactorily superseded by its stranded investment policy rulemaking, expected in early 1995.

The issue of stranded investment may well parallel what transpired with deregulation of natural gas pipelines. There, with customers having to share in take-or-pay contractural provisions, stranded investment was primarily a transitional problem during the period of deregulation. How important it is for a purchasing utility or retail customer is very likely to depend on their current contractural agreement. The importance of this to a cogenerator primarily regards a requirements utility or a retail customer to which power is intended to be sold.

Another new concept in regard to which elements of cost to include in a transmission rate draws directly on recent changes in the pricing of natural gas transmission services. There, it was recognized that there's more than one component of the service provided. Because every gas transporter might not need every component of the total service previously offered, it was prudent to break down transmission costs into their major components and to only charge for those elements of service actually provided.

Unbundled pricing, as this is termed, could possibly assume importance in retail wheeling. Costs could be subdivided into transmission, distribution, and customer cost. The customer cost could include the necessity to supply volt-amps reactive to the customer if the NUG that was wheeling power supplied it at close to a 1.0 power factor.

Finally, one other cost element might become important when there is loop flow, or parallel flow, over a neighboring utility's lines. Compensation might have to be paid to the neighboring utility when a portion of the power regularly flows through their transmission lines. Indeed, FERC is requiring such compensation in NU's wheeling tariff by 1997.

Debate over "correct" transmission pricing is intense. FERC will, undoubtedly, continue to refine its pricing policy for cases under its jurisdiction. It may also seek to expand its jurisdiction. In other cases, pricing policy may be determined by individual utilities or by Public Utility Commissions. At any rate, it is almost certain that transmission service pricing rules will not become everywhere uniform. 


\section{IN CONCLUSION}

Wheeling, as facilitated by passage of the 1992 Energy Act, presents an entirely new market to cogenerators. However, regulations are in a state of evolution because of the new considerations which must be provided to NUGs as well as to utilities. Without doubt, the physical design of cogeneration facilities will also evolve as they adapt to peak as well as baseload electricity needs.

Although there are many uncertainties, opportunities exist for project developers through membership in a number of industry organizations to directly influence change in favor of increased competition. With continued innovation by project developers, implementation of EPAct may turn out to be as important as PURPA was in the expansion of competition and energy conservation within the electric utility industry.

\section{INFORMATION SOURCES}

Contracting

"Avoiding Common Pitfalls and Pratfalls;" J. H. Chiles \& G. D. Stewart, I ndependent Energy, Mar 1990.

"Public Acceptance: A Siting Imperative;" S. O'Neill \& J. Gorman, IGTH-Vol. 7, ASME 1992 COGEN-TURBO.

"Terms and Conditions of Existing Transmission Services Agreements;" Edison Electric Institute Rate Regulation Department, No. 04-85-05, 1984.

Industry Associations American Cogeneration Association, Washington, DC, 202-625-3800.

American Public Power Association, Washington, DC, 202-467-2900.

Council of Industrial Boiler Owners, Burke, VA, 703-250-9042.

Electric Generation Association, Washington, DC, 202-965-1134.

Electricity Consumers Resource Council, Washington, DC, 202-682-1390.

National Rural Electric Cooperative Association, Washington, DC, 202-857-9500.

Opportunity Costs American Paper Institute filing before FERC concerning opportunity cost pricing in NU/PSNH merger, 12/30/91.

Penelec Case $\quad$ "Pennsylvania Electric Company;" 58 FERC 161,278 at 61,873, reh'g. denied, 60 FERC $\rceil 61,034$ (1992).

"Request of Pennsylvania Electric Company for Rehearing;" FERC Docket No. ER91-313-000, Apr 1992.

Stranded Investment "Entergy Service, Inc.;" FERC Draft Order, Docket No. ER91-569-000 \& ff, Mar 1993.

Transmission Pricing Electric Transmission Access and Pricing Policies: Issues and a Game-Theoretic Evaluation; National Regulatory Research Institute, May 1990.

Principles of Public Utility Rates; J.C. Bonbright, et. al., 1988.

Some Economic Principles for Pricing Wheeled Power; National Regulatory Research Institute, No. NRRI-87-7, Aug 1987.

"Transmission Pricing Issues;" FERC Staff Discussion Paper, Jul 1993. 


\section{ADDITIONAL REFERENCES}

"A Municipality's Perspective on Electricity Transmission Access Questions," Public Utilities Fortnightly, 2/6/86.

"A Negotiated Alternative to Mandatory Wheeling," Energy Law Journal, M. A. Wallace, v10, n1, 89.

"Agreement with Respect to Regional Transmission Arrangement for the New England Power Pool," Northeast Utilities, 2/23/93.

Alternative Models of Electric Power Deregulation, Edison Electric Institute, 82.

An Approach for Determining Transfer Capability Objectives, Public Svc. Elec. and Gas, EPRI EL-3425, 3/84.

California's Electric Services Industry: Perspectives on the Past, Strategies for the Future, California Public Utilities Commission, $2 / 93$.

Capacity and Generation of Non-Utility Sources of Energy, 1990, Edison Electric Institute, 12/91.

Case Studies of Transmission Bottlenecks, Office of Technology Assessment Contractor Report, Casazza, Schultz and Associates, 11/30/88.

Case Studies on Increasing Transmission Access, Office of Technology Assessment Contractor Report, Casazza, Schultz and Associates, 3/88.

Cogeneration \& Independent Power Production: Market Insight and Outlook, Resource Dynamics Corp., 90.

"Competition and Access to the Bottleneck: The Scope of Contract Carrier Regulation under the Federal Power and Natural Gas Acts," 18 Land and Water Review, H. L. Reiter, pp 1-80, 83.

Competition in Electricity: New Markets and New Structures, J. Plummer and S. Troppman, eds., 90.

"Conference Report on H.R. 776, Comprehensive National Energy Policy Act," Congressional Record, No.142-Part V, p H1256 \& ff., 10/5/92.

Cost of Electricity Transmission and Distribution, Oak Ridge National Laboratory, ORNLTM-1052, 9/88.

Current Practice and Emerging Issues in Transmission Rate Design, Edison Electric Institute, 85.

Electric Power Transmission and Wheeling. A Technical Primer, Edison Electric Institute, 90.

Electric Power Transmission: Federal Role in System Use and Regulation, General Accounting Office, 4/88.

Electric Power Wheeling and Dealing, Congressional Office of Technology Assessment, 5/89.

Electric Trade in the U.S. 1990, U.S. DOE Energy Information Administration, 92.

Electric Transmission Access and Pricing Policies: Issues and a Game-Theoretic Evaluation, National Regulatory Research Institute, 5/90.

"Electric Utility Deregulation: Analyzing the Prospects for Competitive Generation," Annual Review of Energy, W.A. Brownell, pp 229-262, 84. 


\section{REFERENCES}

Electricity Transfers and Reliability, North American Electric Reliability Council, 89.

Electricity's Future: A Special Report by the ELCON, Electricity Consumers Resource Council, $7 / 87$.

"Electricity-Energy-Transactions-Technology: The Key to Bulk Power Supply Policies," Annual Review of Energy, 88.

Engineering and Reliability Effects of Increased Wheeling and Transmission, Edison Electric Institute, 88.

"FACTS for Electricity," Public Power, pp 50-52, Mar-Apr 91.

"FACTS Panel Session Transcript," EPRI Conference, 11/16/90.

"FACTS - Flexible AC Transmission System," EPRI Conference, TR 100504 (Project 3002), 3/92.

"Federal Regulation and Development of Power," United States Code, Title 16 - Conservation, chap 12.

FERC Draft Order (re Entergy Service, Inc.), FERC Docket No. ER91-569-000, 3/93.

FERC Northeast Utilities Service Company (re: Public Service Company of New Hampshire) Opinion, FERC, Opinion No. 364-A, 58 FERC \$61, 070, 1/29/89.

FERC Order (re Pennsylvania Electric Co.), FERC Docket No. ER-313-000, 3/10/91.

"FERC Proposes Rules for RTGs," Electric Light and Power, 1/93.

Filing before FERC concerning opportunity cost pricing in NU/PSNH merger, American Paper Institute, $12 / 91$.

Filing before FERC concerning opportunity cost pricing in NU/PSNH merger, MASSPOWER, 12/30/91.

"Forecast 92," Electrical World, 11/92.

"Free Market Electricity: Potential Impacts on Utility Pooling and Coordination," Public Utilities Fortnightly, 2/18/88.

Future Cogeneration Technologies, Electric Power Research Institute, EPRI CU-6795, 5/90.

"Ideas for Breaking the Transmission Logjam," Electricity Journal, D. Garrett, 12/91.

IEEE Guide for Interfacing Dispersed Storage and Generation Facilities with Electric Utility Systems, Inst. of Electrical and Electronic Engineers, ANSI/IEEE Std. 1001-1988, 4/89.

Industrial Energy Technology, U.S. DOE, DOE/IET-92/1, 92.

Integrating Non-Utility Generators: Reliability Concerns for Integrating Non-Utility Generators with the Bulk Electric System, North American Reliability Council, 92.

Interutility Bulk Power Transactions, U.S. DOE Energy Information Administration, DOE/EIA-0418, 10/83.

"Keystone Electricity Draft," Keystone Energy Futures, 1/27/88.

"Legal and Regulatory Constraints on Competition in Electric Power Supply," S.H. Porter et al, Public Utilities Fortnightly, v123, n11, 89.

"Markets for Wheeling Cogenerated Power," R.G. Tessmer, COGEN, Winter 94.

Moving Power: Flexibility for the Future, National Governors Association, 86. 
New Electric Power Techniques: Problems and Prospects for the 90s, Congressional Office of Technology Assessment, OTA-E-246, 7/85.

Non-Technical Impediments to Power Transfers, The National Regulatory Research Institute, 9/87.

"Opportunity Costs as a Legitimate Component of the Cost of Transmission Service," Public Utilities Fortnightly, 12/7/89.

Optimization of Reactive VAR Sources in System Planning, Scientific Systems, Inc., EPRI EL-3729, $11 / 84$.

Pricing of Transfer Services in Bulk Power Markets, Edison Electric Institute, 87.

Principles of Public Utility Rates, J.C. Bonbright et al, 88.

"Problems of Price Transportation: Two Proposals to Encourage Competition from Alternative Energy Sources," 10 Harvard Environmental Law Review, Y.P. Bland, 86.

"Problems with PUHCA Reform Implementation," Paper presented at PowerGen '92, H. Pyle, Houston Industries, Inc., Orlando, FL, 11/17/92.

"Public Acceptance: A Siting Imperative," Paper presented at ASME COGEN-TURBO, S. O'Neill \& J. Gorman, IGTI-Vol. 7, 92.

"Public Utility Holding Company Act," United States Code, Title 15 - Commerce and Trade.

"Regulations Under the Public Utility Regulatory Policies Act of 1978," Code of Federal Regulations, 18CFR, $\$ 290,292,294,300 \& 301$.

"Regulatory Uncertainties that can Affect Wheeling Projects," R.G. Tessmer, COGEN, Winter 94.

Reliability Concepts in Bulk Power Electrical Systems, North American Electric Reliability Council, 85.

Reliability Considerations for Integrating Non-Utility Generating Facilities with the Bulk Electric System, North American Electric Reliability Council, 87.

"Retail Wheeling in the Electric Utility Industry, It's Working," Cogeneration and Resource Recovery, Jul/Aug 92.

"RTGs: The Emergence of an Industry Consensus," Public Power, Jan-Feb 93.

Some Economic Principles for Pricing Wheeled Power, National Regulatory Research Inst., NRRI-87-7, 8/87.

Statistical Yearbook of the Electric Utility Industry/1990, Edison Electric Institute, 10/91.

Survey of Transmission Services Provided by Investor-Owned Utilities, Edison Electric Institute, 84.

"Technical and Economic Constraints on Competition in Electric Power Supply," Public Utilities Fortnightly, v22, n10, 88.

Technical Background and Considerations in Proposed Increased Wheeling Transmission Access and NonUtility Generation, Office of Technology Assessment Contractor Report, Power Technologies, Inc., 3/30/88.

Technical Limits to Transmission System Operation, Power Technologies, Inc., EPRI EL-5859, 6/88.

Technological Considerations in Proposed Scenarios for Increasing Competition in the Electric Utility Industry, Office of Technical Assessment Contractor Report, Power Technologies, Inc., 3/30/88. 


\section{REFERENCES}

Terms and Conditions of Existing Transmission Services Agreements, Edison Electric Institute Rate Regulation Dept., 04-85-05, 84.

The Changing Structure of the Electric Power Industry, 1970-91, U.S. DOE Energy Information Administration (draft report).

The Evaluation of Transactions in Interconnected Systems, National Regulatory Research Institute, 88.

"The Implications of Deregulation for Electrical Utilities," Comment for the Reason Foundation Conference on Deregulating Public Utilities,W.W. Berry, 87.

The National Energy Strategy, U.S. DOE, 91.

The Potential for Industrial Cogeneration by 1990, U.S. DOE Contractor Report, Resource Planning Associates, Inc., 81.

The Reliability of Independent Power: Operating System, Planning, Fuel, and Financial, National Independent Energy Producers, 11/91.

The Third Annual Transmission Symposium Conference Papers, sponsored by Public Utilities Reports, The Management Exchange and Palmer Bellevue Corp., Washington, D.C., 10/28-29/91.

"The Time Has Come for Retail Wheeling," D.O. Dahlan and S.K. Achinger, Paper presented at the 15th World Energy Engineering Congress, 10/29/92.

"The Transitional Bulk Power Market," Public Utilities Fortnightly, 11/26/87.

The Vital Link: Electricity Transmission and the Public Interest, Edison Electric Institute, 86.

The Wheeling and Transmission Manual, ed. L. Weiss and S. Spiewak, 91.

"Tie-Riding Free Loaders - The True Impediment to Transmission Access," Public Utilities Fortnightly, $12 / 21 / 89$.

"Transmission Access," IEEE Power Engineering Review, 4/90.

Transmission Access and Wheeling: A Summary of State Laws and Regulations, Edison Electric Institute, 89.

Transmission Task Force's Report to the Commission, Federal Energy Regulatory Commission, 10/89.

"U.S. Electricity Statistics," Public Power, Jan-Feb 92.

"Wheeling Cogenerated Power: Institutional Barriers and Potential Solutions," R.G. Tessmer, Paper presented at PowerGen '92, Orlando, FL, 11/18/92.

Wheeling Cogenerated Power, Phase I Report, U.S. DOE Contractor Report, ERC, Inc., DE/CE/40942-1.

Wheeling in the Electric Utility Industry, Congressional Research Service, A. Kaufman et al, 2/12/87. 